\title{
AVALIAÇÃO LONGITUDINAL DA EFETIVIDADE DAS PLACAS OCLUSAIS REPOSICIONADORAS NO CONTROLE DE PATOLOGIAS DA ATM: COMPARAÇÃO COM PLACAS OCLUSAIS ESTABILIZADORAS E UM GRUPO CONTROLE
}

\author{
JOÃO EVANDRO DA SILVA MIRANDA
}

Tese apresentada à Faculdade de Odontologia de Bauru da Universidade de São Paulo, como parte dos requisitos para obtenção do título de Doutor em Odontologia, na área de Reabilitação Oral.

(Edição Revisada)

BAURU 


\title{
AVALIAÇÃO LONGITUDINAL DA EFETIVIDADE DAS PLACAS OCLUSAIS REPOSICIONADORAS NO CONTROLE DE PATOLOGIAS DA ATM: COMPARAÇÃO COM PLACAS OCLUSAIS ESTABILIZADORAS E UM GRUPO CONTROLE
}

\author{
JOÃO EVANDRO DA SILVA MIRANDA
}

Tese apresentada à Faculdade de Odontologia de Bauru da Universidade de São Paulo, como parte dos requisitos para obtenção do título de Doutor em Odontologia, na área de Reabilitação Oral.

Orientador: Prof. Dr. Paulo César Rodrigues Conti.

BAURU 
Miranda, João Evandro da Silva

M672e Avaliação longitudinal da efetividade das placas oclusais reposicionadoras no controle de patologias da ATM: comparação com placas oclusais estabilizadoras e um grupo controle / João Evandro da Silva Miranda.-- Bauru, 2000.

208p.: il.; $30 \mathrm{~cm}$.

Tese. (Doutorado)--Faculdade de Odontologia de Bauru, USP.

Orientador: Prof. Dr. Paulo César Rodrigues Conti

Autorizo, exclusivamente para fins acadêmicos e científicos a reprodução total ou parcial desta tese por processos fotocopiadores e outros meios eletrônicos

João Evandro da Silva Miranda

Pesquisa aprovada na comissão de ética da Faculdade de Odontologia de Bauru - USP - de acordo com o Protocolo № CEP 09320 


\section{João Evandro da Silva Miranda}

16 de Setembro de 1959

$1979-1982$

$1983-1984$

1988 - 1989

1993

1995 - 1997

$1997-2000$

Associações
Nascimento

Belém - Pará

Curso de graduação em Odontologia na Universidade Federal do Pará

Curso de Formação de Oficiais Dentistas na Escola de Saúde do Exército - Rio de Janeiro.

Curso de Especialização em Dentística Restauradora na Associação Brasileira de Odontologia - Secção do Pará

Professor do Departamento de Prótese do Curso de Odontologia da Universidade Federal do Pará

Curso de Pós Graduação em Reabilitação Oral - Prótese, em nivel de Mestrado, na Faculdade de Odontologia de Bauru da Universidade de São Paulo

Curso de Pós Graduação em Reabilitação Oral - Prótese, em nivel de Doutorado, na Faculdade de Odontologia de Bauru, da Universidade de São Paulo

Associação Brasileira de Odontologia Associação dos Pós-Graduandos da Faculdade de Odontologia de Bauru da Universidade de São Paulo. APG-FOB-USP

Academia Brasileira de Osseointegração. 


\section{Agradeço}

Aos meus pais, Miranda e Celeste, verdadeiros mestres a mostrar o caminho do amor e da educação, o meu agradecimento pelo ensinamento maior. Tenho certeza, de que por muitos anos ainda poderei ouvi-los com poucas palavras, sábias orientações e muitos exemplos de vida.

À Marilene, minha esposa e amiga, por mais este incentivo. Por nos abastecer com amor, carinho e tranqüilidade necessários durante todos estes anos.

Aos meus filhos João, Diego e Milene que souberam compreender os momentos de ausência durante esta fase de dedicação ao Curso.

Aos meus verdadeiros irmãos e amigos Evilázio e Silvinha, Natalina e Cesário, Lena e João, Fátima, Max e Clara, Andréa, Daniel, Dulce, Edilene e Omar, pelo apoio.

Aos Srs. Juarez e Marizete, pelas muitas palavras de incentivo durante todos estes anos em que estivemos ausentes.

À compreensão de todos que me querem bem, pela renúncia e tempo de convivio subtraídos para a realização deste ideal

Dedico este trabalho 
Ao professor

Doutor Paulo César Rodrigues Conti

Agradeço não só pela confiança, orientação e ensinamentos valiosos, mas por me ajudar a construir uma fase de minha vida.

Sua firmeza, segurança e domínio durante a realização deste trabalho, serviram-me de estímulo constante e certamente, servirão de exemplo por muito tempo.

O meu profundo reconhecimento 


\section{Ao Doutor}

Guilherme Pinto de Souza

Seu apoio decisivo jamais será esquecido. Tem muito de seu exemplo no calor desta conquista. Obrigado por sua ajuda na construção desta fase importante de minha vida profissional.

Eu, Marilene, João, Diego e Milene lhe somos eternamente gratos pela motivação, amizade e carinho. 


\section{Ao Doutor}

Dagoberto Sinimbú de Lima

Existem pessoas admiráveis em toda sua plenitude, a quem obrigado é pouco. Pessoas exemplares na dignidade, no caráter e na amizade. Tenho certeza que você vibrou, torceu e incentivou sonhos em buscas de novas conquistas.

O meu sincero reconhecimento 
Ao Dr. Heli Brosco e a Dra. Maria Lúcia Rubo Resende, do serviço de Implantodontia do Hospital de Anomalias Craniofaciais da USP, pelas oportunidades oferecidas durante o período em que permaneci neste centro.

A todos os Professores da FOB-USP, pelos constantes ensinamentos e pelo exemplo de dedicação ao ensino e pesquisa, o meu profundo agradecimento, em especial àqueles que fazem o Departamento de Prótese do Curso de Odontologia da FOB, Prof. Dr. Accácio Lins do Valle, Prof. Dr. Carlos Reis Araujo, Prof. Dr. José Henrique Rubo, Prof Dr. José Valdez Conti, Prof. Dr. Valércio Bonachela, Prof. Dr. Gerson Bonfante, Prof. Dr. Milton Carlos G. Salvador, Prof. Dr. Paulo Martins, Prof. Dr. Wellington Bonachela, Prof. Dr. Renato de Freitas, Profa. Dra. Lucimar Falavinha Vieira e Profa Dra. Eid Muniz Asckar. 
Aos meus colegas Aloisio, Daniel, Henrique, Luiz, Luciano, Marcelo, Materson, Rudys, Sérgio, Stefania e Zeno, que formaram a turma de 1995 do curso de Mestrado em Reabilitação Oral da FOB. O prazer da amizade, da sinceridade e do respeito nunca serão esquecidos.

Aos colegas da turma de Doutorado de 1995 Josué Alves, Stefan Dekon, Domingos, Júnior, João Henrique, Luiz Santiago e Paulo Rocha, pelo apoio indispensável durante o início do curso

Aos colegas da turma de mestrado de 1997, Anuar, Mário, Nelsinho, Juliano, Letícia, Dani, Andréa, Carlinhos, Vinicius Janson, Sérgio, Wagner e Vinicius, pelo convivio fraternal durante todos estes anos.

Aos colegas do Curso de Pós Graduação em Dentística, Ortodontia, Periodontia, Odontopediatria, Cirurgia, Diagnóstico Oral, Patologia, Endodontia e Materiais Dentários, pelo convivio durante todos

A toda a equipe do Laboratório de Ortodontia do Centrinho, Ana, Lorival e Wagner, pelo apoio e ajuda durante a fase laboratorial de confecção dos aparelhos necessários para o desenvolvimento desta pesquisa.

A todos os pacientes, que souberam compreender a necessidade da pesquisa, o meu muito obrigado. 


\section{Agradecimento especial}

A todos meus professores do Curso de Graduação da Faculdade de Odontologia da Universidade Federal do Pará, que certamente, em muito contribuíram para a minha formação profissional.

Ao Prof. Dr. Acácio Macedo Ceteno, pelo primeiro incentivo a ingressar no Magistério de Ensino Superior e oportunidades a mim oferecidas nos primeiros anos de minha vida profissional.

Ao Meu Mestre e amigo Dagoberto Sinimbu de Lima, pela confiança, amizade e apoio durante mais esta trajetória. Seu exemplo de sinceridade, amor e dedicação ao próximo merecem ser seguidos.

Ao Dr. Roberto Travassos, por todo seu incentivo no inicio de meu curso, sempre nos alimentado com palavras de força e de certeza na conquista do ideal.

Ao Materson e a Paula, Sérgio e Maria Carmen, Henrique e Letícia pelas muitas horas de convivência fraterna e ajuda mútua. A força de nossa união foi o fluido de nossas muitas aspirações.

Ao Prof. Dr. Wellington Bonachela, pelo apoio sincero e fraternal durante os primeiros dias em Bauru. 
Aos meus colegas Bruno, Ana Claudia, Serginho, Helena, Rose, Aline pelo apoio e convivio em Bauru.

Ao Dr Aladim Gomes Lameira, por todo o seu apoi durante o tempo em que permaneci no curso de mestrado e doutorado

Ao Dr. João Carlos Flexa Ribeiro pela palavra de incentivo, segura e sincera no momento de iniciar esta luta em busca de um ideal.

Ao Prof. Dr. Max Pinto da Costa da Rocha e Magnólia pelo incentivo, orientações e amizade em todos estes anos de permanência no mestrado e doutorado.

Ao Meu colega Cícero Almeida de Andrade pelo apoio e intercâmbio de idéias durante o curso.

Ao Prof. Dr. Leonardo Fonseca, Ex-Chefe do Departamento de Prótese da Universidade Federal do Pará, pelo incentivo, atenção e por todo seu empenho junto à Universidade Federal do Pará, viabilizando minha matrícula no Curso de Mestrado.

Ao Prof. Dr. Carlos Laércio Affonso os meus sinceros agradecimentos, pelos ensinamentos e muitas palavras de incentivo.

Ao Prof. Dr. Augusto César Affonso Filho, e a Profa. Dra. Tânia Rodrigues professores do curso de especialização em Periodontia da ABO - Pará pelo apoio durante todo o tempo em que permaneci 
realizando o curso de doutoramento.

À Funcionária Mara, do Departamento de Prótese da Faculdade de Odontologia da Universidade Federal do Pará, por sua gentileza durante todo o período em permaneci realizando o mestrado e doutorado

Ao Dr. Eduardo Jannuzi e sua esposa Andreia, dois mineiros que aprendi a admirar e tornaram-se meus irmãos. Palavras de incentivo constantes, foram Importantes para vencer mais esta etapa e consolidar uma grande amizade 


\section{Agradeço ainda}

À Universidade Federal do Pará, na pessoa do Magnífico Reitor Prof. Dr. Cristovão Diniz.

À CAPES pelo apoio durante a realização do Curso.

A todo Corpo Docente da Faculdade de Odontologia da Universidade Federal do Pará pelo incentivo e confiança em mim depositada.

A Faculdade de Odontologia de Bauru da Universidade de São Paulo, representada na figura de seu Diretor Prof. Dr. Aimar Pavarini

Aos colegas da Associação Brasileira de Odontologia Secção do Pará, referência no aprimoramento dos Profissionais da

À Bibliotecária Valéria pela correção das referências deste trabalho.

Aos funcionários do Departamento de Prótese da FOBUSP, Débora, Didi, Luiz, Reivanildo, Marcelo, Geraldo, Angela, Luzia, Edna e Lílian por toda atenção e carinho a mim dispensado durante estes anos.

Ao Serviço de Triagem da Faculdade de Odontologia de Bauru da Universidade de São Paulo ao proporcionar a condição para seleção de pacientes, fundamental à parte experimental da pesquisa.

A todos os funcionários da FOB, que com boa vontade e dedicação atenderam com gentileza nossas solicitações no sentido de tornar possivel a realização desta pesquisa. 


\section{SUMÁRIO}

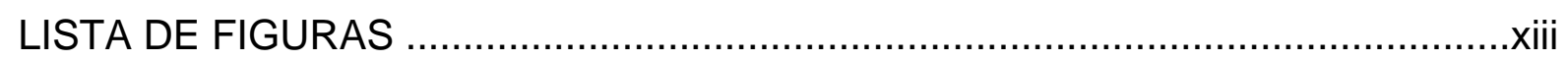

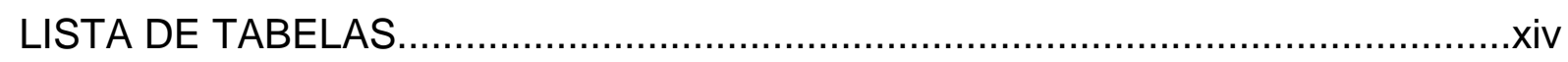

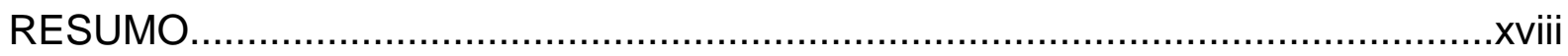

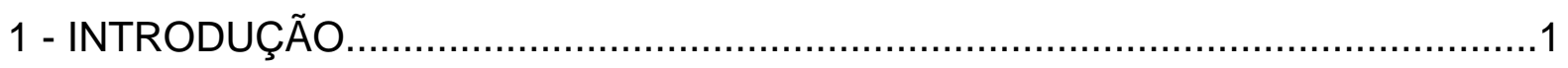

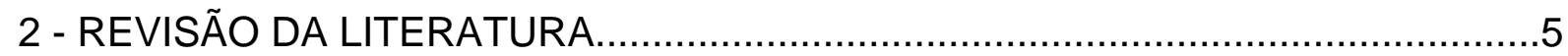

3 - PROPOSIÇÃO

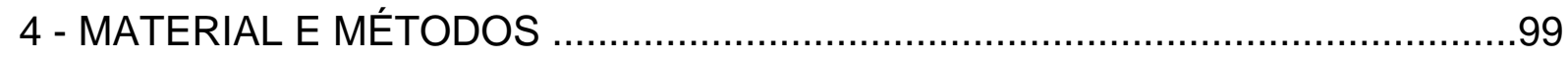

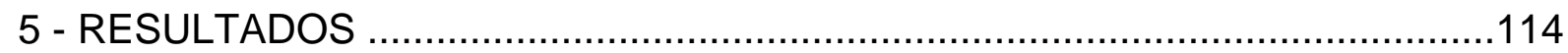

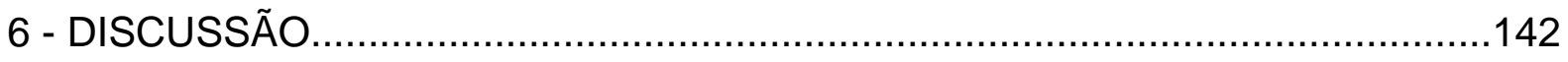

7 - CONCLUSÕES

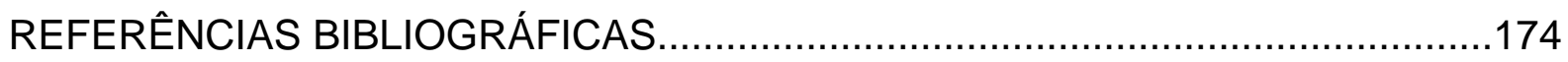

ANEXOS

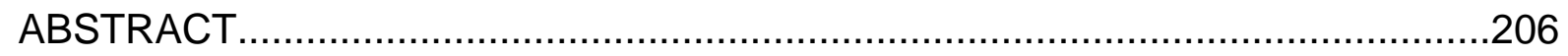




\section{LISTA DE FIGURAS}

FIGURA 1- $\quad$ Placa oclusal estabilizadora em posição ...................... 110

FIGURA 2 Placa oclusal reposicionadora em posição...................... 111

FIGURA 3 Variação da abertura bucal nos diferentes grupos............. 120

FIGURA 4 Variação da lateralidade esquerda nos diferentes grupos ... 122

FIGURA 5 Variação da lateralidade direita nos diferentes grupos....... 124

FIGURA 6 Variação da protrusão nos diferentes grupos................. 126

FIGURA 7 Variação do número de contatos oclusais nos diferentes grupos....................................................... 128

FIGURA 8 Variação dos valores da Escala de Análise Visual de dor (EAV) nos diferentes grupos. 


\section{LISTA DE TABELAS}

TABELA 1 Média de distribuição da idade entre os grupos e o respectivo desvio padrão

TABELA 2 Distribuição da amostra entre os grupos de acordo com sexo.

TABELA 3 Distribuição percentual de pacientes submetidos ao tratamento ortodôntico.

TABELA 4 Distribuição do relato de hábitos parafuncionais (bruxismo e apertamento) entre os grupos

TABELA 5 Distribuição da média de abertura (em milimetros) entre os grupos nos diferentes periodos de mensuração

TABELA 6 Teste de ANOVA a dois critérios para mensurações repetidas para a variável abertura bucal.

TABELA 7 Distribuição média dos valores de lateralidade esquerda (em milimetros) entre os grupos nos diferentes periodos de mensuração.

TABELA 8 Teste de ANOVA a dois critérios para mensurações repetidas para a variável lateralidade esquerda

TABELA 9 Distribuição média dos valores de lateralidade direita (em milímetros) entre os grupos nos diferentes períodos de mensuração 
TABELA 10 Teste de ANOVA a dois critérios para mensurações repetidas para a variável lateralidade direita.

TABELA 11 Distribuição média dos valores do movimento protrusivo (em milimetros) entre os grupos nos diferentes períodos de mensuração.

TABELA 12 Teste de ANOVA a dois critérios para mensurações repetidas para variável protrusão

TABELA 13 Distribuição da média do número de contatos oclusais entre os grupos nos diferentes períodos de mensuração...

TABELA 14 Teste de ANOVA a dois critérios para mensurações repetidas para a variável contatos oclusais

TABELA 15 Distribuição de média dos valores de EAV nos diferentes períodos de mensuração entre os grupos (em $\mathrm{mm}$ ).

TABELA 16 Comparações individuais (Student - Newman - Keuls) dos resultados obtidos para o grupo I em relação aos valores de EAV

TABELA 17 Comparações individuais (Student - Newman - Keuls) dos resultados obtidos para o grupo II em relação aos valores de EAV.....

TABELA 18 Comparações individuais (Student - Newman - Keuls) dos resultados obtidos para o grupo III em relação aos valores de EAV. 
TABELA 19 Avaliação inter grupos da EAV nos diferentes períodos de mensuração (teste de Kruskal-Wallis).....

TABELA 20 Avaliação da presença de ruído articular (inicial e final) em toda a amostra $(p<0,001)$

TABELA 21 Avaliação da presença de ruído articular (inicial e final) no grupo I $(\mathrm{p}=0,04)$.

TABELA 22 Avaliação da presença de ruído articular (inicial e final) no grupo II $(\mathrm{p}=0,02)$. . .

TABELA 23 Avaliação da presença de ruído articular (inicial e final) no grupo III $(\mathrm{p}=0,13)$

TABELA 24 Valores de "p" ( teste de Mc Nemar ) na comparação da sensibilidade da ATM à palpação nos diferentes períodos. 136

TABELA 25 Relato da amostra em relação a alteração na oclusão nos diferentes períodos de mensuração

TABELA 26 Relato da amostra em relação ao ruído nos diferentes periodos de mensuração......

TABELA 27 Relato da amostra em relação ao conforto nos diferentes períodos de mensuração 
RESUMO 


\section{Resumo}

O objetivo desse estudo foi avaliar a efetividade das placas oclusais reposicionadoras no controle de patologias intra-articulares da ATM, quando comparadas a um tratamento convencional (placa estabilizadora) e um grupo sem tratamento (controle).

A amostra contou de 52 pacientes portadores de sinais e sintomas de desordens intra-articulares da ATM, divididos, aleatoriamente em três grupos, de acordo com o procedimento empregado: grupo I $(n=20)$, utilizou placa estabilizadora, grupo II $(n=18)$ utilizou placa reposicionadora e grupo III $(\mathrm{n}=14)$, sem nenhum tratamento.

Toda a amostra foi acompanhada durante um ano, sendo avaliada através de questionários anamnésicos, palpação muscular e da ATM, movimentação mandibular e detecção de sons articulares.

Uma avaliação da condição oclusal também foi realizada nos diferentes períodos de exame.

Os resultados demonstraram uma maior efetividade das placas reposicionadoras na redução inicial da dor relatada pelo paciente, assim como uma diminuição na sensibilidade a palpação na ATM.

Todos os grupos mostraram-se semelhantes após seis 
meses de controle em relação aos sintomas, assim como em relação aos ruídos articulares. Os índices de palpação muscular mostraram-se melhor para todos os grupos, sendo que a oclusão também não se alterou significantemente.

Baseado no acima exposto, conclui-se que a terapia de uso parcial das placas reposicionadoras constitui-se num meio efetivo de controle das patologias intra-articulares da ATM. 
1 - INTRODUÇÃ0 


\section{1 - Introdução}

As Disfunções Temporomandibulares (DTM) englobam uma série de diferentes problemas e incluem alterações na musculatura mastigatória, na articulação temporomandibular (ATM) ou em ambas, afetando o sistema estomatognático como um todo, por meio de sinais e sintomas que muitas vezes limitam e incapacitam as atividades fisiológicas.

Estudos relacionados à epidemiologia, à etiologia, e modalidades de tratamento terapêuticas das DTM têm sido, nesses últimos anos, motivo de muitos estudos por parte dos pesquisadores. Tal fato é devido ao aumento de profissionais envolvidos no tratamento de pacientes com DTM, sem contudo obter o sucesso esperado. Paralelamente, o que se nota é que um grande número de individuos apresenta-se com esses problemas entre a população em geral, o que gera a necessidade de um melhor entendimento dos processos fisiológicos e sociais, envolvidos nestas patologias.

Muitas pesquisas têm sido realizadas com a finalidade de compreender melhor a fisiologia da ATM, bem como toda a sintomatologia dolorosa dessa articulação. Paralelamente, o número de pacientes portadores de DTM, que procura as clinicas odontológicas, tanto particulares quanto de instituições de ensino, têm aumentado consideravelmente. 
Para McNEILL ${ }^{92}$, 1980, os sintomas mais comuns da disfunção são contração e dor nos músculos da mandíbula, cabeça e pescoço, dor na ATM, limitação dos movimentos mandibulares, desgastes anormais nos dentes e periodonto.

As modalidades de tratamento propostas, têm variado de acordo com a filosofia dos autores sobre a etiologia dos sintomas, surgindo, então, várias formas de terapia, algumas vezes utilizadas associadamente, visando restabelecer a fisiologia das estruturas em questão

Entre as diversas formas de terapias propostas para as DTM encontram-se as placas oclusais estabilizadoras e reposicionadoras. GLASS; GLAROS; MCGLYNN ${ }^{44}$ relataram, em uma avaliação com 10000 membros da Associação Odontológica Americana, que o uso de placas oclusais havia sido o tratamento de eleição entre os especialistas nessa área para dor miofascial.

Nos Estados Unidos, de acordo com PIERCE et all ${ }^{112}$, pelo menos três milhões de placas oclusais são confeccionadas e instaladas todos os anos.

Apesar das placas reposicionadoras serem extensivamente utilizadas para o tratamento de pacientes que apresentam o estalido e dores articulares, poucos estudos longitudinais têm sido realizados avaliando a sua efetividade no tratamento específicos das patologias intra-articulares. 
Além disso, há uma deficiência na literatura de trabalhos em relação ao protocolo de utilização desses aparelhos sendo que outras formas de terapia irreversiveis, particularmente nos casos de deslocamento anterior de disco, têm sido descritas. Reabilitação Oral e ortodontia são métodos freqüentemente citados com esse objetivo.

Essa abordagem invasiva torna-se preocupante, uma vez que grupos de pacientes sem nenhum tipo de tratamento muitas vezes apresentam remissão de sintomas, caracterizando o aspecto autolimitante das DTM.

Dessa forma, a finalidade desta pesquisa é, por meio de metodologia específica, avaliar a efetividade do uso de dois tipos de placas oclusais no controle de patologias intra-articulares da ATM, quando comparados com um grupo controle. 
2 - REVISÃO DE LITERATURA 


\section{2 - Revisão da Literatura}

O estudo das Disfunções Temporomandibulares (DTM) vem despertando grande interesse entre os pesquisadores, fornecendo informações valiosas a respeito de técnicas, exames, terminologias, meios diagnósticos e tratamentos, objetivando-se um melhor entendimento e o ensino nesta área da Odontologia. Nesse contexto, os aparelhos oclusais representam uma das formas terapêuticas mais antigas e utilizadas.

Nesta revisão da literatura, manteve-se a terminologia original de cada trabalho, em função das várias denominações utilizadas durante as diferentes épocas em que se deu a pesquisa.

Apesar dos distúrbios do sistema estomatognático possuírem descrições muito remotas, somente no século passado é que as primeiras publicações científicas nesta área foram relatadas por ANNANDALE 6 , que, em 1887, descreveu algumas formas de cirurgias para o reposicionamento do disco articular em pacientes com limitação dos movimentos mandibulares.

Em 1918, PRENTISS ${ }^{113}$ introduziu a Teoria do Deslocamento Mecânico da Mandibula. Para esse autor, a perda da dimensão vertical era responsável pela disfunção da ATM. O fechamento excessivo da mandíbula levaria à perda da contenção por falta de molares e 
pré-molares, produzindo um movimento do côndilo em direção distal, o que resultaria em uma pressão direta sobre a tuba auditiva (trompa de Eustáquio), estruturas do ouvido e o nervo aurículo temporal. O autor concluiu que um colapso oclusal com conseqüente diminuição da dimensão vertical de oclusão seria responsável pela sintomatologia otológica em nível da ATM.

Em 1920, WRIGHT ${ }^{154}$, concordando com Prentiss, confirmou que a retrusão do côndilo em pacientes portadores de problemas de oclusão poderia causar reabsorção da placa timpânica, constrição dos condutos e irritação das estruturas adjacentes, incluindo a artéria e o nervo corda do tímpano, podendo causar perda auditiva parcial ou total.

GOODFRIEND ${ }^{46}$, em 1933, sugeriu que a alteração no relacionamento mandibular normal deve-se a um deslocamento súperoposterior do côndilo, o qual resultaria no alongamento dos ligamentos articulares e no relaxamento dos músculos, causando atrofia do disco e da superficie articular, bem como uma reabsorção óssea final como parte de um processo degenerativo. Acreditava que os ruídos articulares eram provavelmente causados pela frouxidão dos ligamentos que unem o disco ao côndilo e que os sintomas do ouvido eram causados pela pressão do nervo auriculotemporal.

COSTEN29, em 1934, atribuía à oclusão a causa das dores musculares e de ouvido sentida pelos pacientes. Segundo a descrição 
desse otorrinolaringologista, a perda dos dentes posteriores levava o côndilo a pressionar as estruturas retrocondilares, devido à sobremordida, trazendo como sintomas dor ao redor dos ouvidos, zumbidos, dores de cabeça, secura na boca e na garganta, ruídos articulares, além de compressão dos vasos e nervos auriculotemporais e corda do tímpano. Seus estudos foram baseados em observações realizadas em 11 pacientes com estes sintomas. Recomendava a reposição dos dentes perdidos como forma de minimizar os sintomas apresentados, pois seus pacientes apresentavam melhora nos sintomas após interposição de uma rolha entre os dentes. Com este seu estudo, definiu-se a origem e sintomas dos problemas articulares. Esse conjunto de sintomas foi denominado mais tarde de "Sindrome de Costen". Sua teoria, segundo descreve, apôiava-se em bases anatômicas extraídas dos trabalhos de GOODFRIEND ${ }^{46}$ realizados um ano antes, nos quais, os deslocamentos dos côndilos para posterior na fossa glenóide, levava à lesão de vários elementos. Entre esses elementos estava a Trompa de Eustáquio, que sofreria compressão pelo côndilo, e sendo exacerbada pela distensão da cápsula articular e dos ligamentos, ocasionando a surdez. A dor seria resultante da pressão sobre diferentes nervos como o corda do tímpano, responsável pela sensação de secura, formigamento e dor nas bordas da língua. A dor surda na cefaléia seria resultante de uma irritação dural, devido à profunda erosão óssea nas fossas glenóideas, provocada pelo atrito condilar, da qual resultava uma lâmina óssea delgada e fina no teto da 
cavidade glenóide, o que permitiria compressão da dura-máter pelos côndilos.

O mesmo COSTEN30, em 1936, voltou a se referir aos sintomas otológicos e relatou que a diminuição da audição, relatada por alguns de seus pacientes, estava associada ao deslocamento posterior do disco com pressão nas estruturas otológicas e disfunção do músculo tensor palatino.

Em 1939, COSTEN ${ }^{31}$ sugeriu a integração de médicos e dentistas para o diagnóstico e tratamento das disfunções na ATM. Relatou haver vários sinais e sintomas associados à ATM, como reumatismo, dor na área pré-auricular, dores cervicais, nevralgias do quinto par de nervos cranianos e ruídos articulares. Assim, a disfunção da ATM torna-se um problema comum a médicos e dentistas.

A partir da década de 50, alguns estudos começaram a mudar gradualmente aquilo que se pensava sobre a etiologia, iniciando-se uma fase com grande ênfase para oclusão. Paralelamente, outros fatores começaram a ganhar importância na tentativa de explicar a sintomatologia associada à DTM.

SCHWARTZ ${ }^{121}$, em 1955, sugeriu pela primeira vez a denominação de Síndrome Dor Disfunção da ATM, ao afirmar que sua causa era primariamente a disfunção dos músculos mastigatórios. Atribuiu um papel primário a fatores psicogênicos e às alterações oclusais, um papel 
secundário. A finalidade de seu trabalho era de definir com maior clareza a entidade clínica e explorar seus mecanismos. Segundo o autor, nesta sindrome existem fatores predisponentes, precipitantes, contribuintes e agravantes e, as anormalidades da oclusão eram apenas fatores contribuintes. Em alguns casos no grupo estudado por esse autor, havia muita dor e pouca disfunção e em outros casos havia muita disfunção e pouca dor, porém sempre esses sintomas estavam associados e em proporções diferentes. A limitação dolorosa era o sintoma de disfunção mais prevalente e parecia originar-se de um espasmo muscular e se autoperpetuar por um mecanismo de retroalimentação. Relatou ainda, estalidos na ATM, subluxações e em alguns casos, limitações totalmente indolores e de longa duração. Segundo o autor, a síndrome se manifestava sob forma de uma incoordenação funcional dos músculos mandibulares com sintomas de estalidos na articulação, subluxações ou deslocamentos recorrentes. A esses sintomas, seguia-se em muitos casos, o espasmo dos músculos mastigadores, que se caracterizava pela limitação dolorosa dos movimentos mandibulares. Quando não havia recuperação espontânea, persistia a contratura ou seja, a limitação dos movimentos sem dor.

Nesse mesmo ano, SHORE126 estudou os sinais e os sintomas mais freqüentes em pacientes portadores de disfunção da ATM, relatando que $90 \%$ destas disfunções são provocadas por anomalias oclusais. Os sinais e sintomas mais freqüentes foram: estalido na articulação acompanhado por crepitação, alterações nos movimentos de abertura e 
fechamento, movimentos excessivos da mandíbula, ciclo vicioso e espasmo muscular.

GRIFFIN; SHAPE53, em 1962, demonstraram que o disco articular é constituído de fibras elásticas e colágenas e que as fibras elásticas são espessas e bem orientadas. Geralmente se encontram na face superior da zona bilaminar, assim como na face lateral do disco. Os autores relacionam os ruídos da disfunção temporomandibular com uma hipermobilidade dos movimentos excursivos da mandíbula, conseqüente de excessivas modificações substitutivas nas fibras do disco.

Em 1966, KROGH; OLSSON70 descreveram que a tensão psíquica e a desarmonia oclusal podem desencadear distúrbios funcionais no sistema estomatognático. Segundo os autores, esses distúrbios se caracterizam por uma hipertonicidade muscular, dor nas articulações, dentes e/ou músculos e pela presença de hábitos parafuncionais. Descreveram como formas de tratamento a psicoterapia, aconselhamento, placas, ajuste oclusal e tratamento ortodôntico.

Em 1967, LAGER ${ }^{72}$ descreveu que se a recaptura do disco ocorresse, uma terapia longa com placa oclusal poderia permitir a volta da posição maxilo mandibular, sem a necessidade de restauração oclusal.

Em 1969, surgiu a Teoria Psicofiosiológica para explicar a etiologia das DTM. Segundo LASKIN ${ }^{73}$, existem quatro sinais cardinais da síndrome da dor-disfunção: dor, sensibilidade muscular, 
estalido da ATM e limitação da função da mandíbula. Além disso, o paciente deve apresentar ausência de sinais clinicos e radiográficos de alterações orgânicas da ATM e ausência de sensibilidade na ATM quando palpada via meato auditivo externo. Expondo sérias críticas às teorias baseadas na oclusão dentária, descreveu que o espasmo muscular pode ser causado de três maneiras diferentes: sobrextensão, maior contração ou fadiga muscular, sendo a fadiga muscular a causa mais comum, causada por hábitos orais crônicos, os quais seriam mecanismos de liberação de tensão. Entre esses podem ser citados o apertamento dos dentes e o bruxismo, que levaria a uma hiperatividade muscular e conseqüentemente à fadiga muscular. Dessa forma, o autor explicou que a maioria dos casos envolve mais o aspecto emocional do que fatores mecânicos. Segundo sua teoria, o espasmo muscular leva à dor, à limitação e a uma leve mudança na posição da mandíbula o que determinava uma oclusão incorreta. Caso essa alteração na posição mandibular se prolongasse, poderia ocorrer uma acomodação dos dentes. Desse modo, foi explicado como as desarmonias oclusais podem surgir em uma dentição funcional como um resultado do problema e não como a causa do mesmo. Para o autor, principalmente nas fases iniciais do problema, havia mais alterações musculares do que na ATM. Além disso, encontrou um alto grau de sucesso clinico no tratamento desses pacientes com diferentes tratamentos que não alteram a oclusão, ou mesmo quando os pacientes apenas pensavam que estavam recebendo tratamento. 
BELL' ${ }^{8}$ em 1969, ressaltou a importância de se abordar o paciente portador da síndrome de dor-disfunção miofascial tendo em mente a diferenciação que se deve realizar em relação a outras disfunções do sistema mastigatório. Para o autor, a má-oclusão crônica é o fator etiológico das disfunções mastigatórias, devendo ser diferenciada da má-loclusão aguda, que é um sintoma antes de ser um agente causal. Para o autor, espasmo muscular que vem de movimentos bruscos e incoordenados, fadiga muscular, alterações no meio bucal, má oclusão, doenças crônicas, doenças agudas e dor somática ou visceral profunda, podem provocar limitações mandibulares e dor nos músculos e em outras áreas.

FARRAR ${ }^{39}$, em 1971, ao descrever as fases para o diagnóstico e tratamento do deslocamento anterior de disco com redução, verificou que ao se posicionar a mandíbula anteriormente, o côndilo assumia um posicionamento normal em relação ao disco com eliminação do ruído articular e redução dos sintomas dolorosos em poucos dias. O autor foi o primeiro a indicar o uso da placa reposicionadora nos casos de deslocamento de disco articular, com a finalidade de recapturar e manter o disco em posição. O tempo sugerido de terapia com o uso deste aparelho foi de 24 horas por dia por um período de 3 a 6 meses.

Em 1971, GREENE; LASKIN52 estudaram 71 pacientes com síndrome dor disfunção com os seguintes sinais: sensibilidade muscular, limitações de abertura e desvio durante a abertura. Todos os 
pacientes receberam inicialmente uma placa não oclusiva como forma de tratamento. Os pacientes que não obtiveram melhora, receberam uma placa oclusiva total. Os resultados mostraram que $50 \%$ dos pacientes que receberam placas não oclusivas e $80 \%$ dos que receberam placas com cobertura total, apresentaram melhora. Ainda comentaram que na literatura há várias hipóteses sobre a eficácia da placa oclusiva:1) Prover um melhor relacionamento craniomandibular, 2) Prover um relaxamento muscular, 3) Efeito psicológico devido ao placebo.

FARRAR ${ }^{40}$, em 1972, explicando o tratamento de pacientes com deslocamento anterior do disco articular, descreveu que os mesmos freqüentemente perderam suporte dentário posterior no lado afetado e, além da diminuição da dimensão vertical, contatos deflectivos dos dentes levaram a mandíbula para trás. Com a aplicação dos princípios da teoria do reposicionamento da ATM, é então induzida uma mudança na relação côndilo-disco, que implica em colocar a mandíbula numa posição mais anterior e inferior. Essa posição mandibular é mantida por uma placa de reposicionamento anterior, que possui indentações e rampas no lado relativo ao disco deslocado. A premissa básica dessa abordagem é que o reposicionamento do disco ocorra e, após um período de quatro a seis semanas remove-se a placa oclusal e ajusta-se a oclusão por desgastes ou reconstrução protética, mantendo a mandíbula na posição terapêutica obtida. 
Em estudo realizado em 1972, GREENE; LASKIN50, observaram a relação profissional/paciente no efeito placebo. Cinqüenta pacientes com síndrome dor disfunção receberam uma droga placebo dita como nova e muito boa, que resolveria seus problemas musculares. Os resultados encontrados foram: 26 relataram melhora, 8 ao ponto de serem dispensados do tratamento, 20 não observaram nenhuma mudança e 4 tiveram efeitos colaterais como náusea, diarréia e vertigem. Mais uma vez, os sintomas subjetivos como dor e sensibilidade tiveram melhora, sendo que persistiram problemas como estalido e limitações (sinais objetivos).

Em 1972, GREENE e LASKIN49 estudaram a utilização de três tipos de placas oclusais para aliviar os sintomas de paciente com a Sindrome de Dor e Disfunção Miofascial. As utilizadas foram a placa oclusal estabilizadora, uma placa com cobertura parcial onde somente os dentes anteriores entravam em contato e a placa não oclusiva utilizada como placebo. Dos 71 pacientes do estudo, 87\% relataram alguma melhora em suas condições. Também 40\% dos pacientes mostraram diminuição em seus sintomas com o uso de uma placa placebo não oclusiva, a qual não modificava os contatos oclusais ou alterava o posicionamento mandibular. $\mathrm{O}$ estudo demonstrou que a placa de cobertura oclusal total obteve maior índice de sucesso. Este grande efeito clínico provavelmente é devido à obtenção de uma posição de descanso mais estável da mandíbula, proporcionada pela plataforma posterior bilateral. Para os autores, o estalido foi o sintoma de DTM mais resistente ao tratamento. 
Para verificar a prevalência de desordens funcionais do sistema mastigatório e fatores relacionados, AGERBERG; CARLSSON ${ }^{1}$, em 1972, avaliaram 1106 pacientes com idade entre 25 e 74 anos. Pela análise dos resultados, $24 \%$ dos pacientes relataram dores de cabeça e facial, $39 \%$ da amostra relataram a presença de estalido na ATM, sendo esse mais freqüente nas mulheres. Hábitos parafuncionais como apertamento e bruxismo também foram relatados e, segundo os autores, a alta freqüência destas disfunções na população em geral faz com que os cirurgiões-dentistas devam se interessar mais pelo estudo do diagnóstico e tratamento das mesmas.

BOEVER ${ }^{11}$, em 1973, relatou que altas prevalências de crepitação e estalidos são encontrados em todos os relatos da literatura e, que podem persistir mesmo após o tratamento. O autor relacionou os estalidos com as mudanças estruturais da superficie do disco e da articulação assim como, com as subluxações e incoordenação muscular.

\section{Em 1974 AGERBERG; CARLSSON ${ }^{2}$ reavaliaram} pacientes tratados de DTM, após de 3 a 5 anos de tratamento. Os pacientes haviam descrito a sintomatologia inicial apresentada como severa e depois do tratamento $75 \%$ alegaram pouco ou nenhum problema. O tratamento foi baseado na utilização de placas oclusais estabilizadoras e fisioterapia mandibular realizada em 65 pacientes, que também apresentavam mialgia. Os autores encontraram melhora em sintomas dolorosos, com utilização de 
aparelhos estabilizadores, porém sem relato na melhoria do estalido. Concluíram que há necessidade de acompanhamento dos pacientes com desordens funcionais, com a finalidade de avaliar sintomas residuais e reinstituir o tratamento conveniente ou encaminhar o paciente para outra terapia, se necessário.

Avaliando a distribuição de sinais e sintomas de DTM de acordo com o gênero e idade, HELKIMO ${ }^{57}$, em 1974, encontrou uma prevalência semelhante entre homens e mulheres, porém as mulheres apresentaram uma freqüência maior de dor de cabeça, no pescoço e ombros, fadiga na musculatura mandibular e um pior estado de saúde bucal. A distribuição dos sinais e sintomas, em relação à idade dos pacientes demonstrou maior freqüência com o aumento da idade. O menor índice de ambos os escores anamnésico e clínico, foi encontrado nos jovens entre 15 e 24 anos.

Em 1975, AGERBERG; CARLSSON ${ }^{3}$ analisaram os sintomas mais freqüentes em pacientes com DCM. Para isto, selecionaram um grupo aleatório e outro formado por portadores de Disfunções Craniomandibulares. Os resultados demonstraram que os sintomas mais freqüentes foram os ruídos articulares com uma incidência de 39\% na população aleatória e $79 \%$ na população sintomática.

McCALL et al88 (1976) demonstraram que pacientes com disfunção músculoesqueletal têm uma menor velocidade de fechamento 
mandibular e que o uso de uma placa lisa de mordida, combinada com ajuste oclusal posterior, promove uma melhora estatisticamente significante no problema.

No ano de 1976, GOODMAN; GREENE; LASKIN ${ }^{47}$ estudaram o efeito do ajuste oclusal em 25 pacientes portadores de espasmo muscular. Como tratamento, os autores realizaram um ajuste oclusal, realizado em baixa rotação com pedras abrasivas na superficie lingual dos molares inferiores e vestibular dos molares superiores, isto após um condicionamento prévio dos pacientes. Como resultado obtiveram que 16 pacientes tiveram todos os sintomas resolvidos e 9 descreveram insucesso, mas com leve alivio. Os autores acharam injustificável um tratamento irreversível, já que por métodos conservadores bons resultados são obtidos.

Em 1976, TOLLER ${ }^{138}$ descreveu que os mecanismos de produção de estalidos são associados com alterações dos movimentos do disco em relação ao posicionamento mandibular. Para o autor, um dos mecanismos de produção desses sons origina-se quando, durante o movimento inicial de abertura, ocorre um pequeno deslize do condilo para frente na cavidade articular, enquanto o disco permanece aderido a este. Em uma abertura maior, a união entre disco e côndilo seria rompida, fazendo com que o disco deslizasse subitamente para trás em relação ao côndilo, resultando o estalido. 
Em 1976, HELKIMO58 afirmou que os sintomas de disfunção são bem mais comuns do que se supunha e que não há grande diferença na freqüência de disfunções entre os homens e as mulheres. Concluiu também que sintomas de Disfunções Temporomandibulares são encontrados em pessoas de todas as idades com uma leve diferença qualitativa entre as pessoas mais idosas; e que não há um fator etiológico predominante de disfunção do sistema mastigatório nas populações estudadas. Entre outras conclusões, citou também que há uma certa correlação entre o grau de disfunção e o estado geral de saúde, o número de dentes ausentes e a má oclusão dentária. O autor sugere que, para facilitar as comparações futuras entre diferentes métodos e interpretação de resultados, é necessário usar os mesmos critérios de diagnósticos e coletar dados recorrendo a índices confiáveis, que permitam a constatação da prevalência de diferentes sintomas e suas severidades. A ajuda de um índice de disfunção de aceitação geral poderia ser útil na elucidação dos aspectos ainda obscuros da etiologia e do progresso das doenças de disfunção. Afirmam finalmente, que mais pesquisas epidemiológicas de diferentes populações são necessárias para ampliar o conhecimento nesse campo.

CARRARO; CAFESSE ${ }^{16}$, em 1978 avaliaram os efeitos das placas oclusais sobre a sintomatologia da ATM e encontraram melhoria nos sintomas articulares quando do uso de placas estabilizadoras. Tratando 20 pacientes com essa placa, relataram total remissão dos sintomas em $30 \%$ dos pacientes, diminuição em 40\% e nenhuma alteração em 30\%. Dos 27 
pacientes com mialgia presente, $85 \%$ foram considerados curados ou obtiveram alguma melhora com essa terapia.

Em 1979, FARRAR; McCARTY41 relataram que, na presença do disco deslocado anteriormente, os ligamentos posteriores estão estirados no interior do espaço articular entre o côndilo e a fossa. Dessa maneira, tais ligamentos funcionam como uma base onde se assenta o côndilo. Esta posição herniada dos ligamentos posteriores torna-se mais fibrosa e avascular. Isso representa um tipo de remodelação adaptativa ou uma resposta tecidual a função normal.

Para McNAMARA; CARLSON89, em 1979, um dos perigos de seguir-se procedimentos de posicionamento anterior da mandibula ou quaisquer outros métodos de reposicionamento e realinhamento é que a cura de um problema pode induzir a outros mais sérios. A mudança da posição condilar, mesmo eliminando os estalidos por algum tempo, pode induzir alterações de remodelação a longo prazo na ATM. Relataram, também, que o reposicionamento mandibular excessivo é prejudicial à ATM, podendo levar à reabsorção condilar anterior.

CLARK et $\mathrm{al}^{22}$, em 1979, estudaram 25 pacientes com sintomas de dor miofascial e função anormal da mandíbula, os quais foram tratados com uma placa miorrelaxante lisa de cobertura total. O nível de atividade noturna do músculo masseter foi monitorado antes, durante e após a terapia por placa oclusal utilizada na arcada superior. Relataram que 
$52 \%$ apresentaram redução nos niveis de atividade muscular noturna comprovada por eletromiografia durante o tratamento, enquanto que $28 \%$ mantiveram niveis estáveis e $20 \%$ sofreram um aumento das atividades eletromiográficas noturnas. Após a remoção das placas, 92\% voltaram aos niveis anteriores do tratamento, ou seja, observou-se novamente o retorno das atividades eletromiográficas pré-tratamento com a retirada das placas. Os autores concluíram que a terapia com placas levou a um maior índice de sucesso na redução das atividades eletromiográficas noturnas em pacientes com sintomas de disfunção menos severos.

OGUS ${ }^{100}$, em 1979, fez uma análise sobre alterações degenerativas da ATM em adultos jovens. Relatou existirem dois tipos de sobrecarga: uma absoluta e uma relativa. A sobrecarga relativa ocorre sobre a cartilagem defeituosa na presença de um disco articular normal, processo esse que ocorre durante o processo de envelhecimento. Já a sobrecarga absoluta ocorre quando a cartilagem articular está normal, sendo que a falha ocorre como resposta a eventos traumáticos únicos ou associados. Concluiu que uma sobrecarga articular é o princípio básico na etiologia das alterações degenerativas articulares.

Ainda em 1979, WEINBERG ${ }^{141}$ salientou que o estresse e fatores oclusais têm sido associados com a sindrome da dor e disfunção da ATM. Em alguns pacientes, a oclusão não é o fator principal, já em outros representa um papel importante na etiologia. Em sua opinião, há evidências 
clínicas e eletromiográficas conclusivas em relatar uma relação direta de causa e efeito entre interferências oclusais e DTM. Sugeriu, porém, que a oclusão não é o único ou principal fator em todos os pacientes. O autor concluiu que a razão do conflito permanece não resolvido, uma vez que o critério para "má-oclusão" é indefinido e controvertido.

GOHARIAN; NEFF45, em 1980, avaliaram 13 pacientes com a finalidade de analisar o efeito de aparelhos oclusais sobre a dor facial e na ATM. Os autores obtiveram a cura em quatro pacientes, melhoria dos sintomas em sete manutenção dos sintomas em dois indivíduos. Concluíram que, os aparelhos oclusais podem ser efetivos na melhoria da sintomatologia dolorosa.

Em 1980, BEARD e CLAYTON7 ${ }^{7}$ conduziram um estudo para determinar o que ocorreria com sintomas de disfunção em pacientes tratados apenas com placas oclusais. Quatrocentos e oitenta e seis pantogramas foram realizados em 15 pacientes experimentais em um período que variava de cinco meses a um ano. Cinco pacientes controle foram monitorados neste mesmo período, sem nenhum tratamento. Os pacientes do grupo experimental com disfunção da ATM foram tratados com placas oclusais lisas. As placas foram utilizadas até que os sintomas fossem reduzidos e o Índice de Reprodutibilidade Pantográfica (PRI - Pantographic Reproducibility Index) pudesse ser reproduzido. As placas foram removidas sem ajustes oclusais e os pacientes foram analisados pantograficamente. 
Análise estatística foi realizada nos resultados de PRI para determinar o relacionamento entre os pacientes de ambos os grupos. Os pacientes tratados tiveram uma queda de 21,7 pontos durante a terapia com placas, quando comparados com os 3,8 pontos dos pacientes controle. Todos os pacientes tiveram um aumento no nível de pontos PRI logo que se removiam as placas oclusais. Os autores concluíram que o uso de placas oclusais como única modalidade terapêutica é insuficiente para o tratamento das incoordenações musculares.

MAGNUSSON; CARLSSON ${ }^{84}$, em 1979, discordaram de muitos autores ao descreverem que os aparelhos oclusais não são efetivos na redução dos sintomas dolorosos que acometem a ATM.

Avaliando os sintomas de 138 pacientes portadores de Síndrome Dor-Disfunção-Miofacial (SDDMF), WEINBERG ${ }^{142}$, em 1980, encontrou no exame de palpação muscular 58\% dos pacientes com dor bilateral, 31\% com dor unilateral e $9 \%$ com dor na ATM. Salientou a dificuldade em estabelecer um método científico diagnóstico, devido à complexidade da síndrome. Apresentou como sinais patognomônicos de DTM, ruídos articulares e dor na abertura.

RAMFJORD; BLANKENSHIP115 em 1981, avaliaram a adaptação de macacos Rhesus a aumentos experimentais na dimensão vertical de oclusão. Neste estudo, os autores encontraram que tal aumento não provocou efeitos patológicos nas articulações temporomandibulares. 
Assim, de acordo com esses autores, o pressuposto de que uma dimensão vertical anormal seja causadora de disfunção craniomandibular não apresenta consistência.

Em 1982, ISBERG-HOLM; WESTESSON63, com a finalidade de analisar o movimento do disco e côndilo na autópsia de ATM com e sem estalido e de estudar o que causa o estalido, realizaram estudo em cinco espécimes de autópsias de ATM com estalido e quatro com ausência de barulho. Os compartimentos articulares foram visualizados pela remoção da parte lateral da cápsula e disco. Em articulações sem estalido havia uniformidade de movimento condilar, com o disco em posição. Em articulações com estalido o movimento de deslocamento do disco era bem visível. Em quatro articulações com estalido recíprocos, o som foi registrado no instante que o côndilo alcançou o componente temporal, depois de ter passado pelo bordo posterior do disco. Na dissecção, todas articulações demonstraram apresentar um desvio na forma de ambos componentes, temporal e mandibular.

Em 1982, DAHLSTRÖN; CARLSSON; CARLSSON ${ }^{32}$ realizaram estudo clínico com a finalidade de avaliar e comparar os efeitos do "biofeedback" (relaxamento) e terapia com placa oclusal no controle das DTM. Para isto, selecionaram 30 pacientes do gênero feminino entre 20 e 40 anos, sem qualquer razão orgânica óbvia para DTM, que foram aleatoriamente divididos em dois grupos. Um usou placa oclusal noturna por 
seis meses, e outro recebeu treino de "biofeedback". Os pacientes foram reavaliados um mês após e foi observado que ambos os grupos mostraram uma significante redução dos sintomas, tanto subjetiva quanto clinicamente, não apresentando diferença significante. Assim, os dois tratamentos apresentaram igual efetividade nesse periodo de acompanhamento. Para o autor, uma provável explicação para esse efeito similar é que ambos tratamentos reduzem a tensão dos músculos mastigatórios associados com a dor e disfunção.

Em 1982, OKESON, KEMPER e MOODY105 conduziram estudo a fim de avaliar o resultado do tratamento de pacientes com DCM com placas oclusais. Foram utilizados 33 pacientes, os quais foram divididos em dois grupos: pacientes crônicos e agudos, sendo que os crônicos consistiam de 20 pacientes com média de duração dos sintomas de 44.4 meses e o grupo agudo com 13 pacientes com média de duração de 3.8 meses. Os pacientes foram tratados por quatro semanas com placas oclusais e os resultados revelaram um decréscimo na dor, aumento na máxima distância interincisal com conforto e aumento na máxima abertura mandibular.

Em 1983, LEDERMAN; CLAYTON75 estudaram 50 pacientes com as faces oclusais restauradas com próteses parciais fixas, os quais apresentavam um alto percentual (68\%) de disfunção da ATM. Para determinar a significância das interferências oclusais, placas oclusais foram 
confeccionadas para dez dos pacientes com disfunção moderada ou severa. O PRI foi utilizado para determinar a presença ou ausência de disfunção. Os pontos PRI da disfunção foram reduzidos em todos os dez pacientes após o uso das placas oclusais. Os achados indicam que a terapia com placas oclusais não é um tratamento, pois quando removidas, ocorre uma reativação das interferências oclusais. Portanto, segundo os autores, o tratamento seria a remoção das interferências oclusais.

Em 1983, ERIKSSON, WESTESSON ${ }^{38}$ submeteram pacientes que apresentavam estalido seguido de limitação de abertura, a exames clínicos e radiográficos, incluindo artrografia. Nos pacientes que apresentavam uma limitação de movimento, o disco deslocado anteriormente estava bloqueando a translação condilar para anterior. De acordo com os resultados, os pacientes que apresentavam limitação de abertura apresentavam mais dor e sinais de disfunção mandíbula, maiores alterações de tecido duro e maior freqüência de perfuração e deformação do disco, quando comparados com pacientes que possuem somente o estalido. Estes achados podem justificar dois diferentes diagnósticos: deslocamento anterior com e sem redução. Para os autores, o deslocamento sem redução parece ser uma disfunção mais avançada e pode, em alguns casos, ser precursora da osteoartrose.

Em 1983, SCAPINO 119 avaliando aspectos histopatológicos associados com o mal posicionamento do disco articular, 
descreveu que o desarranjo interno freqüentemente resulta em um posicionamento posterior do côndilo, comprimindo as estruturas retrodiscais. O autor descreveu mudanças patológicas no disco, incluindo alterações na forma e na orientação e arquitetura do colágeno interno, além de patologias na inserção posterior. Relatou ainda, a presença de uma massa compacta ou fibrose na porção mais anterior da inserção posterior, resultante de uma sobrecarga condilar anormal.

MEJERSCO; CARLSSON93 em 1983, avaliaram os resultados no tratamento de dor e disfunção da ATM pela análise da freqüência e severidade dos distúrbios funcionais do sistema estomatognático. Para isto, analisaram 154 mulheres com DTM durante sete anos. Os resultados destes sete anos foram comparados com registros realizados antes do tratamento. Oitenta e quatro por cento dos pacientes relataram que o tratamento executado resultou em remissão dos sintomas, $80 \%$ dos pacientes tiveram poucos ou nenhum sintomas recorrentes. Sintomas recorrentes com algum significado foram encontrados em menos de $20 \%$ dos pacientes e somente $14 \%$ retornaram para novo tratamento. Concluíram que com a utilização de tratamento conservador e dentro do período de análise, os pacientes têm pouca recorrência de sintomas. Assim, a utilização de placas estabilizadoras associadas ao aconselhamento e outras formas de controle não cirúrgico, podem ser efetivas na redução de sintomas dolorosos, uma vez que a maioria dos pacientes com DTM tem mínima recorrência dos sintomas após sete anos de tratamento conservador. 
GREENE; LASKIN51, em 1983, avaliaram os resultados a curto e longo prazo de tratamentos reversíveis e conservadores, incluindo placebo, em 175 pacientes com Disfunção Temporomandibular. Então, compararam com outras dez publicações onde os autores usaram tratamento conservador, irreversivel e ambos. Os resultados foram semelhantes, sendo que os autores sugeriram que o tratamento conservador e reversível são apropriados e suficientes para a maioria dos pacientes. Grandes alterações de posição de côndilo e nas relações maxilomandibulares não são apropriados para tratamentos desses pacientes.

Em 1983, HARGREAVES; WARDLE55 analisando as modalidades terapêuticas para a dor e disfunção miofascial, descreveram que as mesmas podem ser de origem sistêmica ou local. Afastaram o tratamento cirúrgico como forma de terapia, concluindo que uma abordagem mais conservadora conduz a um controle mais efetivo da sintomatologia do paciente e a um melhor controle dos casos.

Utilizando uma amostra de mil pacientes, com a finalidade de estudar a prevalência dos sinais clínicos mais comuns de dor e disfunção miofascial, GROSS; GALE ${ }^{4}$, em 1983, descreveram que uma porcentagem de $35 \%$ apresentava ruídos articulares. Concluíram que a presença desses sinais com ausência de dor, não indica necessariamente que devam ser tratados. 
Em 1984, GRABER 48 avaliou o efeito do reposicionamento anterior, concluindo que quando o côndilo é levado para anterior em relação à fossa, a neuromusculatura pode se adaptar a esta nova posição com a aquisição de um novo padrão neuromuscular. Além disto, há uma diminuição na compressão sobre as estruturas retrodiscais.

Em 1984, OWEN107 encontrou evidências de reabsorção condilar quando de um posicionamento condilar anterior excessivo, concluindo que para a manutenção da integridade condilar, somente um minimo de reposicionamento anterior pode ser realizado. O autor relatou que a mordida aberta posterior, que eventualmente ocorre após o uso do aparelho de reposicionamento anterior, poder ser corrigido com a erupção passiva dos dentes posteriores.

Em 1984, MANZIONE et al ${ }^{86}$ utilizaram artrografias com a finalidade de monitorar a recaptura do disco durante a utilização de aparelhos de reposicionamento anterior. Os autores concluíram que a utilização destes aparelhos para o deslocamento anterior de disco com redução de forma incorreta pode permitir ou determinar a progressão da doença. Alertaram para o fato de que o desaparecimento do estalido, nem sempre indica um sinal positivo de redução.

Para CLARK ${ }^{18}$, em1984, a simples remissão ou mesmo o desaparecimento total de sintomas, como estalido e dor após o uso de placas não significa, necessariamente, a resolução do problema. Por outro 
lado, a persistência ou agravamento dos sintomas sugere um diagnóstico incorreto, com o uso ou construção inadequados das mesmas. Neste mesmo estudo, descreveu ainda que o fato de terapias com placas oclusais, em certos grupos de pacientes, serem bem sucedidas não prova que a teoria do desengajamento oclusal, defendida por alguns na tentativa de explicar o mecanismo de ação destes aparelhos, esteja correta. Ele advoga que, se tais placas funcionam, isso talvez seja devido à estabilização dos dentes e redistribuição de forças, além de outros fatores discutidos na teoria da consciência cognitiva. Com relação à teoria do realinhamento maxilomandibular, o autor relatou que o alívio dos sintomas obtido após o realinhamento da mandíbula à maxila, pelo uso de uma placa de mordida, pressupõe que a posição mandibular antes existente não era correta. $\mathrm{O}$ autor afirma que essa abordagem é simplista e deve ser reconsiderada, além de que outras explicações para o alívio dos sintomas devem ser exploradas. Se referindo à teoria da conscientização, CLARK ${ }^{18}$ descreveu ainda que a crescente conscientização do paciente a respeito do posicionamento e uso da mandíbula influenciam-no a aprender quais posições ou atividades são prejudiciais, diminuindo o fator contribuinte para a disfunção.

Ainda, em 1984, CLARK ${ }^{19}$ analisou o tratamento de ruídos articulares placa de reposicionamento anterior. Para isto descreveu os resultados do tratamento de 25 pacientes com placas reposicionadoras. De 14 pacientes que completaram o tratamento, 12 (86\%) descreveram em questionário que tinham melhorado com o tratamento. Os 11 pacientes que 
não continuaram com o uso da placa de reposicionamento, seis foram tratados com placas de estabilização. Somente um destes pacientes descreveu melhora significativa. Pela análise, os pacientes apresentaram melhoras entre um a dois anos. Em sua pesquisa, metade da amostra avaliada que apresentava-se assintomática apresentava estalido, e a terapia com placas de reposicionamento anterior apresentou melhores resultados.

Em 1985, SINGH; BERRY128 analisaram as variações oclusais que ocorriam pelas interferências mecânicas causadas pelo uso de placas oclusais com material resiliente. Para isto avaliaram dez pacientes, entre 16 e 21 anos, que não tinham nenhuma história de disfunção. A localização e severidade dos contatos oclusais foram marcados antes do uso da placa oclusal em cada paciente. Essa placa oclusal foi posicionada por 3, 5 e 7 horas, e os contatos oclusais foram registrados depois de cada um desses intervalos. Os resultados mostraram que o número de dentes em contato baixa gradualmente após o uso de placa oclusal por 5 a 6 horas; após esse tempo os contatos aumentam. Mudanças oclusais são esperadas quando placas oclusais são usadas. No entanto, os dentes e os músculos devem readaptar-se a um alterado ciclo mastigatório, que pode ou não necessitar de um ajuste oclusal. Parece que materiais restauradores mais duros que o esmalte e extração dental para tratamento ortodôntico podem predispor a discrepâncias oclusais que podem resultar em disfunção do sistema mastigatório. 
LUNDH; WESTESSON; TILLISTRON80 em 1985, avaliaram a efetividade da placa de reposicionamento anterior na redução especialmente do barulho recíproco em pacientes com disfunção internas da ATM. Para isto realizaram um estudo no qual 70 indivíduos selecionados ao acaso e que apresentavam estalido, receberam placas reposicionadoras, placas estabilizadoras, sendo que um grupo serviu de controle. Nos dois grupos, houve diminuição na fadiga muscular. O grupo que usou a placa de reposicionamento anterior, apresentou um maior grau de diminuição na fadiga muscular e no grau de disfunção articular. Após um ano de observação aquele sinal se manteve em todo o grupo com placa oclusal estabilizadora enquanto que este desapareceu em 22 de 24 pacientes que usaram placa reposicionadora, porém em 18 desses casos o sinal retornou depois que foi interrompido seu uso. Um caso evoluiu para o deslocamento anterior de disco sem redução (closed lock).

Em 1985 WESTESSON; BRONSTEIN; LEIDBERG ${ }^{146}$ estudaram os desarranjos internos da ATM e encontraram que o deslocamento parcial do disco é progressivo e, eventualmente, leva a uma deformação em $31 \%$ das vezes, sendo que um deslocamento completo leva a uma deformação do disco em $77 \%$ das vezes. Segundo os autores, esse fato enfatiza a importância de se tratar precocemente o disco deslocado para reduzir o potencial de danos irreversíveis. 
PALLA; ANTONNI110, em 1985, analisaram a evolução a estalido recíproco. Para tanto selecionaram um grupo de 40 pacientes que apresentava estalido recíproco, diagnosticado por meio de exame de palpação, auscultação, e análise da mobilidade do côndilo pela fluoroscopia e em alguns casos pela de artrografia. Vinte e nove pacientes foram tratados utilizando placa protrusiva. Dez utilizaram placas tipo Michigan com guias e um utilizou os dois tipos de aparelhos alternadamente. Quando a placa protrusiva era instalada a posição terapêutica da mandíbula, que correspondia ao desaparecimento do estalido, era verificada pela fluoroscopia. Os pacientes foram reexaminados num intervalo entre 8 e 9 meses. Vinte e sete pacientes dos 29 que utilizaram a placa protrusiva, estavam livres dos estalidos, no período em que ocorreu a avaliação. Em seis pacientes dos dez que utilizaram as placas tipo Michigan, o estalido tinha desaparecido. Em um paciente com manutenção do estalido, pertencente a este grupo, o mesmo desapareceu somente após transformação da placa tipo Michigan em placa protrusiva. Para os autores, a placa protrusiva é uma forma terapêutica segura na redução de estalidos que acompanha os desarranjos internos da ATM.

LE BELL; KIRVESKARI ${ }^{74}$, em 1985, descreveram o sucesso no tratamento do ruído recíproco com o uso de aparelhos de reposicionamento anterior. Relataram que o posicionamento anterior é efetivo na redução do ruído e que a quantidade do movimento anterior deve ser mínimo, apenas o suficiente para reduzir o deslocamento do disco. 
Em 1985, ANDERSON et $\mathrm{al}^{5}$, em 1985, realizaram um estudo com a finalidade de analisar dois métodos de tratamento para a redução de desarranjos internos da ATM. Compararam o reposicionamento ortopédico mandibular e a terapia com placas oclusais estabilizadoras no tratamento de pacientes com deslocamento anterior de disco com redução. Para isto acompanharam clinicamente dez pacientes que tinham recebido placa reposicionadora e dez pacientes que tinham recebido placa estabilizadora. Com vinte dias de utilização da placa de reposicionamento, os pacientes já experimentavam uma significante diminuição nos sintomas subjetivos e objetivos de desarranjos internos. Após 90 dias de tratamento, em $80 \%$ do grupo que usou placa reposicionadora o estalido tinha desaparecido, enquanto que em nenhum dos pacientes que usaram placas estabilizadoras houve o desaparecimento deste sintoma. Dois casos que haviam recebido placas estabilizadoras evoluíram para deslocamento anterior de disco sem redução "closed lock" durante o tratamento. Descreveram ainda que a sintomatologia dolorosa diminuiu em $60 \%$ da amostra que usou a placa reposicionadora, enquanto que não foi observado o mesmo no grupo que usou placa estabilizadora. Os autores concluíram que as placas oclusais lisas não produzem nenhuma mudança significante no nível de disfunção dos pacientes com disfunção da ATM associados com o deslocamento anterior de disco com redução. Para os autores, ficou clara a superioridade da placa reposicionadora sobre a placa lisa na remissão de 
estalidos articulares, sendo que foi então, sugerida a propondo a utilização deste aparelho com a finalidade de controle deste sinal.

De acordo com SOLBERG ${ }^{130}$, em 1986, um ligamento capsular comprometido pode ser fonte de instabilidade articular. Segundo o autor, na fase da abertura bucal o feixe inferior do pterigoídeo lateral é ativado. O disco gira posteriormente próximo ao côndilo, enquanto o conjunto côndilo-disco se move para frente e para baixo, próximo à eminência articular. A força de tensão do ligamento posterior, em meia abertura, auxilia a ida para trás do disco em rotação próximo ao côndilo. A inatividade do feixe superior do mesmo músculo, durante a abertura, facilita esta ação. É improvável que esse músculo tenha uma forte atuação ao tracionar o disco para frente durante a abertura. Nos movimentos de fechamento, o disco gira anteriormente, sendo que o feixe superior do pterigóideo lateral é ativado com o intuito de evitar um retorno brusco por parte do disco, pela ação do ligamento posterior.

Em estudo microscópico realizado em 1986, De BONT et al. ${ }^{36}$ avaliaram a osteoartrite e os desarranjos internos da ATM. Para isto, estudaram 22 espécimes de autópsias em microscópio de luz. Encontraram oito articulações com posicionamento normal do côndilo, oito articulações com deslocamento anterior do disco e deslocamento parcial do disco em cinco articulações. Uma articulação tinha o disco perfurado. Verificaram que articulações com hipermobilidade condilar e "estalido" recíproco não 
apresentam mais alterações degenerativas do que as articulações hipermóveis e que não apresentavam o "estalido". Com base nesses achados os autores não encontraram relacionamento entre desarranjos internos e osteoartrite.

CLARK ${ }^{20}$, em 1986, descreveu a técnica de confecção, inserção e ajustes dos aparelhos de posicionamento anterior. O autor relatou que, apesar de alguns relatos de intrusão de dentes posteriores com o uso do aparelho de reposicionamento anterior, isto só é observado quando não há a cobertura de todos os dentes posteriores com o aparelho. Ressaltou ainda que a restauração de uma oclusão funcionalmente aceitável, além de difícil de ser conseguida, é dispendiosa ao paciente.

Em 1986, ISBERG-HOLM; ISACSSON62 avaliaram a reação da inserção posterior a retrusão mandibular, em estudo realizado em macacos. Neste estudo, resina composta e estruturas metálicas foram realizadas com a finalidade de facilitar o posicionamento retrusivo da mandíbula. Depois de cinco semanas a avaliação histológica demonstrou afinamento e diminuição na espessura na banda posterior do disco, semelhante ao que havia sido descrito por Scapino ${ }^{119}$ e ainda, um aumento no número de vasos com espessamento do endotélio em toda a inserção posterior. De acordo com o autor estes resultados demonstram que a pressão condilar posterior sobre os tecidos retrodiscais pode determinar uma migração de mediadores químicos e o aparecimento de inflamação. 
Em 1986, MOLONEY; HOWARD ${ }^{96}$ avaliaram o uso da placa de reposicionamento anterior no controle de casos de desarranjos internos. Relataram que muita atenção foi dada a terapias com placas de reposicionamento, devido ao seu potencial de mudanças irreversíveis. Em certos pacientes, mesmo se os seus discos não pudessem ser recapturados, não havia previsão para se conseguir manter esta relação e talvez o uso do reposicionador fosse contra-indicado. Descreveram que somente $36 \%$ de 241 pacientes tratados com placas reposicionadoras, permaneceram sem o estalido depois de três anos de controle e que, o aparelho reposicionamento foi menos efetivo no controle de estalido que ocorre no final de abertura quando comparado com aquele que ocorre no início da abertura. Concluíram que a placa de reposicionamento anterior não foi eficiente em manter o disco recapturado a longo prazo em mais de $36 \%$ dos pacientes examinados. Para os autores, um dos fatores que contribuem para isto, é o fato que na presença de deslocamento anterior de disco com ou sem redução sugeridos pela história clínica e exame, existe uma probabilidade bem elevada de que o disco esteja também distorcido.

Avaliando clínica e eletromiograficamente o efeito a longo prazo do uso da placa oclusal estabilizadora sobre os músculos masseter e temporal em pacientes com disfunção funcionais e bruxismo noturnos, SHEIKHOLESLAM et al125, em 1986, mostraram que, de 31 pacientes que tiveram seus sinais e sintomas de disfunção e bruxismo noturno reduzidos pelo uso prolongado ( 3 a 6 meses) de placas oclusais, 
cerca de $80 \%$ apresentaram recorrência dos sintomas dentro de 1 a 4 semanas após a remoção das placas oclusais.

A maioria dos trabalhos confirma a necessidade de crescimento para que ocorra alterações permanentes com o uso de aparelhos ortopédicos funcionais. WILLIANSON ${ }^{149}$, em 1986, desenvolveu uma linha de pesquisa sobre o tratamento de pacientes com DTM, utilizando aparelhos ortopédicos. Em um caso descrito, o autor tratou uma paciente de 20 anos com ruído articular e limitação de movimento. A paciente foi diagnosticada como apresentando deslocamento anterior de disco com redução na ATM direita. Paciente utilizou placa de reposicionamento anterior superior e inferior. A inferior foi utilizada durante o dia e a superior durante a noite. Após 3 a 4 meses de reposicionamento anterior, a paciente foi tratada com uma placa de reposicionamento anterior superior, até a estabilização da mandíbula. Após este período era realizado uma avaliação oclusal com a finalidade de se determinar o tratamento necessário. Para o autor, o caso representou uma mudança ortopédica mandibular que resultou efetivamente no fechamento da mordida aberta apresentada pela paciente. De acordo com autor, pela sobreposição mandibular, ocorreu um aumento no comprimento mandibular de $2 \mathrm{~mm}$. Foi sugerido que isto ocorreu de duas maneiras: por remodelação do côndilo devido à presença de fibras intactas na superfície articular, e redução do disco deslocado, que poderia aumentar a altura facial posterior, deslocando a mandíbula mais anteriormente. 
Em 1986, WILLIANSON ${ }^{150}$, em outro estudo, relatou o sucesso no tratamento de uma paciente de 17 anos que apresentava deslocamento anterior de disco sem redução no lado direito. A paciente utilizou aparelho de reposicionamento anterior, o que resultou em um aumento no comprimento mandibular, segundo o autor devido à recaptura do disco ou devido à remodelação do condido. O autor finalizava o caso com aparelho ortodôntico fixo.

O relacionamento entre alterações oclusais e articulares e a importância dos fatores oclusais no aparecimento dos possiveis sintomas foram estudados, em 1986, por DE LAAT; VAN STENBERGME; LESAFFRE ${ }^{37}$. Para isto, avaliaram 121 pacientes assintomáticos. O estalido nas ATM ocorreu com grande freqüência nos pacientes que apresentavam poucos dentes e instabilidade oclusal, enquanto que a dor nas ATM não se relacionou claramente com fatores oclusais.

Em 1987, RUBINOFF; GROSS; Mc CALL ${ }^{117}$, relataram o efeito da placa oclusal sobre o tratamento das disfunções temporomandibulares. Trinta pacientes foram selecionados com sinais e sintomas da disfunção, sem haver tido recentemente qualquer tipo de terapia oclusal, sem terceiros molares com problemas ou portadores de qualquer tipo de patologia orgânica sobre a ATM. Dezenove pessoas receberam uma placa oclusiva total com contatos bilaterais simultâneos e estáveis, guia anterior e canina, sendo que outras 15 pessoas receberam 
uma placa não oclusiva, que cobria somente o palato. Estas placas deveriam ser usadas 24 horas por dia, removendo só para se alimentar e fisioterapia era recomendada para aliviar a dor. Como resultado, após seis semanas, observaram que ambas as placas aliviaram os sintomas igualmente, porém a placa oclusal foi mais efetiva para a redução dos sinais da disfunção.

OKESON $^{101}$ (1987), avaliando o efeito das placas lisas de mordida e das placas oclusais resilientes sobre o bruxismo noturno, sugeriu que as primeiras reduzem a atividade muscular noturna na maioria dos pacientes, ao passo que as placas oclusais resilientes aumentam tal atividade, contra indicando o seu uso.

Em 1987 WILLIANSON; SHEFFIELD ${ }^{151}$ avaliaram 300 pacientes que apresentavam desarranjos internos tratados com placa de reposicionamento anterior. Depois da eliminação dos sintomas, os pacientes passaram a utilizar uma aparelho de posicionamento superior com a finalidade de guiar o complexo côndilo-disco para a parte superior da fossa articular. Todos os pacientes que experimentaram uma recidiva foram orientados a retornar com o aparelho inicial ou a realizar a artroplastia. Três a cinco anos depois os pacientes foram indagados sobre a presença de dor, disfunção e sintomas remanescentes. Os pacientes foram reexaminados, a disfunção foi graduada pelo grau de palpação e auscultação. Os resultados mostraram que 90\% (270) dos pacientes iniciais estavam livres de dor e com função satisfatória. Dos 30 pacientes que não tinham controlado a dor, 28 
estavam assintomáticos, enquanto usavam a placa de reposicionamento anterior.

Em 1987, HELKIMO; WESTLING56 realizaram um estudo comparativo dos resultados de 55 casos com diagnóstico de deslocamento anterior de disco (com e sem redução), com 342 outros casos com DTM e sem deslocamento de disco. Todos os casos haviam recebido tratamento convencional que consistiu de fisioterapia e placa estabilizadora. Após um ano, 69\% dos pacientes com deslocamento de disco melhoram enquanto no outro grupo, $74 \%$ obtiveram melhora.

Em 1988, CLARK; LANHAN; FLACK ${ }^{21}$ utilizando placas reposicionados descreveram uma redução de 39\% nos estalidos e em outros sintomas após 19 meses de acompanhamento.

Em 1988, ITO et al64. estudaram a capacidade do aparelho de reposicionamento anterior em manter a coordenação côndilodisco durante a fase de apertamento. Para isto, trataram um paciente que apresentava estalido recíproco com o uso de placa de reposicionamento anterior. Utilizaram um aparelho computadorizado mediram e registraram o grau de mobilidade condilar e avaliaram ainda se a posição do disco "recapturado" era mantida durante o mastigação de alimentos fibrosos. Para os autores, quando a paciente mastiga do lado da articulação saudável, o disco permanece em posição não sendo observada qualquer disfunção. Quando ocorre a mastigação no lado em que há o desarranjo interno, ocorria 
disfunção em alguns casos. De acordo com os resultados este estudo indicou algumas limitações do uso de aparelhos de reposicionamento anterior e porque eles não alcançam um sucesso total.

Em 1988, ISAKSSON; ISBERG PERSSON61 avaliaram a perda de controle dos movimentos mandibulares de pacientes com desarranjos internos. Para isto selecionaram uma amostra de 50 pacientes para avaliar a habilidade de realizar os movimentos de lateralidade e de protrusão. Dos 50 pacientes, 22 falharam em realizar o movimento. Submetidos à avaliação radiográfica, 18 dos 22, apresentavam deslocamento de disco sem redução e os quatro restantes apresentavam deslocamento de disco com redução. De acordo com os autores, esta perda de controle deve-se ao fato de que os mecanorreceptores não são equilibradamente distribuídos na cápsula articular, porém são concentrados no interior da região posterior. Estes mecanorreceptores são os principais responsáveis pela percepção e movimento mandibular, além do que eles exercem efeitos sobre a coordenação dos músculos mandibulares. Os autores propuseram que na presença de desarranjos interno, a porção posterior do disco vascularizada e inervada e a porção posterior da cápsula são puxadas para frente, entre o componente ósseo da articulação, sendo comprimidos. Em vários pacientes, quando o reposicionamento anterior era realizado, a coordenação retornava.

Em 1988, OWEN 108 descreveu que o reposicionamento anterior normalmente produz uma mordida aberta posterior, e uma 
reconstrução ou procedimentos ortodônticos são utilizados com a finalidade de restabelecer uma oclusão funcional. $\mathrm{Na}$ seqüência de tratamento preconizada por este autor, após o uso da placa oclusal os espasmos musculares são reduzidos ou eliminados em 70 a $80 \%$ das vezes. Ocasionalmente, eles podem persistir, requerendo um cobertura maxilar completa com guia anterior e suave reposicionamento anterior, para controlar melhor o bruxismo e o apertamento. Se o paciente continuar com hábitos parafuncionais e a placa, com cobertura completa, não resolver os espasmos musculares e/ou os problemas de deslocamento condilar, então o bionator é usado. O bionator, conforme descreve o autor, é espesso o suficiente e controla a postura mandibular, evitando que o paciente durma sem o aparelho e tornando o bruxismo praticamente impossivel. Para os pacientes com espasmos musculares e hábitos parafuncionais, o bionator pode ser construído no arco normal de fechamento mandibular. Se deslocamento anterior do disco também é um problema, o bionator pode ser construído anteriormente, para servir como uma placa de reposicionamento anterior. Para este autor, existe uma controvérsia quanto à etiologia do estalido: se é de origem muscular ou o resultado de um desarranjo interno. Desde que o estalido simples de abertura denote ser de origem muscular, a placa oclusal, parece corrigir o problema. Se estalido persiste após o uso deste aparelho, uma placa de reposionamento anterior esta indicada, pois existe suspeita de degeneração interna. Para paciente com estalidos recíprocos, após o uso de uma placa pivotante, se o mesmo persistir também 
esta indicado o uso de uma placa de reposicionamento anterior. O autor, ainda, relatou desconhecer se o paciente iria tolerar bem, a longo prazo, o aumento da dimensão vertical que acompanha o reposicionamento anterior. Muitos dos seu pacientes estavam fora do tratamento por 3 a 4 anos até a data de publicação deste trabalho, sem nenhum aparecimento de problemas, mas uma observação contínua está indicada com a finalidade de avaliar os resultados a longo prazo.

Em 1988, LUNDH; WESTESSON; KOOP81 descreveram os resultados de três anos de avaliação de 15 casos de pacientes com estalido que substituíram as placas de reposicionamento anterior por onlays cimentados nos dentes posteriores. Treze pacientes estavam livres do estalido depois do tratamento e $82 \%$ tinham um posicionamento normal do disco (dois casos tinham deslocamento anterior do disco.

WENNEBERG; NYSTROM; CARLSSON ${ }^{144}$, em 1988, compararam o efeito de dois tipos de tratamentos em 30 pacientes com DTM e dor de cabeça os quais foram divididos em dois grupos. Um grupo recebeu ajuste oclusal e o outro, tratamento de rotina, incluindo aparelho miorrelaxante. Os resultados do tratamento foram avaliados por meio de um questionário, escalas visuais e exame clínico Os pacientes que receberam placa oclusal e exercícios apresentaram uma diminuição significante no escore de disfunção clínica utilizado, quando comparado aos pacientes que receberam ajuste oclusal, 
embora os dois grupos relatassem uma diminuição dos sintomas. Os autores concluem que, devido ao caráter multifatorial da etiologia das DTM e do pequeno papel desempenhado pela oclusão, a combinação de métodos simples como placa oclusal, exercícios e aconselhamento traz melhores resultados do que o ajuste oclusal utilizado isoladamente.

WESTESSON; LUNDH ${ }^{145}$ em 1988, acompanharam 18 pacientes que utilizaram placas reposicionadoras de disco por um período de seis meses, por meio de artrografia e tomografia realizadas antes e depois desse período estipulado para o tratamento. Observaram uma recorrência de deslocamento do disco em 33\% dos casos.

Segundo CELENZA ${ }^{17}$, 1988, no início da formação da ATM as células mesenquimais são comprimidas dando origem a duas fissuras que formarão os compartimentos sinoviais superior e inferior. As células entre essas fissuras se condensam para formar o disco articular. Com a continuação desta compressão as células da porção posterior formam um ligamento que se estende da porção posterior do disco articular e liga-se à parte anterior do osso martelo formando o ligamento discomaleolar. Segundo CELENZA ${ }^{17}$, este ligamento ocasiona duas situações diferentes: (1) quando o ligamento não é interrompido pelas porções ósseas da ATM, qualquer alteração na posição do conjunto côndilo-disco provocará reflexos no ouvido e, (2) quando o ligamento é interrompido suas fibras saem da 
porção póstero-inferior e superior do disco e fixam-se às paredes ósseas da ATM. As fibras da lâmina superior são elásticas, enquanto as da lâmina inferior são de tecido conjuntivo fibroso denso. As fibras elásticas ajudam no retorno do disco à sua posição na fossa articular e, as fibras não elásticas da lâmina inferior ajudam a evitar o deslocamento anterior do disco. Ainda de acordo com este autor, numa situação ideal e de normalidade na ATM, a face ântero-superior dos côndilos se articula com a área central do disco articular. Essa articulação acontece no compartimento sinovial inferior. O complexo côndilo-disco assim relacionado, articula-se com a parede pósterosuperior da eminência articular. Essa articulação acontece no compartimento sinovial superior. O movimento de rotação acontece no compartimento inferior e os movimentos de translação ocorrem no compartimento superior.

Em 1988, PAGE109 utilizou um aparelho de reposicionamento anterior em uma paciente de 47 anos, que apresentava dor e disfunção da ATM, com a finalidade de corrigir uma classe II dental e esquelética severa, reposicionando a mandíbula para baixo e para frente. Em poucos dias a paciente sentiu alívio dos sintomas. Segundo o autor, quando indicada a abertura da mordida e o reposicionamento mandibular para frente e para baixo (por meio de ortopedia funcional dos maxilares) efeitos profundos ocorrem, o que alivia a sintomatologia dolorosa. 
OKESON102, em 1988, avaliando o uso de placas de reposicionamento anterior em pacientes com desarranjos internos para o controle de dor e estalido, observou uma efetividade maior destes aparelhos quando utilizados para o controle da dor do que para o controle do estalido. Ao questionar a necessidade da manutenção da mandíbula numa posição anteriorizada para pacientes com desordens do disco, propôs o retorno gradual da mesma à sua posição original, por meio de reajustes na placa oclusal. Toda a amostra utilizou o aparelho por um período de oito semanas. Posteriormente, os pacientes gradualmente retornaram à posição original em um período de duas a quatro semanas. Toda a amostra era formada de indivíduos que apresentavam desarranjos internos e foram divididos em três grupos: A) indivíduos que apresentavam deslocamento anterior de disco com redução durante a abertura. B) indivíduos que apresentavam deslocamento anterior de disco sem redução mas que tinham o disco reduzido pela manipulação manual. C) indivíduos que apresentavam deslocamento anterior de disco sem redução mas que não tinham o disco reduzido pela manipulação manual. O autor verificou que após o período inicial de dois meses com o posicionamento anterior, $80 \%$ dos pacientes estavam livres de dor e estalido. Depois de avaliar os pacientes depois de dois anos e meio, $65 \%$ dos pacientes tinham retornado com o barulho. $48 \%$ dos pacientes tinham reduzido a cefaléia e a dor muscular à palpação tinha reduzido de $65 \%$ para $30 \%$ pós tratamento. Destes pacientes, $79 \%$ apresentaram um aumento na abertura e somente $9 \%$ mantinham o padrão de dor inicial. 
Apesar de $65 \%$ dos pacientes terem retornado com o barulho articular, somente $25 \%$ tinham dor. Quando os pacientes foram questionados sobre o quanto o tratamento tinha melhorado ou curado sua sintomas, $80 \%$ responderam positivamente. Dessa forma, de 40 pacientes tratados dessa maneira, $65 \%$ apresentaram estalidos após dois anos e meio e $25 \%$ continuaram com dor.

Ainda nesse ano, LUNDH et al ${ }^{82}$ utilizaram radiografias com a finalidade de guiar o posicionamento anterior da mandibula em casos de desarranjos internos. Após seis meses de tratamento, os "overlays" utilizados para realizar o reposicionamento anterior foram removidos, e todos os pacientes apresentaram mordida aberta posterior. Os pacientes foram acompanhados por vários meses depois deste período de utilização, e em todos os casos, a mordida aberta apresentada foi gradualmente reduzida e a posição de intercuspidação foi restabelecida. Estes resultados indicam que a intrusão que ocorre com o uso contínuo e a longo prazo dos aparelhos de reposicionamento anterior, é reversivel e pode ser tratada com uma erupção passiva.

CARPENTIER et al. ${ }^{15}$, em 1988, fizeram um estudo anatômico demonstrando que a maioria das fibras do músculo pterigoideo lateral superior está inserida no côndilo e não no disco articular. Como muitas das fibras do pterigóideo lateral superior passam sob a porção anterior do disco para inserirem-se no côndilo, sua contração vai resultar 
num empurramento do disco para cima enquanto o côndilo é estabilizado durante o movimento mandibular. Considerando esta organização anatômica das fibras desse músculo, não é provável que a explicação para o deslocamento anterior do disco articular seja a atividade de espasmo desse músculo. Hipotonicidade, não hipertonicidade, do pterigóideo lateral superior pode contribuir para um deslocamento anterior do disco articular.

Também em 1988, LUNDH et al.83, realizaram um estudo radiográfico em sete indivíduos com a finalidade de avaliar as mudanças no posicionamento mandibular em relação à maxila, depois do reposicionamento para recapturar o disco. O período de acompanhamento de 6 a 9 meses. Neste estudo, "overlays" metálicos foram cimentados nos dentes posteriores com a finalidade de manter a posição recapturada em lugar de uma placa oclusal. A diferença no posicionamento mandibular entre o sem tratamento e o com reposicionamento era maior na vertical do que na horizontal. A média de mudança no posicionamento vertical mandibular foi de $2,5 \mathrm{~mm}$, enquanto que a modificação protrusiva foi de $0,5 \mathrm{~mm}$. De acordo com os resultados, os autores descreveram que é necessário uma espessura de $3 \mathrm{~mm}$ na banda posterior do disco para que o disco seja mantido com sucesso em posição entre o côndilo e a fossa. Quando os indivíduos foram reavaliados entre 6 a 8 meses mais tarde, uma alta discrepância horizontal foi observada. (70\% a $80 \%)$, enquanto que poucas modificações no plano vertical foi observado (12\%). Este estudo apresentou uma grande variação nas mudanças de posição necessária para que ocorra o reposicionamento do 
disco. Os autores descreveram ainda que muitos estudos prévios têm enfatizado o componente protrusivo como o fator mais importante na recaptura do disco articular, sendo que este artigo em particular, identificou que o componente vertical também é importante na estabilidade a longo prazo. No final do estudo, cinco dos sete pacientes tinham mantido o disco recapturado. Os autores atribuem este fato ao deslize horizontal para a posição original da mandíbula devido à ação muscular.

Entretanto, segundo BOERO ${ }^{10}$ em 1989, após a remoção da placa reposicionadora anterior, é comum a volta dos sintomas, especialmente dos estalidos. Ele afirmou que o aumento do tempo de terapia com a placa oclusal não melhora os resultados do tratamento, além de citar que, em alguns casos, o tipo de deslocamento ocorrido no disco articular impossibilita sua recaptura. O autor cita ainda a possibilidade de fazerem-se alterações permanentes na oclusão, visando manter a mandíbula na sua posição mais anterior e assintomática.

STEGENGA; DE BONT; BOERING ${ }^{131}$, em 1989, descreveram que, por haver muitas explicações divergentes para a etiologia das DTM, a causa real dos desarranjos internos da articulação é ainda desconhecida. Na literatura odontológica, a DTM é considerada como sendo uma patologia totalmente dissociada da osteoartrose da ATM, baseando-se na observação que a osteoartrose, em geral, é uma doença articular relacionada à idade, enquanto que as DTM ocorrem em pessoas jovens. 
Durante a vida, a ATM mantém um equilíbrio entre forma e função pelo remodelamento tecidual. Entretanto, o equilíbrio entre forma e função pode ser perturbado, dando início a um processo de degeneração tecidual, isto é, osteoartrose. Deve-se fazer uma distinção entre os fatores que iniciam e os fatores que agravam um processo osteoartrótico. Embora muitas pesquisas sejam desenvolvidas nesse sentido, a causa inicial da osteoartrose ainda é desconhecida. Uma sobrecarga funcional parece ocorrer de forma absoluta ou relativa devido a uma diminuição intrínseca da capacidade funcional da articulação, especialmente devido a uma redução quantitativa ou qualitativa do fluido sinovial. Já os fatores que não são capazes de gerar uma lesão na cartilagem, podem ser agravantes significativos, do processo de osteoartrose. Hiperatividade muscular associada ao bruxismo provavelmente é um desses fatores. O deslocamento do disco deveria ser entendido como uma conseqüência e não como uma causa da osteoartrose da ATM. Isso não quer dizer que um trauma direto na ATM não possa inverter esse processo, constituindo-se num fator desequilibrante funcional e levando a uma osteoartrose. Fatores sistêmicos também devem ser considerados no processo.

MOLINA ${ }^{95}$, em 1989, afirmou que a eliminação da informação proprioceptiva promovida pelas placas lisas de mordida rompe o ciclo vicioso de contração muscular. Quando associadas com terapia oclusal, promovem a recuperação do tônus de contração e repouso fisiológicos, o que ajuda a eliminar ou diminuir os reflexos de apertamento dental. 
Ainda em 1989, BEWER ${ }^{9}$ avaliou o principal mecanismo responsável pelo processo de aderência. O autor descreveu que modificações sinoviais intracapsulares acompanham os desarranjos internos. As adesões fibrosas limitam o movimento de translação normal, resultando em uma diminuição do movimento realizado no compartimento superior e em aumento no movimento rotacional realizado no compartimento inferior. Descreveu ainda que o disco fica mais inferiorizado em relação à eminência articular quando comparado com o seu posicionamento mais superior normal. Para os autores, o reposicionamento anterior pode colocar temporariamente o côndilo abaixo e atrás em relação a sua referência central no disco. No entanto, se o disco não translada livremente com o côndilo, o complexo côndilo-disco não realiza sua função normalmente e a disfunção ocorrerá a menos que o posicionamento anterior seja mantido. Subseqüentemente, a tentativa de retornar o complexo côndilo-disco superiormente na vertente da eminência articular será um insucesso devido à falta de translação do disco.

Em 1989, LUNDH e WESTESSON78 avaliando 15 pacientes com deslocamento de disco, realizaram modificações oclusais para manter o disco na posição recapturada. O acompanhamento destes 15 pacientes foi realizado em um período de 1 a 7 anos. Nenhum paciente tinha experimentado sucesso com a tentativa de tratamento utilizado placas estabilizadoras, terapia física, ajuste oclusal, aconselhamento, e medicação. Três pacientes foram diagnosticados como portadores de deslocamento 
anterior de disco sem redução, no entanto durante uma artrografia, as articulações foram manipuladas e os discos foram reposicionados com sucesso sobre o côndilo. Neste caso, o aparelho foi construído mantendo este relacionamento. Os 12 pacientes remanescentes tinham um deslocamento anterior de disco com redução e os aparelhos foram construídos na posição terapêutica de redução. Os pacientes que usaram o aparelho, ficaram em uso por um período que variou de 6 a 32 meses (média de dez meses). As mudanças oclusais foram conseguidas por meio de reabilitações protéticas em 11 pacientes e ortodônticas em quatro. Após três anos, a função articular fora melhorada, a intensidade da dor diminuída e a dor, tanto muscular como articular, diminuída. Radiografias em 11 pacientes demonstraram posição ântero-inferior do côndilo na maioria deles, mas com mudanças ósseas mínimas. Artrografias mostraram os discos em posição correta em $82 \%$ dos casos. Estes resultados sugerem que uma mudança permanente da oclusão com o objetivo de eliminar a posição anormal do disco pode ser um tratamento efetivo para desarranjos, quando métodos convencionais falharam no alívio dos sintomas. A extensão do tratamento dental necessário para manter o disco em uma correta posição deve, contudo, ser considerada relativa à severidade dos sintomas.

Em 1989, WINDMER ${ }^{153}$ descreveu que a simples presença de ruídos articulares não evidencia presença de patologia articular. Outros sintomas devem ser avaliados pois muitos estudos epidemiológicos 
apresentavam populações com ruídos articulares, porém sem qualquer evidência de sinais e sintomas de possivel progressão da doença.

KERSTENS et al. ${ }^{67}$, em 1989, mediram radiograficamente o ângulo da eminência articular de 179 ATM com deslocamento anterior do disco e compararam com 400 articulações saudáveis de adultos jovens. A média da angulação das eminências articulares dos pacientes com deslocamento de disco, num grupo com média de idade de 26,3 anos (faixa etária entre 17 e 49 anos) foi de 63,9, enquanto que nos pacientes com ATM saudáveis, num grupo com idade média de 25,6 anos (faixa etária entre 18 e 32 anos) foi de 49,40, numa diferença estatisticamente significante de $14,5^{\circ}$. Não foi notada diferença na angulação das articulações com deslocamento de disco com ou sem redução. Também não houve diferença estatisticamente significativa entre os pacientes que responderam aos tratamentos conservadores e aqueles tratados cirurgicamente. Como o disco articular mantém o contato entre as porções articulares durante os movimentos mandibulares, isto significa que quanto maior for a inclinação da eminência articular, maior será a amplitude de rotação posterior do disco sobre o côndilo. Para os autores a inclinação extrema e altura da eminência parecem predispor o deslocamento anterior do disco articular.

TALLENTS et al ${ }^{137}$ em 1990, afirmaram que o reposicionamento anterior da mandibula, proporcionado pele placa é efetivo 
para recapturar o disco articular. Para os autores, o objetivo maior do tratamento é eliminar o estalido articular e, dessa forma, sugeriram a estabilização da mandíbula numa posição anteriorizada por meio de procedimentos ortodônticos ou protéticos.

\section{Em 1990, WARD, BEHRENTS e GOLDBERG 140} descreveram os achados encontrados após a reposicionamento anterior em porcos. De acordo com os autores, houve um aumento na pressão do líquido sinovial e a diminuição com duas horas após a sua remoção. O posicionamento posterior da mandíbula leva a um aumento na pressão com uma diminuição parcial depois de duas horas, porém sem retorno ao nível inicial depois das oito semanas em que durou o experimento.

Em 1990, TADDEY135 fazendo uma análise da seqüência de utilização de aparelhos ortopédicos utilizados com a finalidade de tratar as DTM, relatou que solicita como rotina a utilização de aparelhos durante 24 horas por um período mínimo de três meses. Para o autor os aparelhos ortopédicos mandibulares são confortáveis e produzem pouco estresse psicológico, sendo muito aceitos pelo paciente. Rotineiramente o autor constrói aparelhos de estabilização maxilar e mandibular, instruindo o paciente a usar o mandibular durante o dia e o maxilar durante a noite. Depois que o problema da dor é resolvido, normalmente de 2 a 4 semanas, altera os aparelhos de reposicionamento para aparelhos de estabilização. 
Em 1991, SCAPINO120 analisou a estrutura, função e o aspecto de imagens da ATM. Para isto, estudou a função da estrutura intracapsular pela ressonância magnética e artrografia. Com o côndilo posicionado anteriormente, o autor observou um aumento no líquido sinovial, associado a um aumento da inserção posterior. Isso permitiria uma melhor nutrição das superficies articulares e criaria um ambiente melhor para o reparo e regeneração. Para o autor, os achados de diminuição da pressão intra-articular com o posicionamento condilar anterior são consistentes seus achados de aumento no espaço articular.

Em 1991, WEINBERG ${ }^{143}$ avaliando os métodos de desprogramação muscular para facilitar a realização de procedimentos oclusais corretivos, descreveu o uso de placas oclusais com esta finalidade uma vez que as mesmas, influenciam na propriocepção do ligamento periodontal e na desprogramação do padrão habitual de funcionamento muscular. Indicou também a sua utilização, com a finalidade de relaxamento muscular.

Em estudo epidemiológico realizado em 1991, LUNDH; WESTESSON79 examinando pacientes com deslocamento do disco e comparando com um grupo sem deslocamento, levantaram o questionamento sobre a importância do posicionamento do disco como prérequisito para o alívio dos sintomas. Para os autores, o posicionamento do côndilo mais anteriormente e inferiormente à fossa mandibular, pode ser 
suficiente para a redução do quadro clínico que acompanham os pacientes com patologias intra-articular. Para isto, propuseram o uso de placa protrusiva durante o período de permanência da sintomatologia dolorosa

Em 1991, SHAN; YUN ${ }^{124}$ examinaram o efeito da uma placa estabilizadora nos resultados de eletromiografias obtidas dos músculos mastigatórios de 23 pacientes. A mordida máxima destes pacientes foi medida com e sem a placa. Foi encontrado que o valor mioelétrico do músculo masseter do lado envolvido e do lado não envolvido foi reduzido com o uso da placa oclusal. Para os autores, estes resultados indicam que a placa lisa pode diminuir a atividade do músculo masseter e portanto, isso indica um efeito terapêutico com o uso deste aparelhos.

Já TAKENOSHITA et al.136, em 1991, utilizaram um método de avaliação quantitativa dos contatos oclusais por meio do registro da MIH em lâminas de cera especiais que eram fotografadas e então submetidas à análise fotométrica. Segundo os autores, a oclusão está sempre mudando, mesmo em adultos, e suas mudanças são usualmente graduais. Os autores acreditam que nas mudanças internas às ATM com a idade sob condições fisiológicas, a área de contato aumenta igualmente não associada com DTM. A conclusão é que os contatos oclusais não mostraram qualquer associação significante com DTM.

Em uma avaliação da relação entre o número, distribuição e intensidade dos contatos dentários oclusais e o estado 
funcional craniomandibular, GIANNIRI et al.43, em 1991, examinaram 56 pacientes com idades de 16 e 17 anos. Os autores utilizaram a técnica de fotooclusão para avaliar qualitativa e quantitativamente os contatos oclusais, além do exame clínico do sistema mastigatório. Os resultados mostraram a importância dos contatos oclusais efetivos em relação à função craniomandibular. Para os autores, simetria de intensidade mais do que a simetria de quantidade pareceu ser mais importante em relação à função craniomandibular.

Em 1991, SELIGMAN; PULLINGER ${ }^{122}$ em vasta revisão de literatura fizeram uma análise do papel dos fatores oclusais (contatos de trabalho e balanceio, extensão e simetria do desvio RC-MIH, padrão de guia oclusal, parafunção e atrição) na fisiopatologia das DTM. Verificaram, que a maioria dos trabalhos não demonstrou associação entre interferências oclusais e sintomas de DTM, além disso, a presença de interferências é tão comum que falta uma maior especificidade e sensibilidade para definir uma população de pacientes com DTM, como também uma população com potencial para desenvolver disfunção. Alguns estudos sugerem que a falta de desvio RC-MIH pode ser um fator de risco em algumas populações específicas, sendo este um ponto para maiores estudos no futuro. Não há uma associação entre o tamanho do desvio RC-MIH e os sinais e sintomas de DTM. Em relação à presença ou ausência de simetria no desvio RC-MIH, os estudos em populações de não pacientes estão muito misturados, não permitindo definir se a presença de desvio pode provocar sintomas de DTM. 
Tal fato sugere o uso de uma metodologia mais adequada. Alguns estudos analisados pelos autores, avaliaram o padrão de guia oclusal sobre a atividade muscular, mas não sugerem que tipo de guia em particular possa trazer sintomas de DTM ou ao contrário, saúde, assim sugerem mais estudos em população de pacientes diferenciados. Com relação à parafunção os autores relataram ainda que têm aumentado as evidências de que a parafunção não está associada com fatores oclusais crônicos, assim o tratamento para estes problemas deve ser reversivel, com o objetivo de se evitar possíveis danos ou diminuir a complicação e os efeitos de tratamentos irreversíveis. Pela análise dos trabalhos selecionados sobre atrição, verificaram que este hábito não pareceu estar associado aos sinais e sintomas de disfunção, além disso, os homens apresentam maiores niveis de atrição dental que mulheres, muito embora apresentem menos sintomas de DTM. Para os autores, níveis avançados de atrição em pacientes com DTM estão principalmente associados com osteoartrose, sendo um fator secundário às alterações oclusais devido a esta desordem intra-articular e não um resultado de parafunção.

KIRK JUNIOR 68, em 1991, avaliou 30 ATM de 18 pacientes portadoras de desarranjo interno, por meio de tomografia e ressonância magnética, antes e depois de terapia com placa oclusal, ajustada até a eliminação ou até que substancial redução do ruído audivel fosse alcançada. Todos os pacientes tiveram, com o uso da placa, um aumento observável da dimensão vertical e/ou uma postura 
ligeiramente anterior da mandíbula. Os pacientes foram instruídos para usarem a placa continuamente, por um mês, exceto durante as refeições. As imagens posteriores ao tratamento foram obtidas com a placa em posição. Das 30 ATM examinadas, apenas três mostraram evidências de "recaptura de disco". As demais 27 estavam silenciosas com a placa em posição, isso deveu-se ao fato do espaço articular estar aumentado, o que possibilita uma translação condiliana mais suave. Este estudo sugere que as placas utilizadas têm pouca ou nenhuma capacidade de levar o côndilo e o disco a assumirem um relacionamento anatômico mais normal, o que só pode ser constatado pelas imagens objetivas. O autor sugeriu que o termo "captura de disco" ou redução deva ser visto estritamente como um termo clínico.

Em 1991, COHEN; BARAGONA ${ }^{23}$, em um trabalho apresentado e publicado pela Academia Americana de Disfunções Temporomadibulares, alertaram os cientistas e clinicos sobre o diagnóstico e tratamento de Disfunções Temporomandibulares, baseados em métodos científicos geralmente aceitos. Nos seus conceitos de tratamento, sugeriram que uma vez diagnosticados os pacientes com DTM, estes fossem tratados especificamente e o mais rápido possivel a fim de controlar a dor e a disfunção, e então cessavam o tratamento o mais rápido possível, mantendo um controle periódico. Isto implica em curtos períodos de uso ativo do aparelho, fisioterapia intensiva e modificação do comportamento (aconselhamento). Assim que o tratamento estivesse completo e a dor 
controlada, o paciente era liberado, retornando a sua posição maxilomandibular original. Para os autores, existe um grupo de pacientes, contudo, que não responde ao tratamento rapidamente devido a certos fatores complicadores incluídos mas não limitados à etiologia. A terapia longa com aparelhos é conceito de manejo do paciente, que usa aparelhos estabilizadores ortopédicos por um período que seria considerado mais longo do que usualmente necessário para tratamento. Incluído como indicação estariam: o uso de medicação, a fisioterapia, a modificação do comportamento e outros procedimentos. Como os pacientes usam aparelhos por um período de tempo longo, considerações especiais são necessárias para manter o tratamento reversível. Os autores dividem a terapia longa com aparelhos em: fase 1 (reversivel) e fase 2 (irreversivel). Em todos os casos o desenho do aparelho deveria ser feito para prevenir movimentos dentários individuais e, portanto, tornar a terapia reversivel. Aparelhos são necessários para os arcos maxilares e mandibulares, de modo a garantir que o arco dentário fique estabilizado por um período de tempo durante o dia. Quando possivel, um aparelho de cobertura total da maxila é utilizado durante a noite. Esses aparelhos são melhor tolerados quando o paciente não está em uma situação de trabalho ou social. Aparelhos de cobertura mandibular são utilizados geralmente durante o dia. A intenção é fazer, com a troca dos aparelhos, a estabilização de cada arco dentário durante um certo período de tempo em cada dia, fornecendo ao clínico um tratamento mais passível de cooperação. Além disto o risco de movimento dentário é diminuído. Durante 
o período de utilização destes aparelhos a oclusão é monitorizada com a finalidade de permitir a reversibilidade quando assintomática. Isto significa que o paciente não têm dor e têm função tolerável. O paciente deveria ser mantido neste estado assintomático por um período de 1 a 3 meses; então o paciente volta a posição original, pelo processo de liberação progressiva do aparelho. Ainda para os autores, clínicos que têm tratado pacientes com disfunção de ATM, reconhecem que um pequeno número de pacientes não podem ou não deveriam ser liberados completamente dos aparelhos - (Fase 1). A remoção poderia retroinduzir a certos fatores etiológicos, que colocariam necessariamente o paciente de volta ao estado ativo da disfunção. Esses pacientes solicitam alguma forma de estabilização permanente - Fase 2 (irreversivel). Também, estes pacientes normalmente se apresentam com uma necessidade óbvia de reconstrução ou tratamento ortodôntico. Em alguns casos, os pacientes apresentam oclusão deficiente, em razão de perdas dentárias e mudança da mordida; e não deveriam ser reconduzidos à situação de origem. Em outros casos, devido ao bruxismo excessivo, pacientes tiveram perda excessiva da dimensão vertical, que precisava ser restaurada. Classicamente, as formas de tratamento da fase 2 irreversivel incluem a realização de um equilíbrio oclusal, ortodontia, prótese e, em número muito limitado, cirurgia ortognática. Alguns pacientes têm indicações que obrigam o clinico a utilizar os aparelhos ortopédicos com uma forma de manejo da oclusão. Esses pacientes são tratados por métodos de terapia longa com aparelhos. Esse grupo inclui pacientes com prognóstico 
físico instável ou pobre, instabilidade ou doença emocional, limitações econômicas ou falta de desejo de submeter-se a um tratamento, mas que requer estabilização. Como requisitos ao candidato à terapia longa, os autores incluem: 1 - a função não é boa sem algum tipo de estabilização craniomandibular, 2 - haverá um retorno da sintomatologia dolorosa, e o paciente não é candidato para nenhuma outra forma de fase 2 irreversível de tratamento. Paciente com disfunções crônicas comumente devem cair nesta categoria. Pacientes com artrites crônicas que requerem o tratamento fase 2 deveriam ser tratados com aparelhos de longa duração em associação com acompanhamento médico, entre estas condições incluem-se a artrite reumatóide, psoríase e outros distúrbios metabólicos articulares.

STEGENGA et al. ${ }^{133}$, em 1991, descreveram que a cartilagem articular que cobre o côndilo mandibular e a eminência articular, bem como o tecido do disco articular podem ser afetados pelas mudanças degenerativas associadas com osteoartroses. Alterações degenerativas da cartilagem, modificam suas propriedades fisicas, e como resultado, afetam sua possibilidade em resistir a forças compressivas e ao desgaste devido ao estresse que a articulação é submetida. Isso leva a um aumento no atrito entre as superficies articulares, e pode prejudicar o movimento articular levando a uma resposta compensatória ou patológica da cartilagem e dos tecidos adjacentes (cápsula articular, ligamentos, membrana sinovial, osso subcondral e musculatura associada). De acordo com os autores, estas mudanças estruturais são descritas e relatadas como sinais e sintomas de 
DTM, (estalido, travamento e instabilidade, dor, restrição do movimento, crepitação, deformação e mudanças na oclusão). Os autores concluíram ainda que, a hipermobilidade articular é considerada normal a não ser que: a) o paciente apresente história de pelo menos um travamento na posição de boca aberta (história de luxação); b) o paciente apresenta dor, desconforto ou uma interferência com a função normal ou durante o movimento amplo de abertura bucal (bocejo ).

Já em 1992, STEGENGA et. al. ${ }^{132}$ analisaram o significado dos sinais clínicos e dos achados rediográficos com a finalidade de propor uma classificação para as osteoartroses e desarranjos internos da ATM. Verificaram que o estalido recíproco tem sido altamente indicativo de um deslocamento do disco com redução.

Em 1992, YAMAMOTO; LUZ155 analisaram excursões mandibulares máximas em estudantes de Odontologia. O grupo era assintomático. As medidas foram realizadas sob leve pressão bidigital para os movimentos de abertura máxima e de lateralidade direita e esquerda. Os movimentos de abertura e protrusão tiveram os seus valores corrigidos pela adição das medidas dos trespasses vertical e horizontal, respectivamente. De acordo com os resultados, as medidas obtidas para a abertura máxima no gênero masculino, foi de $58,1 \mathrm{~mm}$, e no gênero feminino foi de $53,0 \mathrm{~mm}$. Quanto às lateralidades, a média nos homens foi de 9,5mm tanto para a 
esquerda como para a direita. Houve significante diferença para a abertura máxima de boca entre o gênero masculino e feminino.

LIST et al. ${ }^{77}$, em 1992, realizaram um estudo envolvendo 110 pacientes, sendo 23 homens e 87 mulheres com a finalidade de comparar o efeito da acupuntura e terapia por placa oclusal no tratamento da DTM. Os pacientes foram distribuídos aleatoriamente em três grupos, tratamento por acupuntura, terapia por placa oclusal e grupo controle, e avaliados antes do tratamento, imediatamente após e 6 e 12 meses depois. Ambas as terapias, acupuntura e placa oclusal, reduziram os sintomas quando comparado ao grupo controle, no qual os sintomas permaneceram essencialmente inalterados. No prazo do estudo, a acupuntura apresentou melhores resultados que a terapia por placa oclusal.

Já OKESON103, em 1992 classificou as placas oclusais em: placa lisa, placa reposicionadora anterior, placa de mordida anterior, placa de mordida posterior, placa pivotante e placa resiliente. Apontou como indicação primária da placa de reposicionamento anterior o tratamento das desordens de interferência no disco. Para o autor, estalidos articulares únicos ou reciprocos, travamento intermitente ou crônico da articulação e algumas desordens inflamatórias podem ser tratados com esta placa. Também o autor se posicionou com relação à etiologia do deslocamento de disco. Na sua opinião, se a morfologia do disco está alterada e os ligamentos discais tornam-se alongados, cria-se uma situação que possibilita o disco 
deslizar sobre a superficie articular do côndilo, originando-se as desordens de interferência do disco, termo inicialmente introduzido por Bell, as quais poderiam gerar as desordens inflamatórias. Para o autor, estas desordens inflamatórias são geralmente o resultado das desordens de interferência do disco, crônica ou progressiva. As disfunções da ATM freqüentemente seguem uma trajetória de eventos progressivos, desde os sinais iniciais de uma disfunção até chegar a uma doença articular degenerativa. Essa seqüência de eventos pode ser resumida como se segue:

๑ Articulação normal saudável;

- Condições que permitem um desvio do disco no côndilo;

- Hiperatividade muscular ocasionando uma tração ântero-medial do disco;

- Afinamento da borda posterior do disco;

- Alongamento crescente dos ligamentos retrodiscais inferiores e laterais do disco;

- Deslocamento funcional do disco:

a- estalido único

b - estalido reciproco;

- Deslocamento funcional do disco:

$$
\begin{aligned}
& \text { a - com redução } \\
& \text { b - sem redução (travamento); }
\end{aligned}
$$

- Retrodiscite;

- Doença articular degenerativa. 
Em 1993, WILLIANSON et al. ${ }^{152}$ avaliou a atividade eletromiográfica dos músculos mastigatórios (temporal e masseter) após a terapia com placa estabilizadora em relação cêntrica e placa de reposicionamento anterior. Para isto, selecionou 26 pacientes de maneira aleatória que relataram dor temporomandibular, limitação de movimento e cefaléia. Todos os pacientes apresenteram desarranjos internos, diagnosticados pela auscultação com estetoscópio e palpação da ATM abordando o meato acústico externo. O critério de inclusão para este grupo, foi a presença de dor à palpação da articulação e a presença de estalido durante o movimento. Dez paciente com ausência de qualquer sinal e sintoma de DTM foram utilizados como controle. A análise dos pacientes consistia de história, modelos montados e radiografias lateral, frontal, submentoniana e panorâmica. As placas em relação cêntrica eram construídas de tal forma que durante os movimentos excêntricos havia desoclusão dos dentes posteriores e em cêntrica havia contato posterior bilateral de igual intensidade. Foi realizada manipulação mandibular com a finalidade de conseguir o melhor posicionamento anterior e superior do côndilo mandibular. Os placas de reposicionamento anterior foram construídas com a mandíbula posicionada anteriormente e/ou lateralmente em relação à posição de ruído onde havia menor sensibilidade à palpação para o grupo experimental. A placa de reposicionamento anterior no grupo controle foi construída na posição em que os incisivos assumiam a posição de topo a topo com o maxilar e mandíbula assumindo a linha média. Uma 
análise eletromiográfica foi realizada antes da terapia, na seguinte seqüência. 1- posição de repouso sem a placa, 2- força máxima na posição de intercuspidação 3- força máxima em relação cêntrica com a placa estabilizadora. 4- força máxima com placa protrusiva. Os resultados não mostraram uma significante diminuição da atividade do músculo masseter e temporal com terapia com placas de posicionamento anterior em relação à placa estabilizadora em relação cêntrica.

CARLSON et $\mathrm{al}^{14}$, em 1993, realizaram um estudo com o objetivo de comparar a influência, na atividade muscular, de placas convencionais e neuromusculares (construídas de uma posição tridimensional da mandíbula quando os músculos estão num estado mínimo de atividade eletromiográfica). Foram utilizadas 12 mulheres com DTM, com média de idade de 38 anos. O resultado deste experimento não mostrou diferença na atividade eletromiográfica entre os grupos experimentais. Houve diferença, por outro lado, entre estas e o grupo controle.

Em 1993, OKESON 104 empregou a placa de reposicionamento anterior em pacientes com distúrbio interno por um período de dois meses. Durante a avaliação não houve relato de qualquer alteração oclusal. Foi demonstrado por esta pesquisa que períodos curtos de uso de placa protrusiva não levam a alterações oclusais permanentes.

ORENSTEIN106, em 1993, realizando uma análise crítica sobre a utilização de aparelhos de reposicionamento anterior para o 
controle dos casos de deslocamento anterior do disco, afirmou que no caso do disco permanecer deslocado, há sempre a possibilidade de uma adaptação do tecido retrodiscal, o que levaria à formação de um pseudodisco, o que por si só, justificaria a utilização de métodos de tratamento conservador. Para o autor, o uso da placa reposicionadora no intuito de recapturar o disco e restaurá-lo à sua forma e função originais é uma tentativa fútil. O alívio da dor e o estabelecimento de uma oclusão estável, devem ser o objetivo do uso da placa protrusiva.

Em 1993 GLASS; CLAROS e McCLYNN44 descreveram a larga aceitação das placas orais e sua vasta aplicação na prática odontológica, apesar do pouco conhecimento sobre o seu exato mecanismo de ação. Uma avaliação realizada entre 10.000 membros da Associação Odontológica Americana, identificou a placa oclusal como sendo o tipo de terapia mais utilizada para tratamento das DTM.

Em 1993 KAI $^{65}$ et. al. defenderam que a posição anterior do côndilo pode ultrapassar a capacidade de expansão volumétrica da zona bilaminar, gerando um aumento do fluido sinovial no compartimento articular superior. Relataram ainda que o aparecimento de mordida aberta posterior, após a colocação de placa de reposicionamento anterior, depende do tempo de utilização ininterrupta.

DAWSON ${ }^{35}$, em 1993, na nova edição de seu livro, classificou as placas oclusais em apenas duas categorias: permissivas $e$ 
direcionadoras. As primeiras destravariam a oclusão para suprimir o contato de vertentes dentais desviantes, eliminando assim, o reflexo neuromuscular que controla o fechamento até a máxima intercuspidação e permitindo o retorno dos côndilos ao seu correto assentamento na relação cêntrica. Já as placas direcionadoras seriam desenhadas para posicionar a mandíbula numa relação específica com a maxila, por meio de fossas que promovem uma intercuspidação com os dentes inferiores, visando posicionar ou alinhar os conjuntos côndilo-disco. Ainda para este autor a redução dos sintomas proporcionados pelas placas oclusais não está relacionada com as alterações da dimensão vertical. Segundo o autor, o eixo condilar fica numa posição fixa durante uma abertura de $15 \mathrm{~mm}$ ou mais, antes da translação para a frente. Dentro dessa abertura, mudanças na dimensão vertical não afetariam a posição do eixo terminal de rotação da mandíbula. Descreveu ainda, não ser uma boa conduta alterar a oclusão com a finalidade de compensar o problema criado com posicionamento anterior da mandíbula. Para o autor a estabilidade a longo prazo da posição anterior, será comprometida a menos que a posição alcançada seja confirmada por longo tempo de avaliação clínica.

HOLMGREN; SHEIKHOLLESLAM; RIISE59 em 1993, por outro lado, usando placas totalmente lisas e sem guias canina e protrusiva avaliaram 31 pacientes, sendo 26 mulheres e 5 homens com média de idade de 27 anos, bruxômanos e portadores de DTM. Os autores concluíram, que as mesmas não detêm o bruxismo noturno nem os sinais de 
DTM. Pela análise dos autores, em $61 \%$ dos pacientes foram observados facetas de desgaste na placa na primeira visita, que ocorria duas semanas depois de sua instalação. Em 39\% da amostra os desgastes se mantiveram com o passar do tempo.

Ainda em 1993 TURK, ZAKI e RUDY139 avaliaram a eficácia de duas terapêuticas comumente usadas para tratamento de DTM, aparelhos interoclusais e biofeedback, separadamente e em combinação. Para isto, utilizaram uma amostra de 80 pacientes com DTM, e avaliaram cada terapia separadamente. O resultado demonstrou que o tratamento com placa oclusal foi mais efetivo que o biofeedback na redução da dor. Porém, observou-se uma significante recidiva seis meses depois, fato não observado no grupo tratado por biofeedback. A segunda avaliação que examinou a combinação destas terapias mostrou ser, mais efetiva do que quando instituídas isoladamente, particularmente na redução da dor. Estes resultados suportam a importância de se usar ambas terapias conjuntamente para se obter sucesso no tratamento de pacientes com DTMs.

Também em 1993, PULLINGER; SELIGMAN; GORNBEIN ${ }^{114}$ avaliaram a capacidade de características oclusais comuns em predizer grupos diagnósticos de disfunção. Os grupos de diagnóstico foram: 1) deslocamento do disco com redução; 2) deslocamento do disco sem redução; 3) osteoartrose com história de deslocamento de disco; 4) osteoartrose primária; 5) presença apenas de mialgia (quatro ou mais locais 
de sensibilidade muscular nos músculos mastigatórios, sem sinais e sintomas de qualquer desordem intracapsular). Tanto nos pacientes de disfunção como nos controles assintomáticos, os seguintes fatores foram comuns: diferença de RC e $\mathrm{MIH}$ até $2 \mathrm{~mm}$, assimetria desse desvio, contatos unilaterais em RC, overbite profunda, overjet mínima, discrepâncias da linha média, menos que cinco dentes posteriores ausentes, discrepância na relação maxilomandibular do primeiro molar presença de mordida cruzada. Os resultados mostraram que esses fatores não puderam definir pacientes de disfunção e indivíduos normais. Concluíram que a oclusão não pode ser considerada única e dominante, mas sua contribuição também não deve ser desconsiderada. Para os autores a contribuição da oclusão depende da capacidade adaptativa de cada indivíduo e que uma nova definição de "normal" deve ser feita, incluindo apenas os fatores que não apresentam um risco elevado significante de doença.

MCNEILL91 em 1993, na edição do "Guidelines" da Academia Americana de Disfunções Temporomandibulares, descreveu que Disfunções Temporomandibulares é um termo coletivo que envolve a musculatura mastigatória, a ATM e estruturas associadas, ou ambos. Entretanto, as Disfunções Temporomandibulares coexistem com outras disfunções craniomandibulares e orofaciais. Assim, esse termo é sinônimo de Desordens Craniomandibulares ou Disfunção Craniomandibulares (DCM). Relatou ainda que os estudos epidemiológicos mostram que, embora grande 
percentagem da população apresente sinais e sintomas de disfunção, apenas 5 a $7 \%$ necessitam de tratamento, onde $85,4 \%$ são mulheres.

WILKINSON; CROWLEY148, em 1994, fizeram um estudo histológico dos tecidos retrodiscais buscando melhorar a compreensão do papel da estrutura de elastina que suporta uma rede venosa calibrosa presente nesta região. Essa estrutura permite que essas veias sejam rapidamente preenchidas ou esvaziadas pelos sistemas capilares adjacentes, provendo dessa maneira, o principal mecanismo compensatório da pressão na porção retrodiscal, que aumenta muito de volume durante o movimento de abertura. Neste estudo, foi encontrada elastina tanto na lâmina retrodiscal superior quanto na inferior, o que vai contra os achados de outros autores. Esses achados sugerem que o papel dos tecidos retrodiscais, não é o de atuar como um mecanismo especializado de retração do disco durante o movimento condilar, mas funcionar como o mecanismo primário de compensação volumétrica para a articulação. Esta parece ser a hipótese mais aceitável, uma vez que nas demais teorias existentes para explicar essa compensação, os mecanismos biológicos descritos não são aptos a funcionar em um intervalo de tempo hábil compativel com um movimento rápido de abertura e fechamento que pode se dar em menos de 0,6 segundos.

ALENCAR JUNIOR ${ }^{4}$, em 1994, selecionou 30 pacientes com disfunção craniomandibular de moderada a severa, sem dores à 
palpação na ATM e sem nenhum tratamento prévio. Quinze pacientes receberam uma placa miorrelaxante convencional (PMRC) e 14 placa não oclusiva ( PNO ) usada como placebo. Todos foram, orientados a usarem a placa por 24 horas por 15 dias e nos 45 dias restantes, usarem só a noite. Como resultado, observou aumento da abertura média bucal e eliminação da dor cansaço muscular em 84,6\% (PMRC) e 93,3\% (PNO), eliminação das dores de cabeça em 91,6\% (PMRC) e 84,6\%(PNO), eliminação do estalido em 30\%(PMRC) e 46\% (PNO). Assim, ele verificou a eliminação ou melhoria de diversos sinais e sintomas da disfunção craniomandibular pelo uso de uma placa não oclusiva, o que vem corroborar coma teoria do efeito placebo, que tenta explicar o mecanismo de ação de placas oclusais.

DAO et al. ${ }^{33}$, em 1994, realizaram um estudo duplo cego para avaliar a eficiência terapêtica do uso de placas utilizando uma amostra selecionada ao acaso, uma vez que, a placa têm sido bastante utilizada como forma terapêutica no tratamento das DTMs embora o seu mecanismo de ação permaneça desconhecido. Para os autores muitos dos trabalhos descritos na literatura não incorporam em sua metodologia alguns dos parâmetros importantes e essenciais na realização em testes clínicos. 1a seleção de grupos ao acaso; 2 - a utilização de métodos de medidas confiáveis; 3 - a forma de coleta de dados; 4 - um desenho de estudo do tipo duplo cego; 5 - estudo adequado do tamanho da amostra; 6 - fidelidade dos resultados. Para análise selecionaram uma amostra formada por 63 individuos que foram divididos em três grupos: (1) controle passivo: placa 
oclusal total utilizada durante $30 \mathrm{~min}$ a cada consulta (2) controle ativo: placa palatina utilizada durante 24 horas por dia durante sete semanas e (3) tratamento: placa oclusal total utilizada 24 horas por dia. Em cada uma das sete visitas realizadas durante um período de sete semanas, os indivíduos foram orientados a preencher a escala analógica visual com a finalidade de quantificar a intensidade de dor e o desconforto depois e antes da mastigação experimental. $\mathrm{O}$ efeito da sensibilidade na qualidade da dor foi também avaliada por meio da escala. Todos os tipos de dor foram reduzidos acentuadamente com o tempo, e qualidade de vida melhorada em todos os três grupos. Os resultados mostraram ainda que não houve diferença significante entre os grupos em nenhuma variável analisada. Os dados permitiram deduzir que a redução na intensidade da dor e do desconforto que acompanham a dor miofascial bem como a melhora na qualidade de vida, eram resultados não específicos e não relacionados com o tipo de tratamento.

Em 1994 MOCAYO94 analisou radiograficamente o efeito da placa pivotante na articulação de 20 pacientes com média de idade de 24.3 anos. Todos pacientes exibiam mínimo desgaste dental, mobilidade dental normal e saúde periodontal. Um critério para inclusão neste estudo foi a presença dos segundos molares superior e inferior. O uso da placa oclusal com elevações localizadas simultaneamente na área de $2^{\circ}$ molar causou rebaixamento dos côndilos em 30\% dos pacientes, 35\% 
apresentavam côndilos numa posição protruída e 35\% apresentavam uma situação combinada.

NITZAN99 em 1994, com a finalidade de avaliar a influência da elevação do plano oclusal na pressão intra-articular. Constatou que durante apertamento com a placa oclusal em posição, o nível de pressão intra-articular decresceu $81.2 \%$ quando comparado à pressão observada quando do apertamento ocorria sem a utilização da placa oclusal. O autor descreveu ainda que a redução da carga articular é uma característica que contribui para o sucesso da terapia por placas oclusais.

Em 1994, BROWN, GAUDET, PHILLIPS ${ }^{13}$, com · a finalidade de avaliar as mudanças no posicionamento vertical dos dentes e na altura facial selecionaram 64 pacientes, e analisaram cefalometricamente para medir a mudança vertical de posição dos dentes anteriores e posteriores madibulares. Os resultados mostraram que o uso continuado destes aparelhos não causou intrusão significativa dos dentes posteriores. Os aparelhos foram utilizados por um período que variou entre 1,5 a 4,8 anos. Para a confirmação dos resultados analisaram o uso de placas de reposicionamento anterior ininterruptamente em pacientes que tiveram como critério de inclusão: a) O uso do aparelho por no mínimo seis meses; b) dentição natural e completa; c) ausência de problemas médicos significantes. Pacientes com classe III esquelética foram excluídos da amostra porém foram incluídas algumas classe II esqueléticas. Todas as placas foram 
posicionadas na mandíbula, utilizando para a sua confecção a técnica modificada de Gelb, cobrindo a oclusal e lingual dos dentes posteriores a partir dos caninos até a distal bilateralmente. O bordo incisal dos dentes anteriores inferiores era descoberto. Os superiores não entravam em contato com o aparelho. Todos os pacientes apresentavam a mandíbula projetadas até a posição de topo a topo e a abertura posterior era mínima. Os resultados mostraram que o posicionamento do molar inferior em ralação ao plano mandibular, não sofreu alteração. Os incisivos e molares superiores extruíram $1 \mathrm{~mm}$ enquanto que o molar inferior não se alterou. $\mathrm{O}$ incisivo inferior intruiu $0,6 \mathrm{~mm}$. A altura posterior da face aumentou em média $1,6 \mathrm{~mm}$ e a anterior aumentou em média $2,7 \mathrm{~mm}$. Em $20 \%$ dos pacientes, foi mais frequente a intrusão do molar inferior aproximadamente $1 \mathrm{~mm}$. Em 41 \% foi verificado extrusão dos incisivos superiores de $1 \mathrm{~mm}$ ou mais. A intrusão dos molares superiores ou extrusão dos incisivos superiores ocorreu em $5 \%$ dos pacientes. A diferença que se pode observar foi relacionada ao desenho do aparelho. De acordo com os resultados, existe pouca relação entre pacientes que usam aparelhos com cobertura de incisivo inferior por longo período e achados clínicos de intrusão significante de molar. Há chance de intruir de 1 a $2 \mathrm{~mm}$ e $5 \%$ de chance de intruir $2 \mathrm{~mm}$. Modificações na posição mandibular foram expressas por um aumento vertical na altura anterior e posterior da face. Houve pouca mudança no posicionamento ântero posterior da mandíbula. Os autores concluíram ainda 
que o relacionamento entre a força no dente e movimento intrusivos ou extrusivos é complexo e não está bem entendido.

Em 1994, GAREFIS et al. ${ }^{42}$ realizaram um estudo longitudinal durante dois anos, com a finalidade de avaliar a efetividade do tratamento conservador para as DTM. Para isto avaliaram uma amostra de 195 pacientes sendo 47 homens e 148 mulheres com idade variando entre 16 e 70 anos que apresentavam sinais e sintomas de DTM, tratados de forma conservadora. Ao final de dois anos, os resultados mostraram uma melhora continuada e uma tendência estatisticamente significante para a maioria dos pacientes em mostrar diminuição na severidade dos sintomas. No final deste periodo, 66,7\% dos pacientes apresentavam-se assintomáticos, 25,6\% apresentavam-se com sintomas leves e 3,15 apresentavam sintomas recorrentes.

Em 1994, COHEN; MACAFEE ${ }^{24}$ utilizaram imagens de ressonância magnética com a finalidade de determinar o posicionamento de placas oclusais utilizadas com a finalidade de controlar os desarranjos internos da ATM. Descreveram que estes podem causar sintomas como dor e ruído, descritos subjetivamente como estalido e crepitação, sendo que este quadro clínico pode ser precursor de processos patológicos mais severos, como a doença degenerativa (osteoartrite). Para os autores, o fator mais comum e que predispõe a mudanças degenerativas na ATM é o disco deslocado. Os autores descreveram que durante muito tempo, empregaram- 
se dispositivos intermaxilares com a finalidade de recapturar o disco deslocado. No entanto, a posição do mesmo era avaliada meramente por exame clínico. Com o advento da ressonância magnética nuclear mudou o cenário científico. Atualmente, a posição do disco pode ser visualizada, possibilitando ao profissional tratar os pacientes de forma mais efetiva.

No ano seguinte, em 1995, NELSON98 descreveu que se o aparelho estiver apropriadamente ajustado e a higiene bucal for mantida há poucas contra-indicações para o uso dos aparelhos de estabilização oclusal. Há um potencial de dependência emocional na terapia com placas oclusais. Além disso, o clínico deve ser cuidadoso em indicar terapia com placas em crianças na fase de crescimento, pois o longo tempo de uso pode alterar o padrão de crescimento. Com relação ao mecanismo de ação, o autor descreveu que não há consistência entre as teorias até então existentes para explicar seu mecanismo de ação. O efeito da terapia com placas oclusais requer investigação adicional. O autor, enumerou o que ele chamou de "critérios para um aparelho aceitável":

- Retenção e estabilidade.

- Contatos oclusais provendo estabilização e livres de contatos deflectivos

- Guias de movimentos excursívos.

- Forma da placa: - dimensão vertical mínima

- deve acompanhar o contorno dos dentes

- deve ser lisa e polida 
A popularidade das placas oclusais têm aumentado nos cinco continentes, recebendo diferentes denominações de acordo com o desenho. Embora o seu uso como dispositivo destinado à proteção ser bem aceito, os beneficios associados com o seu uso no tratamento de desordens motoras são controvérsos, e seu valor terapêutico no tratamento das DTM não tem sido bem estabelecido. De acordo com PIERCE ${ }^{112}$, em 1995, aproximadamente três milhões de placas oclusais são fornecidas para a população americana todo o ano, com um custo aproximado de 999 milhões por ano.

Em uma revisão da literatura, MCNAMARA; SELIGMAN e OKESON ${ }^{90}$ em 1995, ressaltaram a interação dos fatores morfológicos e funcionais relativos às DTMs e concluíram que há uma pequena associação dos fatores oclusais na etiologia das disfunções. Mordida aberta anterior esquelética, overjet maior que 6 ou $7 \mathrm{~mm}$, desvios $\mathrm{RC} / \mathrm{MIH}$ maiores que $4 \mathrm{~mm}$, mordida cruzada posterior unilateral e cinco ou mais dentes posteriores perdidos, são os cinco fatores oclusais que estão relacionados com condições diagnósticas específicas de disfunção. Os três primeiros estão associados com artropatias e podem resultar de alterações ósseas ou ligamentares na ATM. Com relação ao tratamento ortodôntico, a literatura indica que um tratamento realizado durante a adolescência não aumenta ou diminui o risco de desenvolvimento de DTM associada com qualquer tipo de conduta ortodôntica ou protocolo para extrações. Uma oclusão estável é o objetivo de qualquer tratamento ortodôntico, mas se o 
resultado deste tratamento não for o de uma oclusão gnatologicamente perfeita, isso não quer dizer que resultará em sintomas de DTM. Desta forma, de acordo com a literatura existente, a relação das DTM com a oclusão e tratamento ortodôntico, é pequena.

HOSOKI et al60, em 1995, descreveram um caso de uma paciente de 38 anos, com dor na ATM, estalido bilateral e travamento, onde utilizaram imagem de ressonância magnética com a finalidade de acompanhar o posicionamento do disco após a terapia com placa oclusal. O efeito da terapia foi avaliada duas vezes: após um mês e um ano e cinco meses com placa oclusal em boca. A ressonância revelou mudanças na posição anterior com redução para uma posição superior do disco na ATM direita. Na articulação esquerda, o disco mudou de uma posição anterior, sem redução, para uma posição anterior com redução, desaparecendo a limitação. Segundo esses achados, a RMN é um instrumento importante na condução de futuros estudos de terapias com placas oclusais no tratamento de pacientes com posição de disco anteriorizado.

Em 1995, BORROMEO, READE ${ }^{12}$, analisaram o tipo de desoclusão - guia canina e função em grupo - na função do músculo masseter de indivíduos normais. Para isto, selecionaram dez indivíduos e confeccionaram dois tipos de aparelhos interoclusais. Exames eletromiográficos foram utilizados para gravar a atividade do músculo masseter durante a posição de relação cêntrica, durante os movimentos de 
lateralidade direita e esquerda e durante apertamento realizado antes e após ajuste do aparelho colocado intencionalmente com interferência. De acordo com os resultados, não houve nenhuma diferença na atividade eletromiográfica do músculo masseter entre o uso de aparelho interoclusal esboçado pela guia canina ou função em grupo nos indivíduos normais.

SIMMONS; GIBBIS ${ }^{127}$, em 1995, realizaram estudo prospectivo envolveu 30 pacientes com sintomas dolorosas da ATM, para avaliar a recaptura dos discos deslocados e alívio dos sintomas por meio de dispositivos de reposicionamento anterior. A ressonância magnética nuclear foi realizada antes e imediatamente após o uso dos dispositivos interoclusais. As RMNs iniciais revelaram 26 articulações com deslocamento anterior de disco com redução em 17 pacientes, sete articulações com deslocamento anterior de disco com redução redução parcial em quatro pacientes; 14 articulações com deslocamento anterior de disco sem redução em 11 pacientes e 13 articulações normais em oito pacientes. A RMN após a colocação das placas mostrou recaptura de disco em 25 dos 26 deslocamentos com redução, o que corresponde a 96\%, mas nenhuma recaptura em articulações com deslocamento parcial ou deslocamento sem redução na abertura da boca. Todas as articulações normais permaneceram iguais. A dor diminuiu nas três categorias, sendo maior o alívio nos casos onde os discos foram recapturados.

Em 1996 MONGINI; IBERTIS;MANFREDI ${ }^{97}$, ao verificar que a literatura não estabelecia claramente que o deslocamento anterior de disco sem 
redução "closed lock" pode ser tratado de maneira conservadora e que existe diferentes técnicas desenvolvidas com a finalidade de manipular a mandíbula para a redução, descreveu os resultados de um acompanhamento a longo prazo em pacientes com deslocamento anterior de disco sem redução tratados de maneira conservadora. Em sua amostra, utilizou 75 pacientes diagnosticados como portadores de deslocamento anterior de disco sem redução baseado nos seguintes aspectos:

A - História prévia de estalido na ATM (excetuando-se os casos em que o barulho apareceu depois de trauma).

B - Aparecimento súbito de restrição de abertura associado a uma deflexão para o lado afetado.

C - limitação de movimento lateral para o lado contralateral.

D - Presença de sensibilidade a palpação no aspecto posterior do côndilo com a boca aberta.

E - Evidência radiográfica de restrição no movimento condilar. No lado afetado durante o movimento de abertura.

Entre os pacientes tratados, sete realizaram ressonância magnética antes e depois do tratamento com a finalidade de confirmar o deslocamento tanto em abertura como em fechamento. O tempo decorrido entre o deslocamento e a análise do paciente variou entre uma semana e dez anos. Em todos os pacientes foi tentada a manipulação 
mandibular. O sucesso com a manipulação foi conseguido em muitos casos. Em cinco casos houve necessidade de várias tentativas e o uso de injeção intracapsular de anestésico. Em um caso os sintomas só foram resolvidos depois da utilização de um aparelho de estabilização com a superficie oclusal de $1 \mathrm{~mm}$ de altura durante 24 horas durante um mês. A melhoria do funcionamento do complexo côndilo-disco foi confirmada por meio de radiografias realizadas com a boca aberta e fechada antes da manipulação. Em três casos, a imagem de ressonância realizada também depois da manipulação confirmou a melhora morfológica e funcional do complexo côndilo disco. Um forte contato da placa com uma rampa para prevenir um movimento retrusivo foi realizado com exceção de dois pacientes. O tratamento adicional incluía: terapia física (laser e/ou TENS) e exercícios de distração em todos os casos; biofeedback (53 casos) e tratamentos farmacológicos. $O$ ajuste na placa dificilmente foi necessário porque o posicionamento mandibular dificilmente alterou em relação à posição de máxima intercuspidação observada antes do tratamento. A decisão de não colocar placa em dois pacientes foi baseado no fato de se assumir que o deslocamento ocorreu em função de aumento de parafunção durante um período limitado de tempo e conseqüentemente as outras formas de terapia utilizadas tinham sido suficientes. O tempo de tratamento foi em média de 36 meses. Para o autor, apesar da descrição de tratamentos cirúrgicos artroscópicos, dos resultados de sua pesquisa e baseado na literatura dos últimos 30 anos, o disco deslocado sem redução pode ser tratado com 
sucesso utilizando-se terapias conservadoras. A ocorrência eventual de um aumento na sintomatologia pode estar associado a casos crônicos. Para o autor, a decisão de qual tipo de tratamento será conduzido depende fundamentalmente da evolução da lesão que é mais importante do que seu início. Isto é claro nos casos que envolve degeneração artrótica. Em outros casos, os achados clínicos de deslocamento de disco são pouco evidentes depois de um período decorrido do início, com um grau abertura vertical acima de muitos acasos agudos porém abaixo do normal. Com relação aos resultados, o autor levanta a questão, se os sintomas reduziram porque foi inserida uma estabilização mandibular ou se eles reduziriam espontaneamente. Para o autor, mudanças adaptativas dos tecidos moles e duros podem ocorrer em certo número de pacientes.

Em 1996, SOLBERG ${ }^{129}$ realizou um estudo onde constatou que os processos envolvidos com DTM ocorrem devido a um desequilíbrio entre forma e função. Quando a demanda funcional na ATM aumenta, há uma mudança compensatória no intuito de manter a forma e a função adequada da articulação. Alterações estruturais e funcionais dos tecidos articulares, assim como a remodelação articular são aparentes mesmo antes dos sintomas clínicos serem evidentes, com a finalidade de manter a forma e a função adequada.

Em 1996, MARTINI; MARTINI; CARANO87 relataram que o deslocamento anterior de disco sem redução tem sido considerado 
fundamentalmente uma anormalidade patofisiológica da articulação. E sob este aspecto, existe um suporte clínico e evidências por meio de ressonância magnética de que a manipulação redutiva pode ser o tratamento de deslocamentos agudos e crônicos. Neste estudo, os autores analisaram 1500 casos tratados e documentados com videotape. Entre todos os casos, somente cinco necessitavam de tratamento cirúrgico. O sucesso do tratamento foi confirmado por meio de 13 imagens de ressonância magnética da ATM, antes e após o tratamento. Em todos os casos de disco deslocado anteriormente, o mesmo foi recapturado e reposicionado encima do côndilo. Os autores concluíram, dizendo que o tempo de travamento não é importante para o sucesso da terapia, baseada em fisioterapia e exercícios assistidos de profissional, uma vez que casos com mais de dois anos de travamento foram tratados com sucesso.

SFONDRINI, et al. ${ }^{123}$, em 1996, utilizando-se de um modelo animal, estudaram as mudanças musculares adaptativas que ocorrem em função do uso de uma placa protrusiva e adoção de uma dieta líquida. Foram examinados os músculos, masseter, temporal e digástrico. Os autores concluíram que os músculos dos ratos podem se adaptar rapidamente à demanda funcional, mudando o tipo de composição das fibras e que, as mudanças parecem se restringir às fibras rápidas. Além disso, as mudanças que ocorrem em função do tipo de alimento não são diferentes daquelas que ocorrem em função do uso de um aparelho e isto deve ser levado em conta para avaliar seus efeitos. Para os autores, os músculos 
mastigatórios apresentam uma capacidade de adaptação à demanda funcional muito grande. A capacidade de mudar suas propriedades em relação às condições do esforço a que são submetidos, a ativação neural e outros fatores representam um determinante potencialmente importante da estrutura e função da boca e dentes. Esta capacidade de adaptação influencia não só nas pequenas modificações que ocorrem durante o movimento ou intensidade de força aplicada, mas também na própria constituição anatômica destes músculos. Observaram que o masseter profundo e o feixe anterior do digástrico, quando sob a ação de alimentos leves, apresentaram uma maior proporção de fibras rápidas e sensiveis à fadiga. Outras alterações observadas ocorreram após a instalação de uma placa protrusiva, em que os músculos masseter e pterigóideo lateral passaram por modificações que levaram ao aumento da quantidade de fibras lentas e resistentes a fadiga. Esta nova demanda funcional foi baseada na transformação das fibras rápidas, com uma diminuição das fibras sensiveis e um aumento nas fibras resistentes a fadiga. As transformações induzidas pela placa oclusal muito provavelmente correspondem a uma adaptação ao aumento da atividade física rítmica que requer fibras menos sensíveis à fadiga. Neste estudo realizado por SFONDRINI ${ }^{123}$, todos os músculos passaram por modificações no tipo de fibra e composição de miosina, sugerindo que todas as fibras são afetadas pelas mudanças nas condições de esforço mecânico. A placa protrusiva aparentemente ativa não somente os músculos de protrusão mas também os de abertura e de elevação da 
mandíbula. Então é possivel especular que as transformações nas fibras musculares podem assumir um papel importante no tratamento clínico.

Ainda em 1996, LEIB; ALDEN76 publicaram um estudo no qual dissertaram a respeito das placas oclusais e suas indicações. Defenderam o grande benefício do uso da placa oclusal reversivel e rígida, cobrindo toda a superfície oclusal, no tratamento da DTM e bruxismo. Salientaram que a terapia com placa de mordida deve sempre ser adotada antes que procedimentos invasivos e onerosos sejam considerados como forma de tratamento.

Em 1997, MAJOR; NEBBE 85 , verificando que a literatura sobre o uso e a efetividade das placas oclusais têm se tornado mais frequentes, realizaram uma avaliação retrospectiva sobre o uso e a efetividade da terapia com estes aparelhos. Para os autores, para se analisar os resultados dos estudos sobre a efetividade de aparelhos oclusais, há necessidade de se examinar o desenho do estudo, assim como os métodos para a coleta de dados. Se a validade e precisão dos instrumentos de medidas são determinadas e descritas anteriormente para utilização, o leitor pode compreender o sucesso e limitações da terapia mais claramente. O autor verificou que: a) os aparelhos oclusais ortopédicos de diferentes desenhos e aplicações, têm sido utilizados no tratamento de Disfunções Temporomandibulares incluindo as disfunção articulares e musculares; b) estes aparelhos têm sido muito utilizados porque estes aparelhos tem caráter 
não invasivo e reversivel no controle dos sintomas; c) ao comparar os resultados de estudos que avaliam o uso destes aparelhos como forma de terapia verificaram que é dificil tal avaliação, devido ao emprego de várias escalas para medir os resultados, devido à avaliação subjetiva dos resultados de pacientes e a variabilidade na descrição dos resultados de tratamento d) as placas são efetivas na redução de dor muscular e de cabeça; e) a placa tem valor limitado na redução de dor articular, exceto as placas de reposicionamento anterior, quando a dor está associada ao estalido; f) tanto objetiva como subjetivamente a extensão do movimento mandibular aumenta com o uso da placa. Com relação ao estalido, a literatura não mais suporta o seu desaparecimento como critério de sucesso, e isto resulta do reconhecimento de que sons articulares são apenas diagnósticos de relacionamento articular anatômico. Os autores afirmam, ainda, que a relevância clínica de que a redução da atividade eletromiográfica é reduzida pela desoclusão posterior, permanece controversa. Descreveu, também, que o efeito placebo deste tipo de aparelho tem sido responsável pela melhora descrita em muitos trabalhos utilizando estes aparelhos, alertando que os mecanismos responsáveis por variáveis puramente psicológicas e que afetam a saúde corporal são complexos e não bem estendidos. Os autores concluíram que o futuro da pesquisa nesta área é a comparação de resultados de modalidade de terapias alternativas incluindo a fisioterapia, biofedback, controle de hábitos e farmacoterapia, quando possível utilizando um modelo duplo cego. 
Em 1997, SUMMER; WESTESSON ${ }^{134}$ realizaram um estudo de acompanhamento clínico e morfológico dos resultados obtidos com a recaptura do disco. Para isto, reavaliaram 75 pacientes e fizeram comparações entre as imagens de ressonância magnética atuais com imagens iniciais realizadas 1 a 6 anos antes do controle, de pacientes que tinham sido tratados para recaptura de disco comprovada radiograficamente. Durante o tratamento, foram utilizados durante o dia aparelhos com inclinações para guiar a mandíbula dentro da posição terapêutica e um aparelho telescópico noturno com a finalidade de prevenir a retrusão da mandíbula durante o sono. O aparelho era confeccionado recobrindo os dentes posteriores com a finalidade de suportar permanentemente a mandíbula na posição terapêutica. Após o tratamento de 115 articulações com deslocamento de disco, 52\% estavam em posição normal, 23\% tinham melhorado sua posição e 25\% mantinham o deslocamento. O alívio de sintomas foi descrito por $95 \%$ dos pacientes que tiveram o disco recapturado, $84 \%$ daqueles que tiveram melhora no seu posicionamento e em $49 \%$ daqueles que mantiveram o disco deslocado. Observaram que o insucesso com este tipo de tratamento foi na ordem de $7 \%$ nas articulações com deslocamento anterior e em 44\% de articulações com deslocamento oblíquo. Em 45\% dos casos que tiveram os discos deslocados, observaram melhora de contorno anatômico. Os autores descreveram que o posicionamento mandibular anterior é efetivo nos casos de deslocamento anterior de disco com redução, basicamente quando o disco encontra-se 
deslocado em direção anterior. Concluíram que esta forma de tratamento pode ser utilizada para os casos no qual houve insucesso com outras formas de terapia mais conservadora, justificando a reconstrução oclusal permanente e desde que o paciente compreenda a necessidade do uso de aparelhos noturnos por longo periodo de tempo. Alertaram para o fato de que o reposicionamento mandibular anterior é menos efetivo nos casos de deslocamento de disco com um componente oblícuo.

Em 1997, KURITA; KURASHINA; KOTANI ${ }^{71}$ realizaram um estudo retrospectivo para avaliar os efeitos de uma terapia com placa oclusal de cobertura total da maxila, sobre os sinais e sintomas de DTM. O estudo envolveu de 232 pacientes que sofriam de dor crônica nos movimentos, "estalido" na ATM e dificuldade de abertura bucal. Todos foram tratados com placas oclusais. Os resultados obtidos foram: $41 \%$ apresentaram uma melhora total e $84 \%$ reportaram algumas melhoras. O estudo concluiu que o uso das placas pode ser um tratamento útil das Desordens Temporomandibulares, especialmente aquelas sem evidência clínica de deslocamento de disco.

Em 1997 KOYANO et al ${ }^{69}$, com a finalidade de avaliar o efeito das placas oclusais de estabilização (com guia anterior e canino) no padrão de movimentos mandibulares, examinaram 12 estudantes saudáveis, classe I de Angle com dentição completa e sem história de tratamento ortodôntico, sendo sete homens e cinco mulheres com média de idade de 
24,4 anos. O exame dos movimentos, feito antes e após a utilização dos aparelhos durante 24 horas, foi realizado utilizando-se um sistema computadorizado desenvolvido pela Universidade de Kyushu, que reproduz os movimentos mandibulares tridimensionalmente. Os resultados mostraram que os movimentos variaram antes e depois do uso do aparelho, sendo que o padrão de fechamento se manteve. O tempo do ciclo mastigatório se manteve igual, o que significa que a mudança temporária na oclusão e/ou propriocepção do ligamento periodontal, não influencia no ritmo ditado pelo SNC, no entanto o tempo de distribuição entre as fases do ciclo (oclusal, abertura e fechamento) foi influenciada pelo uso do aparelho, sendo que o tempo oclusal diminuiu significantemente. Foi observado, ainda, que o desvio durante a abertura diminui após o uso da placa oclusal, com os pacientes apresentado um padrão de abertura mais vertical. Outra observação foi que a amplitude não se alterou além do que, a quantidade de deslocamento lateral que mandíbula realiza durante o movimento mastigatório diminuiu.

Em 1998, SANTACATTERINA et. al. ${ }^{118}$., preocupado com o conflito existente na literatura, descreveu os resultados da literatura das diferentes formas de terapias para o deslocamento anterior de disco com redução (DADC/R). Para isto, realizou um estudo utilizando meta-análise da literatura, com a finalidade de verificar a efetividade de duas formas de terapia mais freqüentemente utilizadas nos casos de DADC/R: a placa oclusal de reposicionamento anterior e a placa de estabilização. Realizou um 
levantamento bibliográfico de 1985 a 1996, utilizando o MEDLINE. O critério de seleção foi baseado na exaustiva descrição do estudo e homogeneidade da amostra. Seis artigos foram selecionados e divididos em dois grupos: a) grupo I: comparando placas de reposicionamento anterior e placas de estabilização e, b) grupo II: avaliando somente placas de reposicionamento anterior. O autor concluiu, em análise desta literatura, que existem duas escolas diferentes de filosofia divididas em: a) os reposicionadores, que acreditam na necessidade terapêutica de refazer a o relacionamento do complexo côndilo disco com a finalidade de se obter saúde clínica; b) os funcionalistas, que acreditam na saúde clínica mesmo nos casos em que o disco permanece deslocado. A meta análise utilizada apresentou bons resultados com o uso de placas de reposicionamento anterior na redução do ruído articular e dor, quando comparada com a placa de estabilização. Assim, o autor concluiu afirmando que à luz da literatura atual, uma correta terapia com placas de reposicionamento anterior é a melhor conduta no controle do ruído e da dor que acompanham casos de DADC/R.

Em 1998, DAO; LAVIGNE ${ }^{34}$ revisaram o mecanismo pelo qual as placas oclusais exercem seus efeitos e avaliaram, ainda, a qualidade das evidências que suportam a sua eficácia (valor terapêutico real) no tratamento do bruxismo. Descreveram que apesar do uso frequente de aparelhos oclusais com a finalidade de tratar Desordens Temporomandibulares e bruxismo, o seu mecanismo de ação permanece controverso. Várias hipóteses têm sido propostas para explicar a sua 
aparente eficiência: incluindo: a - o reposicionamento do côndilo e / ou disco articular; b - redução na atividade eletromiográfica dos músculos mastigatórios, c - modificação do comportamento oral prejudicial ao paciente; d - modificação na oclusão. Por meio de uma revisão da literatura, os autores relataram que todas as teorias acima descritas são fracas e inconsistentes, permanecendo incerto o seu verdadeiro valor terapêutico. Para os autores, os resultados de testes clínicos controlados suportam a efetividade (isto é, apreciação do paciente das mudanças positivas que são percebidas como ocorridas durante o experimento) de placas no controle da dor miofascial. À luz dos dados que suportam sua efetividade mas não sua eficácia, as placas oclusais deveriam ser utilizadas como adjuntas no controle da dor antes do tratamento definitivo. Segundo os autores, para o bruxismo noturno, é prudente limitar seu uso somente para prevenir e limitar o dano dental induzido pela disfunção. Concluem relatando que futuras pesquisas deveriam estudar a história natural e a etiologias da DTM e bruxismo, a fim de que tratamentos específicos possam ser desenvolvidos.

Em 1998, YAP ${ }^{156}$ realizou estudo com o intuito de investigar a curto prazo o efeito de aparelhos estabilizadores no comportamento de parafunções (bruxismo e apertamento) durante o sono, em pacientes com e sem sinais de DTM. Para isto, foi avaliada a presença de sinais e sintomas de DTM antes e três meses após a terapia com aparelho estabilizador. Os resultados revelaram que aparelhos estabilizadores não resolveram as parafunções noturnas em ambos os grupos de pacientes, uma 
vez que a presença de facetas ativas de desgaste nas rampas guias do aparelho foram criadas pela excursão noturna bilateral da mandíbula.

CONTI26 (1998) afirmou que o controle pós reabilitação dos pacientes com desgaste dentário acentuado deve estar voltado para a manutenção e proteção das peças protéticas contra possíveis fraturas. Um meio adequado e indicado é a utilização das placas oclusais lisas, atualmente denominadas placas estabilizadoras, sobre as próteses fixas e/ou removiveis. Estas fazem parte, também, segundo o autor, do controle de pacientes com mobilidade dentária e bruxismo, assim como dos casos de Disfunções Temporomandibulares. $\mathrm{O}$ autor descreveu que o mecanismo de ação das placas oclusais não está totalmente elucidado, mas certamente vai muito além da simples obtenção de uma oclusão ideal. Afirmou que apesar de várias técnicas terem sido propostas para a confecção das placas estabilizadoras ou lisas, a mais aceita é aquela que utiliza a montagem dos modelos em articulador, enceramento e prensagem das placas com resina acrílica de polimerização térmica. Para o autor, a placa deve apresentar contatos simultâneos com os dentes antagonistas e durante os movimentos excursívos da mandíbula deve haver desoclusão lateral pelos caninos e protrusiva pelos dentes anteriores.

Em 1999, WIDMALM147 escreveu um artigo relatando o uso indiscriminado de placas oclusais. Para o autor, apesar da placa oclusal ser o principal meio utilizado para proteger os dentes, melhorar a função 
muscular e articular e diminuir a dor, pode causar alterações irreversiveis e severas devido ao seu uso prolongado, principalmente nos casos de uso ininterrupto de placa protrusiva por um periodo de 4 a 6 semanas. Descreve, que não existe um consenso sobre osmotivos pelos quais o uso das placas tem um efeito benéfico sobre os tecidos articulares. Poucos estudos realmente são resultado da utilização adequada de um grupo controle, quando se estudam estes aparelhos oclusais. O autor, relata ainda, que no caso do uso de placas, do ponto de vista legal é interessante alertar o paciente quanto ao tempo e forma de uso. O autor conclui afirmando que as placas podem ter um valor diagnóstico terapêutico, desde que utilizado em casos selecionados e adequadamente ajustada e controlada, podendo ser danosas para pacientes sem controle. 
3 - PROPOSIÇÃO 


\section{3 - Proposição}

Como observado na Revisão da Literatura, há uma grande diversidade de opiniões em relação à etiologia das DTM, dando origem a várias formas de terapias, entre as quais as placas oclusais reposicionadoras e estabilizadoras.

Dessa forma o presente trabalho, propõe-se a avaliar a efetividade do uso de placas reposicionadoras no controle de patologias intra-articulares, quando comparadas com um tratamento convencional (placas estabilizadoras) e um grupo controle (sem tratamento), durante o período de 1 ano.

A avaliação será realizada por meio de análise de:

a) alteração nos sintomas relatados pelo paciente;

b) alteração nas médias de palpação muscular e da ATM;

c) mudança na movimentação mandibular;

d) alterações de ruídos articulares;

e) alterações nos contatos oclusais;

f) evolução dos sinais e sintomas sem tratamento específico. 


\section{4 - MATERIAL E MÉTODOS}




\section{4 - Material e Métodos}

\section{$\underline{4.1}$ - Amostra}

O presente trabalho foi realizado utilizando-se uma amostra de 52 individuos selecionados ao acaso entre os pacientes que procuraram tratamento no Centro de Dor Orofacial e DTM, do Departamento de Prótese da Faculdade de Odontologia de Bauru da Universidade de São Paulo, inicialmente, controlados em relação a idade e gênero.

Toda amostra foi informada do propósito da pesquisa e do método a ser utilizado e, após cientes dos procedimentos a serem realizados, assinaram uma autorização para pesquisa clínica e execução de instalação dos aparelhos nos casos específicos selecionados de acordo com o método. (anexo I). Não houve qualquer seleção com relação ao aspecto socio economico da amostra.

Os grupos formados (dois experimentais e um controle) foram estipulados de acordo com os critérios abaixo descritos.

O processo de inclusão da amostra foi realizado de maneira aleatória por sorteio, de tal forma que na mesma ordem em que os pacientes foram selecionados para exame, seus nomes eram anotados em lista, de uma maneira seqüencial, onde já havia sido estabelecida 
aleatoriamente, por sorteio, a determinação do grupo ao qual iriam pertencer.

Não foi realizado qualquer outro tipo de tratamento alèm dos abaixo especificados.

\section{Grupo I - Placa estabilizadora}

Constituído por 20 individuos que apresentavam pelo menos um dos seguintes sintomas utilizados como critério de inclusão: história de dor na ATM, ruídos articulares e história de travamento mandibular de origem articular. Foram excluídos aqueles que apresentaram história de artrites sistêmicas e/ou traumas recentes, assim como pacientes com história de cirurgia prévia de ATM.

Estes indivíduos foram orientados a usar a placa somente durante a noite para dormir. Todos os individuos foram orientados a retornar para controle de acordo com as datas previamente assinaladas para reavaliação baseada na ficha B (anexo III) e C (anexo IV), utilizada para reavaliação e para marcação dos contatos oclusais, respectivamente. O aparelho foi utilizado seguindo este protocolo por um período de 12 meses.

\section{Grupo II - placa reposicionadora}

Esse grupo, foi formado por 18 indivíduos, que utilizaram placa oclusal reposicionadora, sendo também selecionado ao 
acaso entre os pacientes que procuram tratamento no Centro de Dor Orofacial e DTM da Faculdade de Odontologia de Bauru-USP e apresentou os mesmos critérios de inclusão e exclusão do grupo anterior ( grupo I ).

Para essa modalidade, os individuos foram orientados a usar a placa ininterruptamente durante uma semana e após este período, somente à noite para dormir. O grau de protrusão mandibular foi individualizado, sendo a placa confeccionada na posição maxilomandibular que eliminou o estalido. O aparelho foi utilizado durante o período de três meses, após o qual foi transformado em placa estabilizadora e mantido por um período de nove meses, totalizando também para este grupo um tempo de uso de um ano.

\section{Grupo III - Controle}

Formado por 14 indivíduos, com os mesmos critérios de inclusão e exclusão acima descritos. Para esse grupo, não foi feito nenhum tipo de tratamento, sendo todos os individuos, também, orientados a realizar retornos, seguindo o mesmo cronograma para os grupos anteriores.

\section{$\underline{4.2}$ - Fichas de exames}

Para a coleta de dados relativos aos sinais e sintomas de DTM foram utilizadas três fichas clinicas específicas, elaboradas a partir 
de fichas preexistentes pertencentes ao Departamento de Prótese da Faculdade de Odontologia de Bauru, da Universidade São Paulo. Cada ficha teve uma finalidade específica como descrito abaixo:

Ficha A: Utilizada para o exame clinico ( anexo II)

Ficha B: Utilizada para a reavaliação ( anexo III )

Ficha C: Utilizada para o mapeamento dos pontos de contato oclusal ( anexo IV)

Em todas as fichas foram registrados os dados pessoais dos indivíduos relativos ao nome, idade, gênero, estado civil, endereço e telefone. A ficha utilizada para o exame clínico, além dos dados pessoais foi subdividida em dois itens: história médica e sintomas de DTM.

Antes de qualquer intervenção, toda amostra foi solicitada a graduar sua dor de acordo com a escala de análise visual (EAV) graduada em milimetros (0 a $10 \mathrm{~mm})$. Tal mensuração foi o parâmetro de acompanhamento subjetivo da evolução dos sintomas nos diferentes grupos.

A ficha utilizada para reavaliação da amostra (anexo III) representava resumidamente a ficha de exame objetivo e subjetivo, e foi utilizada em todas as consultas de acompanhamento durante o desenvolvimento deste trabalho, sendo preenchida a cada retorno, durante o 
controle da amostra. Ainda nesta ficha, constava um item relativo a avaliação final aonde o paciente respondia dados relativos a oclusão e ao estalido (manteve-se, alterou para melhor, alterou para pior). Além destas duas questões, indagou-se também, quando fosse o caso, sobre o conforto da placa ( manteve-se, alterou para melhor, alterou para pior, não sabe).

A ficha de avaliação dos contatos oclusais era composta por diagramas representando os contornos oclusais do arco superior e inferior e tinha como finalidade a anotação da localização dos contatos oclusais na posição de intercuspidação em todas as sessões de reavaliação.

\section{$\underline{4.3 \text { - Métodos }}$}

\subsection{1 - Abertura bucal ativa}

Foi realizado solicitando-se ao paciente para abrir a boca ao máximo. Realizava-se a medição com um paquímetro ${ }^{1}$ da distância entre as bordas incisais superior e inferior, tomando como referência a linha mediana. Nos casos em que o paciente apresentava dor na abertura, pediase para abrir a boca até apresentar a sensação dolorosa, quando então realizava-se a medida. O valor da abertura máxima sempre era corrigido, somando-se o trespasse vertical. 


\subsection{2 - Movimento látero protrusivos ativo}

A análise dos movimentos laterais foi realizada solicitando-se ao paciente para movimentar a mandíbula para um dos lados. A mesuração era feita utilizando-se uma régua posicionada no plano horizontal, e tomando como base uma linha vertical que passava próximo da linha média do incisivo central superior e que se estendia para a vestibular do inferior, fazendo-se a medida da linha superior até linha inferior das excursões laterais máximas.

Solicitou-se ao paciente, também, para realizar o movimento mandibular máximo para frente, e mediu-se o grau de protrusão. Para isso, usou-se uma régua posicionada no plano horizontal, tocando a face vestibular do incisivo central superior, e com o paciente em posição protrusiva, tomou-se a medida até a face vestibular do incisivo central inferior, acrescentado-se, agora, o trespasse horizontal.

\subsection{3 - Trajetória de abertura e fechamento}

Tal procedimento foi realizado observando-se o paciente de frente, confortavelmente sentado na cadeira odontológica, analisando-se o trajeto do movimento de abertura e fechamento, tomando como referência a linha média mandibular, segundo OKESON ${ }^{103}$.

\footnotetext{
${ }^{1}$ Mitutoyo MSG. Co. Ltda, Japão.
} 


\subsection{4. - Análise de ruidos articulares}

As vibrações dos ruídos articulares foram observadas pela inspeção manual, posicionando-se levemente os dedos indicadores na região correspondente ao pólo lateral do côndilo, à frente do meato acústico externo, enquanto o paciente realizava movimentos de abertura e fechamento da boca. O momento em que ocorria o ruído, tanto em fechamento como em abertura, era classificado para cada lado em inicial, intermediário e tardio. Nesse mesmo item foram anotados os achados relacionados a ruídos provenientes de estalidos, crepitação ou hipertranslação condilar. Para um eventual diagnóstico diferencial entre estalidos de abertura tardios e hipertranslação condilar, o paciente era solicitado a realizar movimentos de abertura e fechamento, com a mandíbula em protrusão. A eliminação do estalido indicava clinicamente a presença de deslocamento anterior de disco com redução. A manutenção do ruído associado à abertura excessiva caracterizava a hipertranslação condilar (hipermobilidade da ATM).

\subsection{5 - Palpação da ATM}

Previamente ao exame de palpação, toda a amostra foi orientada quanto à diferença entre sensação de pressão e dor para uma melhor análise da resposta ao procedimento de palpação. Para a avaliação da ATM, foi utilizada a palpação digital bilateral com os dedos indicadores 
posicionados aproximadamente 10 a $20 \mathrm{~mm}$ à frente do conduto auditivo externo. Pressionou-se a região delicadamente e de maneira contínua, com uma carga de aproximadamente 450 a 900 gramas de acordo com PERTES; GROSS 111.

Desta forma, avaliou-se a ATM com boca fechada (aspecto lateral) e boca aberta (aspecto posterior).

A graduação da resposta do paciente à palpação da ATM foi feita nos seguintes valores, de acordo com PERTES; GROSS111.

Valor $0 \rightarrow$ ausência de sensibilidade à palpação

Valor $1 \rightarrow$ sensibilidade leve

Valor $2 \rightarrow$ sensibilidade moderada

Valor $3 \rightarrow$ sensibilidade severa

\section{3 .6 - Exame muscular}

A palpação muscular foi realizada bilateralmente, exercendo-se pressão firme, porém de maneira suave, com uma pressão constante de aproximadamente de 1500 gramas de acordo com CONTI et al25 em 1996.

Assim, baseados nas reações demonstradas pelos indivíduos, o grau de dor foi classificado também em 0 - sem dor, 1 - dor leve, 2 - dor moderada, 3 - dor severa seguindo os critérios de PERTES; GROSS 111. 
Os músculos avaliados durante a palpação foram o masseter superficial e profundo, pteriogóideo medial e temporal (anterior, médio e posterior).

\subsection{7 - Avaliação dos contatos oclusais}

A avaliação dos contatos oclusais foi realizada clinicamente pela marcação e mapeamento dos pontos de contatos oclusais, com o paciente sentado confortavelmente e ocluindo na posição de intercuspidação, sem qualquer pressão sobre o mento. Uma pinça Miller ${ }^{2}$ com fita demarcadora de contato (Accu Film $\mathrm{II}^{3}$ ), foi utilizada para a marcação dos contatos oclusais.

\subsection{8 - Avaliação Dental e Oclusal}

Toda a cavidade bucal foi inspecionada, procurando-se verificar a ausência de dentes, facetas de desgaste e presença de próteses, interferências oclusais e grau de trespasse (vertical e horizontal).

O paciente foi questionado sobre tratamento odontológico e ortodôntico prévio e verificado o grau de higiene e sua condição periodontal.

\footnotetext{
${ }^{2}$ Hu-Fridy Mfg Co. Inc Illinois Chicago, EUA
} 


\subsection{9 - Confecção e instalação das placas}

Todas as placas oclusais estabilizadoras foram processadas laboratorialmente. As placas oclusais reposicionadoras foram parcialmente processadas em laboratório para facilitar a sua confecção.

\section{A - Placas oclusais estabilizadoras (Grupo I)}

Após a montagem em articulador semi-ajustável, as placas oclusais estabilizadoras foram inicialmente enceradas de maneira a se conseguir o maior número de pontos de contato. Nesta fase também se delineou a guia anterior e a desoclusão pelo canino. Após o processo de inclusão e prensagem, o aparelho foi remontado no articulador com a finalidade de reajustar a oclusão para posterior acabamento e polimento.

Todas as placas oclusais estabilizadoras foram confeccionadas seguindo os seguintes critérios:

- Cobertura de todo arco dental superior, com espessura de aproximadamente $2 \mathrm{~mm}$ na região posterior

- Superficie de contato lisa e plana

\footnotetext{
${ }^{3}$ Accu-film II (Red/black) - PARKELL N.Y. - U.S.A
} 


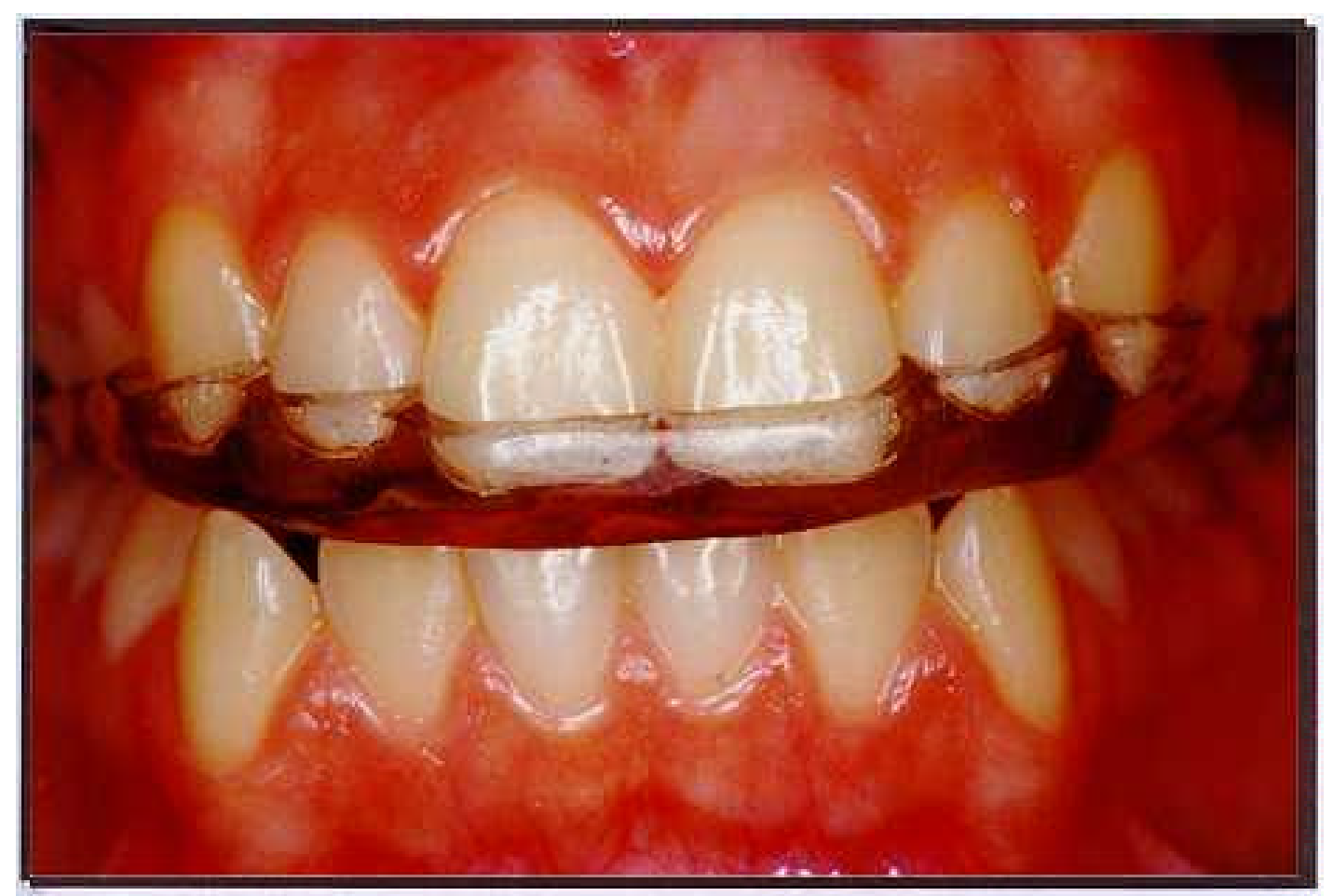

FIGURA 1- Placa oclusal estabilizadora em posição

$\mathrm{Na}$ instalação, os indivíduos foram orientados quanto à freqüência de utilização e cuidados com a placa oclusal.

Quando ocorria alterações nos contatos oclusais após o seu uso, novos ajustes eram realizados na placa com a finalidade de manter o maior número de contatos oclusais no aparelho.

\title{
B - Placa oclusal reposicionadora (Grupo II)
}

\author{
A placa oclusal reposicionadora foi confeccionada \\ seguindo-se basicamente as orientações descritas por OKESON ${ }^{103}$. As
}


moldagens foram realizadas somente no arco superior para a confecção de uma base em resina termopolimerizável. Posteriormente em uma nova sessão clínica, uma camada de resina acrílica, na fase plástica, era adaptada a superficie oclusal da placa e o paciente orientado a fechar a boca em protrusão na posição de abertura onde houvesse a eliminação do ruído articular. O grau de protrusão era ate a posição de topo a topo. Após esta fase, era confeccionada a rampa guia lingual com a finalidade a orientar o posicionamento anterior da mandibula. Finalmente, realizavam-se os acabamentos necessários, assim como o polimento do aparelho.

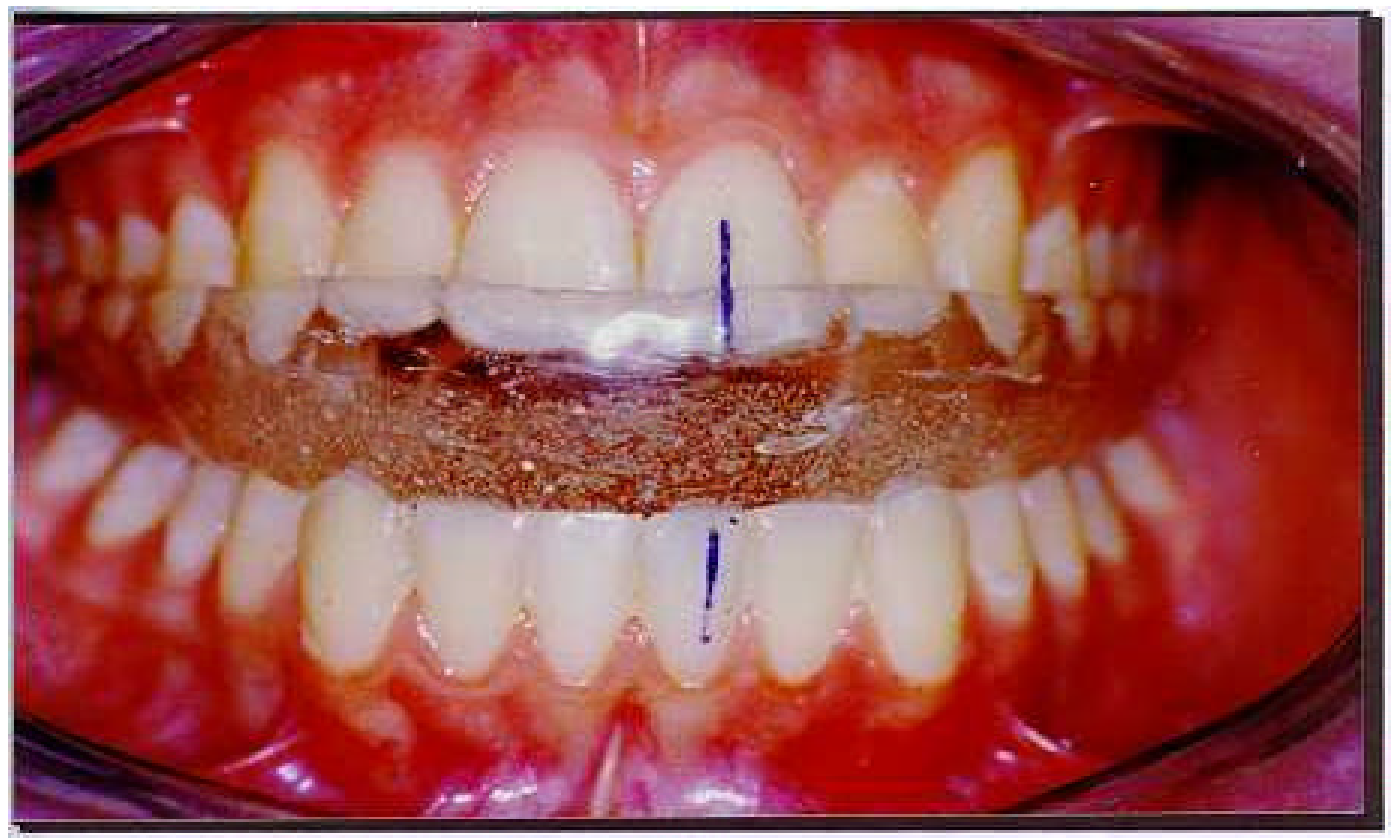

FIGURA 2- Placa oclusal reposicionadora em posição 


\subsubsection{0 - Orientações aos pacientes}

Após realizados todos os exames, e realizadas as moldagens para processamento laboratorial e instalação das placas, os indivíduos foram orientados quanto à seqüência dos retornos. Toda a amostra formada por portadores de placa oclusal de reposicionamento tiveram seus aparelhos transformados em placa oclusal lisa no retorno número 4, que correspondia a três meses de uso.

Retorno 1: uma semana após instalação da placa

Retorno 2: após 15 dias de instalação da placa

Retorno 3: após um mês de instalação da placa

Retorno 4: após três meses de instalação da placa

Retorno 5: após seis meses de instalação da placa

Retorno 6: após um ano de instalação da placa

Para avaliação da intensidade de dor apresentada pelo paciente durante a reavaliação também foi empregada a escala de análise visual de dor de 0 a 10, marcada em uma ficha com um traço horizontal de $100 \mathrm{~mm}$, onde zero é nenhuma dor e dez uma dor insuportável. Assim, o paciente assinalava com um traço vertical, a posição que melhor indicava o grau de dor. O resultado, assim obtido, era transferido em números, obtidos pela medida do início da linha até o traço assinalado. 


\subsubsection{1 - Análise estatística}

- Teste de Análise de variância (ANOVA) a dois critérios para mensurações repetidas foi utilizado para avaliação das variáveis abertura bucal, número de contatos oclusais e movimentação mandibular ativa.

- Teste de Friedman foi usado para análise intragrupos da variável escala de análise visual de dor (EAV).

- Utilizou-se o Teste de Kruskal-Wallis para análise intergrupos para variável escala de análise visual de dor, nos diferentes tempos.

- Teste de associação de Mc Nemar foi realizado para avaliar a redução dos ruídos articulares durante o experimento.

Foi adotado um nível de significância de 95\%.

Quando detectada uma diferença estatisticamente significante, testes de comparações múltiplas foram aplicados, de acordo com os programas estatísticos utilizados (Sigma Stat ${ }^{4}$ e Systat ${ }^{5}$ )

\footnotetext{
${ }^{4}$ SigamStat 2.0 for windows, SPSS Science, Inc, USA, 1997.

${ }^{5}$ Systat 5.02 for windows, Systat, Inc, USA, 1993-1993.
} 


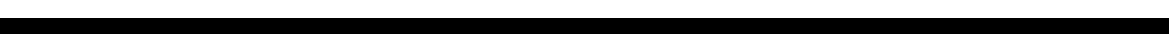

5 - RESULTADOS 


\section{5 - Resultados}

\section{1 - Dados gerais}

A amostra do presente trabalho constou de 52 indivíduos com média de idade de 31,84 anos.

A relação entre a idade da amostra e o grupo ao qual pertenciam está representada na Tabela 1. Observe o equilíbrio das médias de idade entre os grupos.

TABELA 1 - Média de distribuição da idade entre os grupos e o respectivo desvio padrão

\begin{tabular}{ccc}
\hline GRUPO & Idade média & $\boldsymbol{n}$ \\
\hline$I$ & $32,75(11,93)$ & $20(38,46 \%)$ \\
$I I$ & $31,44(13,16)$ & $18(34,61 \%)$ \\
III & $31,07(9,28)$ & $14(26,92 \%)$ \\
\hline TOTAL & $31,84(11,54)$ & $52(100 \%)$ \\
\hline
\end{tabular}

Com relação ao gênero, considerando o total da amostra, 14 indivíduos $(26,92 \%)$ pertenciam ao gênero masculino, enquanto 
38 indivíduos $(73,80 \%)$ pertenciam ao gênero feminino, confirmando a maior prevalência do gênero feminino em amostras de pacientes portadores de DTM.

Analisando a distribuição entre os grupos em relação a esse critério, podemos observar que no grupo I, seis individuos (30\%) pertenciam ao gênero masculino e 14 eram mulheres. Com relação ao grupo II, seis $(33,40 \%)$ individuos eram homens enquanto que 12 (66,6\%) pertenciam ao gênero feminino. No grupo III, pertenciam ao gênero masculino dois indivíduos (14,29\%) enquanto $12(85,71 \%)$ eram do gênero feminino (Tabela 2).

TABELA 2 - Distribuição da amostra entre os grupos de acordo com o gênero

\begin{tabular}{cccc}
\hline GRUPO & masculino & feminino & $\boldsymbol{n}$ \\
\hline$I$ & $6(30,00 \%)$ & $14(70,00 \%)$ & $20(100 \%)$ \\
$I I$ & $6(33,40 \%)$ & $12(66,60 \%)$ & $18(100 \%)$ \\
$I I I$ & $2(14,29 \%)$ & $12(85,70 \%)$ & $14(100 \%)$ \\
\hline$N$ & $14(26,92 \%)$ & $38(73,08)$ & $52(100 \%)$ \\
\hline
\end{tabular}


Analisando os resultados obtidos em relação ao percentual de pacientes que realizaram tratamento ortodôntico, encontraram-se 12 pacientes previamente submetidos ao tratamento ortodôntico, o que representou $23,08 \%$ do total, distribuídos de acordo com a Tabela 3.

TABELA 3 - Distribuição percentual de pacientes submetidos ao tratamento ortodôntico

\begin{tabular}{cccc}
\hline GRUPO & Sim & Não & N \\
\hline$I$ & $5(25,00 \%)$ & $15(75,00 \%)$ & $20(100 \%)$ \\
$I I$ & $5(27,77 \%)$ & $13(72,22 \%)$ & $18(100 \%)$ \\
$I I I$ & $2(14,28 \%)$ & $12(85,71 \%)$ & $14(100 \%)$ \\
\hline TOTAL & $12(23,08 \%)$ & $40(76,92 \%)$ & $52(100 \%)$ \\
\hline
\end{tabular}

Já em relação ao relato de hábitos parafuncionais de apertamento e bruxismo, observa-se, de acordo com a Tabela 4, que aproximadamente metade de toda amostra relatou hábitos de ranger os dentes. 
TABELA 4- Distribuição do relato de hábitos parafuncionais (bruxismo e apertamento) entre os grupos

\begin{tabular}{cccc}
\hline GRUPO & Sim & Não & N \\
\hline$I$ & $12(60,00 \%)$ & $8(40,00 \%)$ & $20(100 \%)$ \\
$I I$ & $9(50,00 \%)$ & $9(50,00 \%)$ & $18(100 \%)$ \\
$I I I$ & $8(57,10 \%)$ & $6(42,90 \%)$ & $14(100 \%)$ \\
\hline$N$ & $29(55,78 \%)$ & $23(44,30 \%)$ & $52(100 \%)$ \\
\hline
\end{tabular}

\section{2 - Abertura Bucal}

Com relação ao grau de abertura bucal, encontrou-se média de abertura inicial e final para o total da amostra de $47.42 \mathrm{~mm}$ e $53,50 \mathrm{~mm}$, respectivamente.

Os resultados da evolução dos graus de abertura bucal nos diversos períodos de mensuração entre os grupos podem ser observados na Tabela 5. Observe a melhora no grau de abertura, independente do grupo. 
TABELA 5 - Distribuição da média de abertura (em milímetros) entre os grupos nos diferentes períodos de mensuração.

\begin{tabular}{cccccccc}
\hline GRUPO & Inicial & $\mathbf{7}$ dias & $\mathbf{1 5}$ dias & $\mathbf{1}$ mês & $\mathbf{3}$ meses & $\mathbf{6}$ meses & $\mathbf{1}$ ano \\
\hline$I$ & 48,20 & 48,20 & 48,15 & 50,15 & 51,65 & 53,20 & 54,45 \\
$I I$ & 46,50 & 46,94 & 48,77 & 50,11 & 51,38 & 51,55 & 52 \\
$I I I$ & 47,57 & 47,92 & 50,07 & 50,42 & 52,42 & 53,35 & 54,07 \\
\hline Total & 47,42 & 47,68 & 48,99 & 50,23 & 51,82 & 52,70 & 53,50 \\
\hline
\end{tabular}

Para a análise dos valores obtidos, quando o critério analisado foi o grau de abertura bucal entre os grupos, utilizou-se o teste de ANOVA a dois critérios (grupo e tempo) para mensurações repetidas.

Os resultados demostraram que, independente do grupo $(p=0,806)$, toda a amostra apresentou melhora, quando a variável tempo foi avaliada. $(\mathrm{p}<0,001)$ (Tabela 6). 
TABELA 6 - Teste de ANOVA a dois critérios para mensurações repetidas para a variável abertura bucal

\begin{tabular}{cccccc}
\hline Fonte de variação & $\boldsymbol{G L}$ & $\boldsymbol{S Q}$ & $\boldsymbol{Q M}$ & $\boldsymbol{F}$ & $\boldsymbol{p}$ \\
\hline Grupo & 2 & 98,302 & 49,151 & 0,217 & $0,806(\mathrm{~ns})$ \\
Tempo & 6 & 1787,343 & 297,891 & 30,836 & $<0,001^{*}$ \\
Grupo X Tempo & 12 & 83,714 & 6,976 & 0,722 & $0,730(\mathrm{~ns})$ \\
Residual & 294 & 153,740 & 0,523 & & \\
\hline
\end{tabular}

GL=graus de liberdade, $\mathrm{SQ}=$ soma dos quadrados, $\mathrm{QM}=$ quadrado médio

$*$ = estatisticamente significante

ns $=$ estatisticamente não significante

A representação desta variável esta representada na Figura 3.

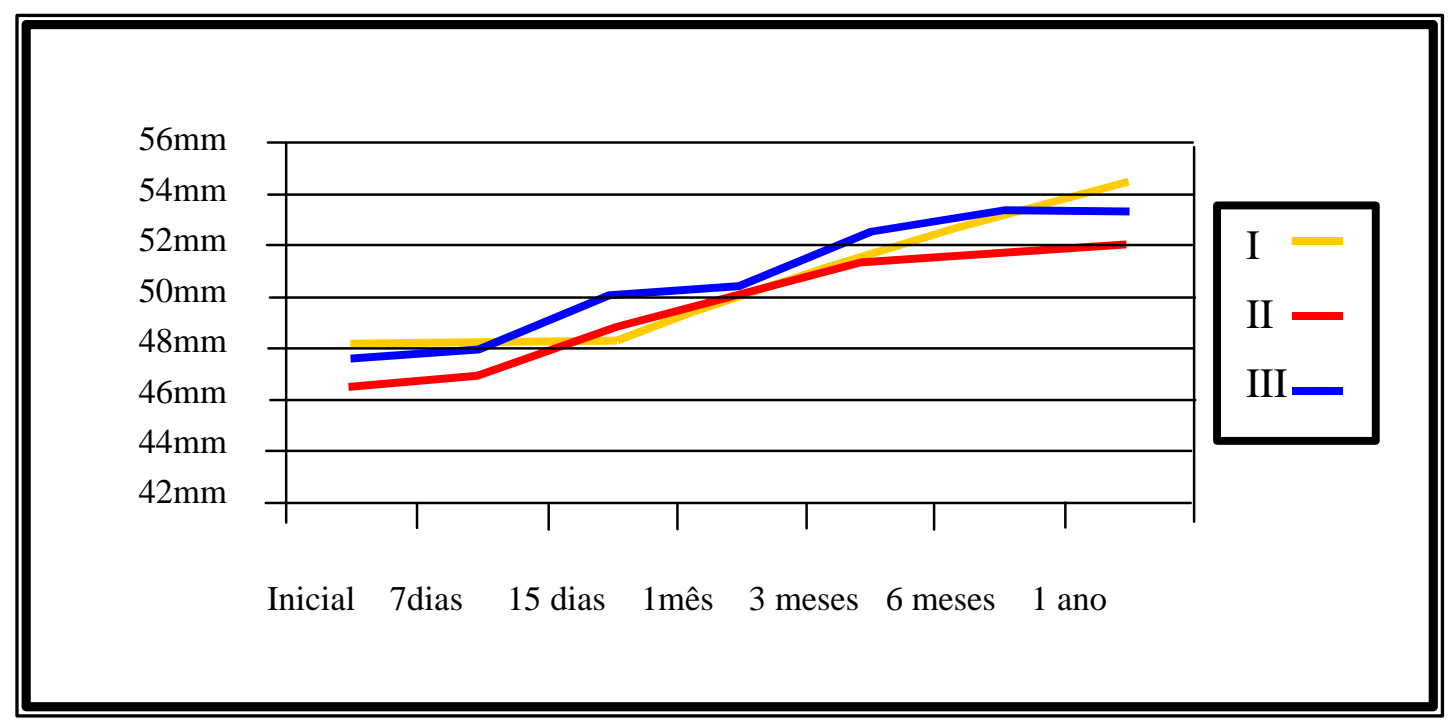

FIGURA 3 - Variação da abertura bucal nos diferentes grupos 


\section{3 - Movimentos excursivos da mandíbula}

A análise dos movimento excursivos da mandíbula (lateralidades esquerda e direita e protrusão) também foi realizada nos diferentes grupos e mensurações executadas.

A Tabela 7 representa a variação do movimento lateral esquerdo nos diferentes períodos de mensurações

TABELA 7 - Distribuição média dos valores de lateralidade esquerda (em milímetros) entre os grupos nos diferentes períodos de mensuração

\begin{tabular}{ccccccccc}
\hline GRUPO & Inicial & $\mathbf{7}$ dias & $\mathbf{1 5}$ dias & $\mathbf{1}$ mês & $\mathbf{3}$ meses & $\mathbf{6}$ meses & $\mathbf{1}$ ano & Média \\
\hline I & 7,00 & 7,00 & 7,05 & 7,20 & 7,40 & 8,10 & 8,45 & 7,45 \\
II & 7,78 & 8,16 & 8,33 & 8,66 & 8,66 & 8,66 & 8,72 & 8,42 \\
III & 7,92 & 7,92 & 8,07 & 8,07 & 8,07 & 8,21 & 8,21 & 8,071 \\
\hline Total & 7,56 & 7,69 & 7,81 & 7,97 & 8,04 & 8,32 & 8,46 & \\
\hline
\end{tabular}

Para análise entre os grupos dos valores obtidos para lateralidade esquerda foi aplicado o teste ANOVA a dois critérios (grupo e tempo) para mensurações repetidas. 
Os resultados demonstraram não haver diferença estatisticamente significantes $(p=0,562)$ entre os grupos, porém, toda a amostra apresentou melhora com o passar do tempo $(\mathrm{p}<0.001)($ Tabela 8$)$.

TABELA 8 - Teste de ANOVA a dois critérios para mensurações repetidas para a variável lateralidade esquerda

\begin{tabular}{cccccc}
\hline Fonte de variação & $\boldsymbol{G L}$ & $\boldsymbol{S Q}$ & $\boldsymbol{Q M}$ & $\boldsymbol{F}$ & $\boldsymbol{p}$ \\
\hline Grupo & 2 & 64,282 & 32,141 & 0,582 & $0,562(\mathrm{~ns})$ \\
Tempo & 6 & 32,117 & 5,353 & 9,569 & $<0,001^{*}$ \\
Grupo X Tempo & 12 & 17,650 & 1,471 & 2,629 & $0,002^{*}$ \\
Residual & 294 & 164,465 & 0,559 & & \\
\end{tabular}

GL= graus de liberdade, $\mathrm{SQ}=$ soma dos quadrados, $\mathrm{QM}=$ quadrado médio

$*$ = estatisticamente significante

ns = estatisticamente não significante

A evolução desta variável está expressa na Figura 4.

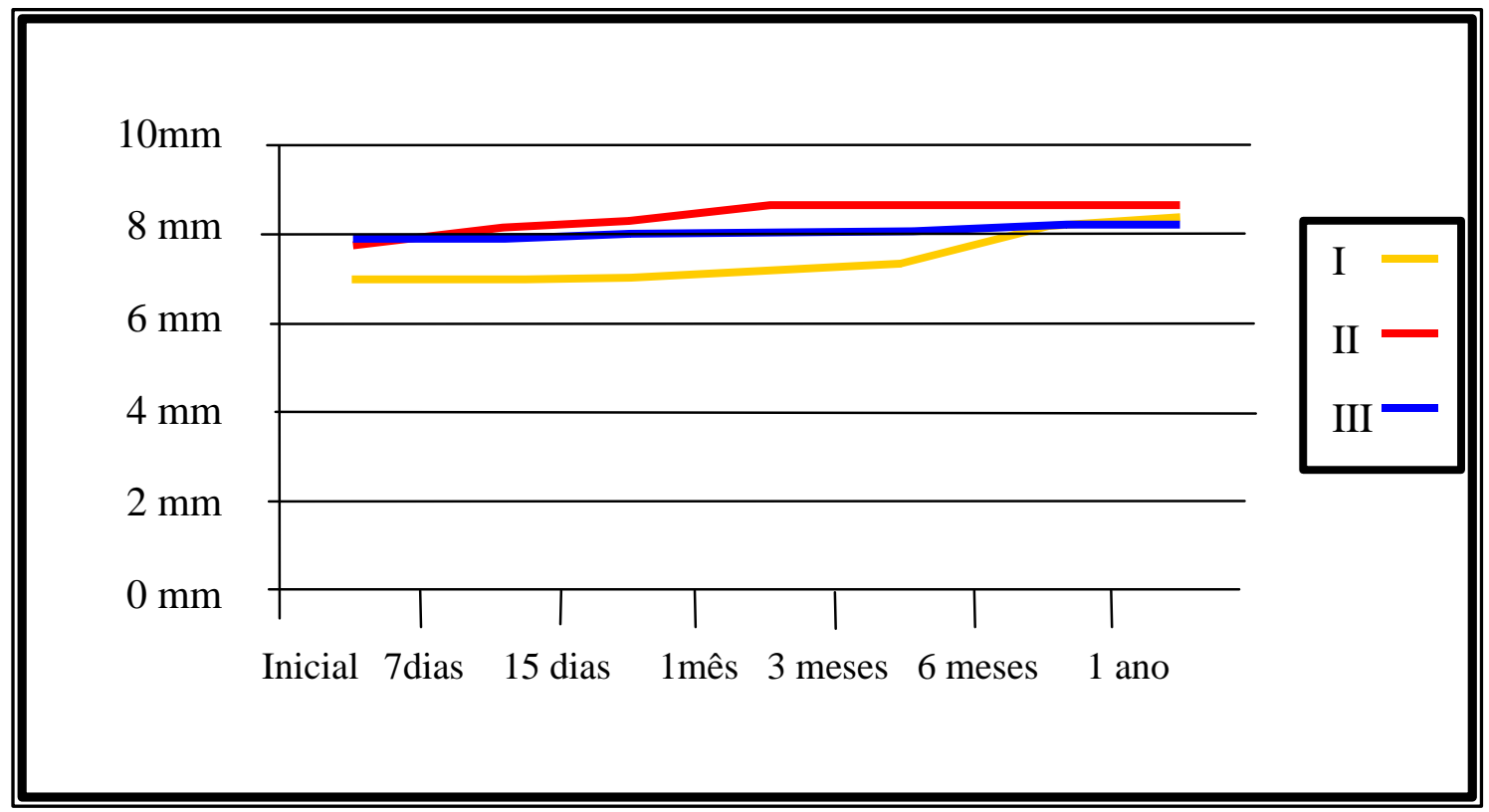

FIGURA 4 - Variação da lateralidade esquerda nos diferentes grupos 
A Tabela 9 ilustra a evolução dos valores de lateralidade direita nos diferentes grupos.

TABELA 9 - Distribuição média dos valores de lateralidade direita (em milímetros) entre os grupos nos diferentes períodos de mensuração

\begin{tabular}{ccccccccc}
\hline GRUPO & Inicial & $\mathbf{7}$ dias & $\mathbf{1 5}$ dias & $\mathbf{1}$ mês & 3 meses & $\mathbf{6}$ meses & $\mathbf{1}$ ano & Média \\
\hline I & 7,40 & 7,45 & 7,85 & 7,95 & 7,85 & 8,40 & 8,75 & 7,95 \\
II & 7,38 & 8,44 & 8,61 & 8,77 & 8,55 & 8,94 & 8,94 & 8,52 \\
III & 6,28 & 6,35 & 6,50 & 6,50 & 6,50 & 6,71 & 6,71 & 6,51 \\
\hline Total & 7,02 & 7,41 & 7,65 & 7,74 & 7,63 & 8,02 & 8,13 & \\
\hline
\end{tabular}

Os resultados da análise do teste ANOVA a dois critérios para mensurações repetidas não detectou diferenças estatisticamente significantes $(p=0,117)$ entre os grupos. Porém, todos os grupos apresentaram melhora com o tempo $(\mathrm{p}<0,001)$ (Tabela 10).

A interação entre o grupo e o tempo também não foi estatisticamente significante. $(p=0,355)$. 
TABELA 10 - Teste de ANOVA a dois critérios para mensurações repetidas para a variável lateralidade direita

\begin{tabular}{cccccc}
\hline Fonte de variação & $\boldsymbol{G L}$ & $\boldsymbol{S Q}$ & $\boldsymbol{Q M}$ & $\boldsymbol{F}$ & $\boldsymbol{p}$ \\
\hline Grupo & 2 & 231,638 & 115,819 & 2,239 & $0,117(\mathrm{~ns})$ \\
Tempo & 6 & 41,999 & 7,000 & 6,708 & $<0,001^{*}$ \\
Grupo X Tempo & 12 & 13,840 & 1,153 & 1,105 & $0,355(\mathrm{~ns})$ \\
Residual & 294 & 306,798 & 1,044 & & \\
\hline
\end{tabular}

GL=graus de liberdade, $\mathrm{SQ}=$ soma dos quadrados, $\mathrm{QM}=$ quadrado médio

$*$ = estatisticamente significante

ns= estatisticamente não significante

A Figura 5 representa a evolução dessa variável durante a execução desse trabalho.

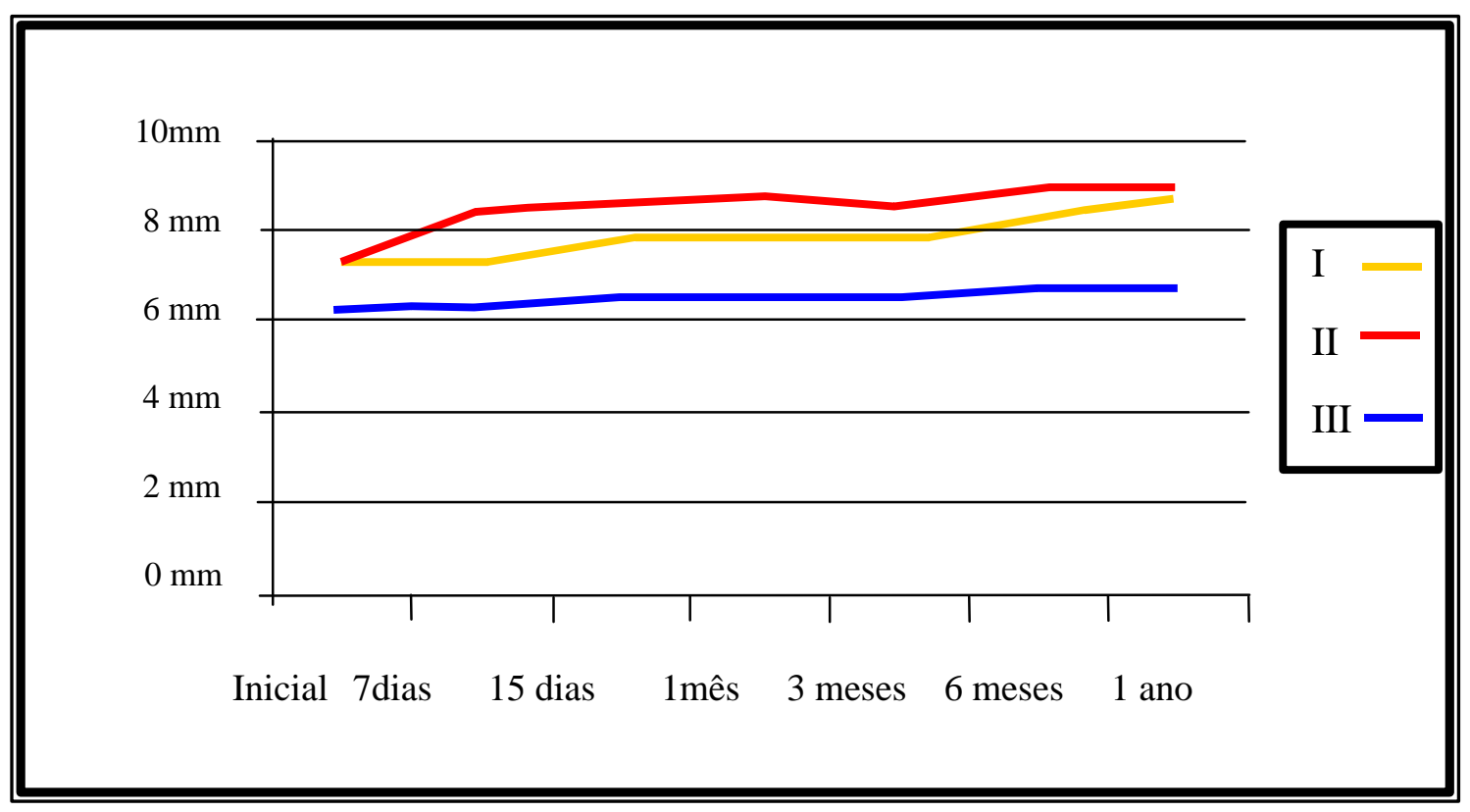

FIGURA 5 - Variação da lateralidade direita nos diferentes grupos 
Já os valores relativos ao movimento protrusivo nos diferentes grupos estão representados na Tabela 11 e Figura 6.

TABELA 11 - Distribuição média dos valores do movimento protrusivo (em milímetros) entre os grupos nos diferentes períodos de mensuração

\begin{tabular}{ccccccccc}
\hline GRUPO & Inicial & $\mathbf{7}$ dias & $\mathbf{1 5}$ dias & $\mathbf{1}$ mês & $\mathbf{3}$ meses & $\mathbf{6}$ meses & $\mathbf{1}$ ano & Média \\
\hline$I$ & 5,50 & 5,50 & 5,75 & 5,80 & 5,60 & 5,80 & 5,80 & 5,67 \\
$I I$ & 5,27 & 5,41 & 5,77 & 6,22 & 6,05 & 6,27 & 6,27 & 5,90 \\
$I I I$ & 6,28 & 6,21 & 6,21 & 6,21 & 6,21 & 6,21 & 6,21 & 6,22 \\
\hline Total & 5,68 & 5,71 & 5,91 & 6,07 & 5,95 & 6,09 & 6,09 & \\
\hline
\end{tabular}

Para análise dos valores obtidos para o movimento protrusivo também foi aplicado o teste ANOVA a dois critérios (grupo e tempo) para mensurações repetidas (Tabela 12).

TABELA 12 - Teste de ANOVA a dois critérios para mensurações repetidas para variável protrusão

\begin{tabular}{cccccc}
\hline Fonte de variação & $\boldsymbol{G L}$ & $\boldsymbol{S Q}$ & $\boldsymbol{Q M}$ & $\boldsymbol{F}$ & $\boldsymbol{p}$ \\
\hline Grupo & 2 & 17.181 & 8.590 & 0.224 & 0.800 (ns) \\
Tempo & 6 & 9,453 & 1,575 & 3,053 & $0,007^{*}$ \\
Grupo X Tempo & 12 & 10,174 & 0,848 & 1,621 & $0,085(\mathrm{~ns})$ \\
Residual & 294 & 153,740 & 0,523 & & \\
\hline
\end{tabular}

$\mathrm{GL}=$ graus de liberdade, $\mathrm{SQ}=$ soma dos quadrados, $\mathrm{QM}=$ quadrado médio

* = estatisticamente significante,

$\mathrm{ns}=$ estatisticamente não significante 
Assim como para os demais movimentos excêntricos, o grau de movimentação protrusiva demonstrou-se maior com o passar do tempo $(p=0,007)$, independente do grupo $(p=0,80)$

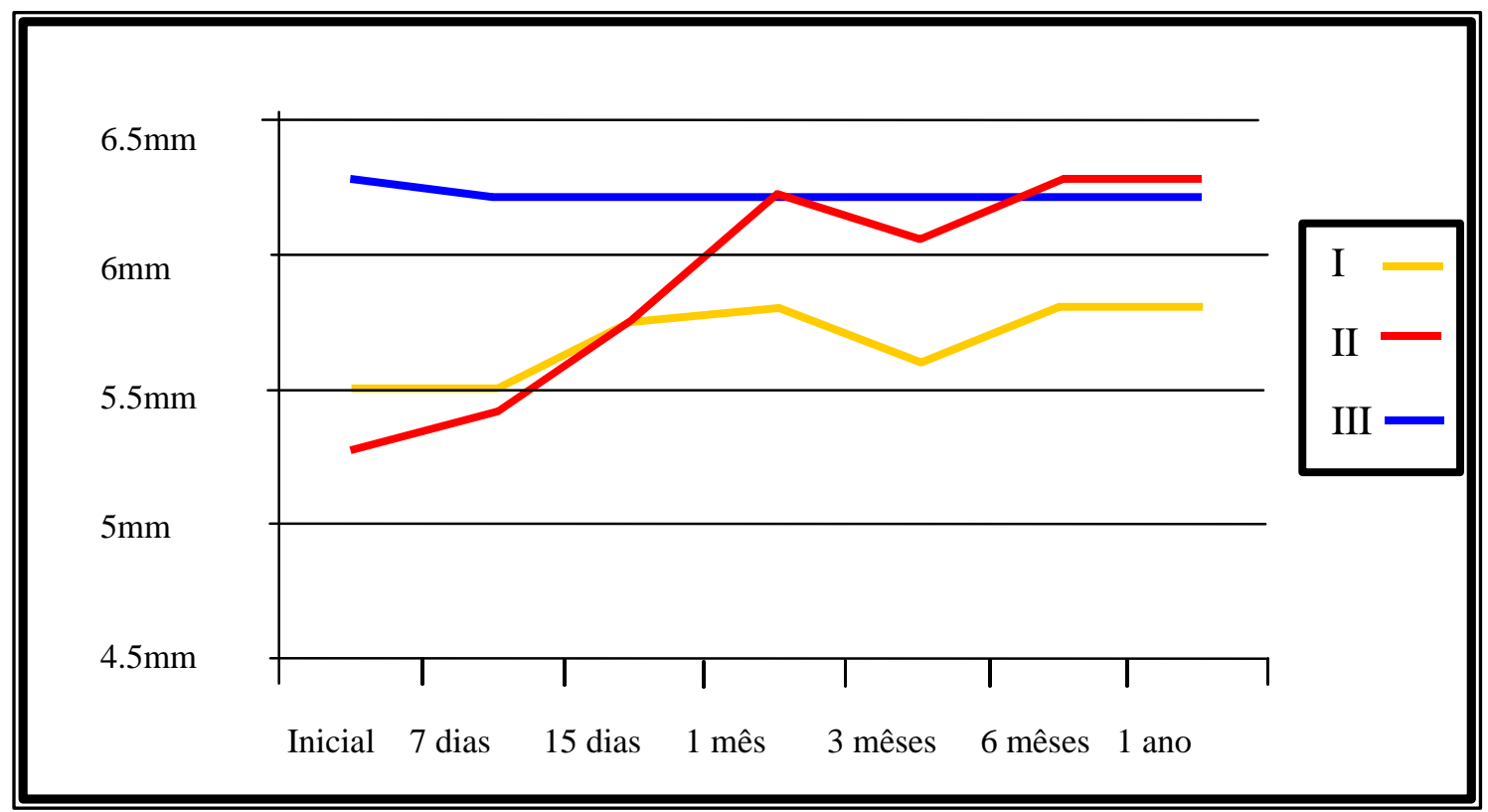

FIGURA 6 - Variação da protrusão nos diferentes grupos

\section{4 - Contatos}

\section{oclusais}

Ao analisar-se o número de contatos oclusais, encontrou-se, uma média de contatos inicial de 26,9 enquanto que, após o acompanhamento de um ano, esse número passou para 29,96, demonstrando, portanto, um ligeiro aumento. 
A Tabela 13 e a Figura 7 expressam as variações ocorridas para essa variável durante a execução dessa pesquisa.

TABELA 13 - Distribuição da média do número de contatos oclusais entre os grupos nos diferentes períodos de mensuração

\begin{tabular}{ccccccccc}
\hline GRUPO & Inicial & $\mathbf{7}$ dias & $\mathbf{1 5}$ dias & $\mathbf{1}$ mês & $\mathbf{3}$ meses & $\mathbf{6}$ meses & $\mathbf{1}$ ano & MÉDIA \\
\hline$I$ & 27,85 & 27,00 & 28,50 & 29,00 & 28,40 & 29,80 & 30,00 & 28,65 \\
$I I$ & 24,83 & 23,27 & 26,44 & 28,44 & 27,22 & 25,55 & 27,33 & 26,15 \\
$I I I$ & 28,21 & 30,57 & 31,14 & 32,64 & 32,28 & 32,57 & 32,57 & 31,42 \\
\hline MÉDIA & 26,96 & 26,94 & 28,69 & 30,29 & 29,30 & 29,30 & 29,96 & 28,97 \\
\hline
\end{tabular}

Quando analisado pelo teste ANOVA a dois critérios para mensurações repetidas, não se obteve variações entre os grupos $(\mathrm{p}=0,132)$. Mais uma vez, o fator tempo demonstrou alterar essa variável $(\mathrm{p}<0,001)$ (Tabela 14).

TABELA 14 - Teste de ANOVA a dois critérios para mensurações repetidas para a variável contatos oclusais

\begin{tabular}{cccccc}
\hline Fonte de variação & $\boldsymbol{G L}$ & $\boldsymbol{S Q}$ & $\boldsymbol{Q M}$ & $\boldsymbol{F}$ & $\boldsymbol{p}$ \\
\hline Grupo & 2 & 1533,860 & 766,930 & 2,112 & $0,132(\mathrm{~ns})$ \\
Tempo & 6 & 516,911 & 86,152 & 2,851 & $0,010^{*}$ \\
Grupo X Tempo & 12 & 178,086 & 14,841 & 0,491 & $0,919(\mathrm{~ns})$ \\
Residual & 294 & 8884,430 & 30,219 & & \\
\hline
\end{tabular}

GL=graus de liberdade, $\mathrm{SQ}=$ soma dos quadrados, $\mathrm{QM}=$ quadrado médio

$*$ = estatisticamente significante

ns = estatisticamente não significante 


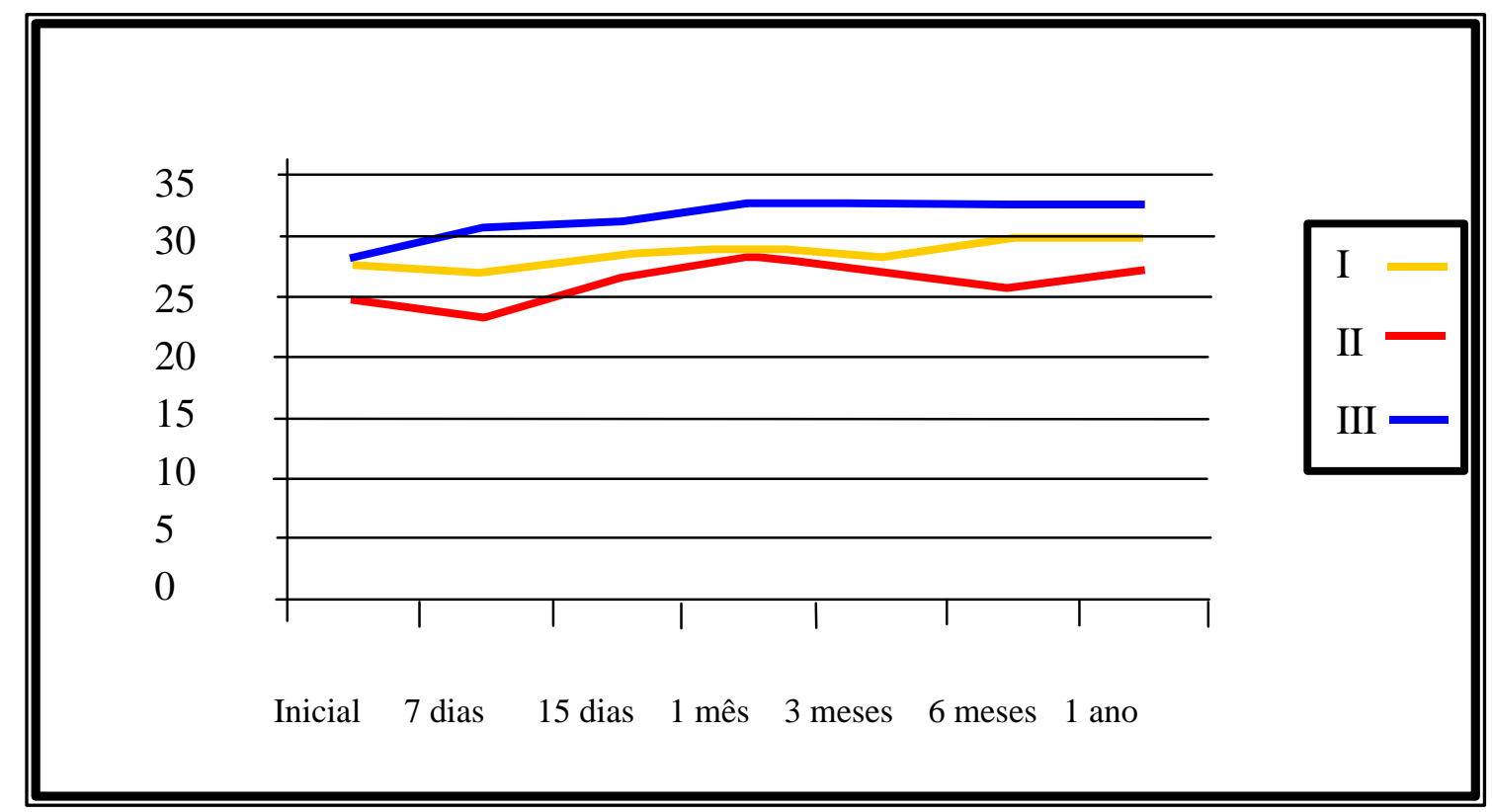

FIGURA 7 - Variação do número de contatos oclusais nos diferentes grupos

\section{5.- Escala de Análise Visual (EAV)}

A análise do relato de dor pela amostra foi realizada através das variações decorrentes do tempo (intra-grupo) e entre os grupos nos diversos períodos de mensuração (inter grupos).

Analisando os resultados obtidos para essa variável, mensurada através da Escala de Análise Visual (EAV), e considerando o total da amostra, obteve-se um valor inicial de $46.84 \mathrm{~mm}$ com desvio padrão de 
$28,77 \mathrm{~mm}$, enquanto que a EAV final foi de $3,38 \mathrm{~mm}$ com desvio padrão de $8,60 \mathrm{~mm}$.

Os resultados mostraram que, independente do grupo, os valores médios da EAV diminuíram. No grupo I, a EAV inicial era, em média, $52,75 \mathrm{~mm}$ e a final de $4,55 \mathrm{~mm}$. No grupo II a EAV inicial era 40,27mm e a final de $1,66 \mathrm{~mm}$ e no grupo III a EAV inicial foi de 47,50mm e a final foi de 3,92mm. A Tabela 15 e a Figura 8 , mostram os valores médios da EAV para os grupos nos diferentes períodos de mensuração.

TABELA 15 - Distribuição de média dos valores de EAV nos diferentes períodos de mensuração entre os grupos (em mm)

\begin{tabular}{cccccccc}
\hline Grupo & Inicial & $\mathbf{7}$ dias & $\mathbf{1 5}$ dias & $\mathbf{1}$ mês & $\mathbf{3}$ meses & $\mathbf{6}$ meses & 1 ano \\
\hline$I$ & 52,75 & 49,5 & 43,2 & 30,3 & 18,5 & 3,5 & 4,55 \\
$I I$ & 40,27 & 27,00 & 18,6 & 7,5 & 3,3 & 1,6 & 1,66 \\
$I I I$ & 47,50 & 39,2 & 30,3 & 25,4 & 15,0 & 2,8 & 3,92 \\
\hline
\end{tabular}

Ao aplicar-se o teste de Friedman para mensurações repetidas, observou-se melhora nos níveis de relato de dor para os três grupos analisados $(\mathrm{p}<0,001)$. Os testes de comparações individuais (Student - Newman, Keuls), entre os diferentes periodos de mensuração, para os grupos I, II e III estão representados na Tabela 16, 17 e 18 respectivamente e na figura 8. 
TABELA 16 - Comparações individuais (Student - Newman - Keuls) dos resultados obtidos para o grupo I em relação aos valores de EAV

\begin{tabular}{|c|c|c|}
\hline Comparação & Diferença & Significância \\
\hline Inicial x 6 meses & 80.0 & $*$ \\
\hline Inicial $\mathrm{x} 1$ ano & 79.0 & $*$ \\
\hline Inicial x 3 meses & 61.0 & $*$ \\
\hline Inicial x 1 mês & 44.0 & $*$ \\
\hline Inicial x 15 dias & 20.5 & $*$ \\
\hline Inicial x 7 dias & 6.0 & $\mathrm{~ns}$ \\
\hline 7 dias x 6 meses & 74.0 & $*$ \\
\hline 7 dias $x 1$ ano & 73.0 & $*$ \\
\hline 7 dias x 3 meses & 55.0 & $*$ \\
\hline 7 dias x 1 mês & 38.0 & $*$ \\
\hline 7 dias $x 15$ dias & 14.5 & $*$ \\
\hline 15 dias x 6 meses & 59.5 & $*$ \\
\hline 15 dias $x 1$ ano & 58.5 & $*$ \\
\hline 15 dias x 3 meses & 40.5 & $*$ \\
\hline 15 dias x 1 mês & 23.5 & $*$ \\
\hline 1 mês x 6 meses & 36.0 & $*$ \\
\hline 1 mês x 1 ano & 35.0 & $*$ \\
\hline 1 mês x 3 meses & 17.0 & $*$ \\
\hline 3 meses x 6 meses & 19.0 & $*$ \\
\hline 3 meses x 1 ano & 18.0 & $*$ \\
\hline 1 ano x 6 meses & 1.0 & ns \\
\hline
\end{tabular}

* = estatisticamente significante

ns = estatisticamente não significante 
TABELA 17 - Comparações individuais (Student - Newman - Keuls) dos resultados obtidos para o grupo II em relação aos valores de EAV

\begin{tabular}{|c|c|c|}
\hline Comparação & Diferença & Significância \\
\hline Inicial $x 6$ meses & 70.5 & $*$ \\
\hline Inicial $x 1$ ano & 70.5 & $*$ \\
\hline Inicial $x 3$ meses & 64.0 & $*$ \\
\hline Inicial x 1 mês & 58.5 & $*$ \\
\hline Inicial $x 15$ dias & 38.5 & $*$ \\
\hline Inicial $x 7$ dias & 19.5 & $*$ \\
\hline 7 dias $x 6$ meses & 51.0 & $*$ \\
\hline 7 dias $x 1$ ano & 51.0 & $*$ \\
\hline 7 dias $x 3$ meses & 45.0 & $*$ \\
\hline 7 dias $x 1$ mês & 39.0 & $*$ \\
\hline 7 dias $x 15$ dias & 19.0 & $*$ \\
\hline 15 dias $x 6$ meses & 32.0 & $*$ \\
\hline 15 dias $\times 1$ ano & 32.0 & $*$ \\
\hline 15 dias $x 3$ meses & 26.0 & $*$ \\
\hline 15 dias $x 1$ mês & 20.0 & $*$ \\
\hline 1 mês $x 6$ meses & 12.0 & $*$ \\
\hline 1 mês $x 1$ ano & 12.0 & $n s$ \\
\hline 1 mês $x 3$ meses & 6.0 & $n s$ \\
\hline 3 meses $x 6$ meses & 6.0 & $n s$ \\
\hline 3 meses $x 1$ ano & 6.0 & $n s$ \\
\hline 1 ano $x 6$ meses & 0.0 & $n s$ \\
\hline
\end{tabular}

* = estatisticamente significante

$\mathrm{ns}=$ estatisticamente não significante 
TABELA 18 - Comparações individuais (Student - Newman - Keuls) dos resultados obtidos para o grupo III em relação aos valores de EAV

\begin{tabular}{|c|c|c|}
\hline Comparação & Diferença & Significância \\
\hline Inicial x 6 meses & 60.0 & $*$ \\
\hline Inicial x 1 ano & 58.5 & $*$ \\
\hline Inicial x 3 meses & 44.0 & $*$ \\
\hline Inicial x 1 mês & 34.0 & $*$ \\
\hline Inicial x 15 dias & 20.5 & $*$ \\
\hline Inicial x 7 dias & 7.0 & ns \\
\hline 7 dias x 6 meses & 53.0 & $*$ \\
\hline 7 dias $x 1$ ano & 51.5 & $*$ \\
\hline 7 dias x 3 meses & 37.5 & $*$ \\
\hline 7 dias x 1 mês & 27.0 & $*$ \\
\hline 7 dias $x 15$ dias & 13.5 & $*$ \\
\hline 15 dias x 6 meses & 39.5 & $*$ \\
\hline 15 dias $x 1$ ano & 38.0 & $*$ \\
\hline 15 dias x 3 meses & 23.5 & $*$ \\
\hline 15 dias x 1 mês & 13.5 & $*$ \\
\hline 1 mês x 6 meses & 26.0 & $*$ \\
\hline 1 mês x 1 ano & 24.5 & $*$ \\
\hline 1 mês x 3 meses & 10.0 & $*$ \\
\hline 3 meses x 6 meses & 16.0 & $*$ \\
\hline 3 meses $x 1$ ano & 14.5 & $*$ \\
\hline 1 ano $\times 6$ meses & 1.5 & $\mathrm{~ns}$ \\
\hline
\end{tabular}

* = estatisticamente significante

ns = estatisticamente não significante 


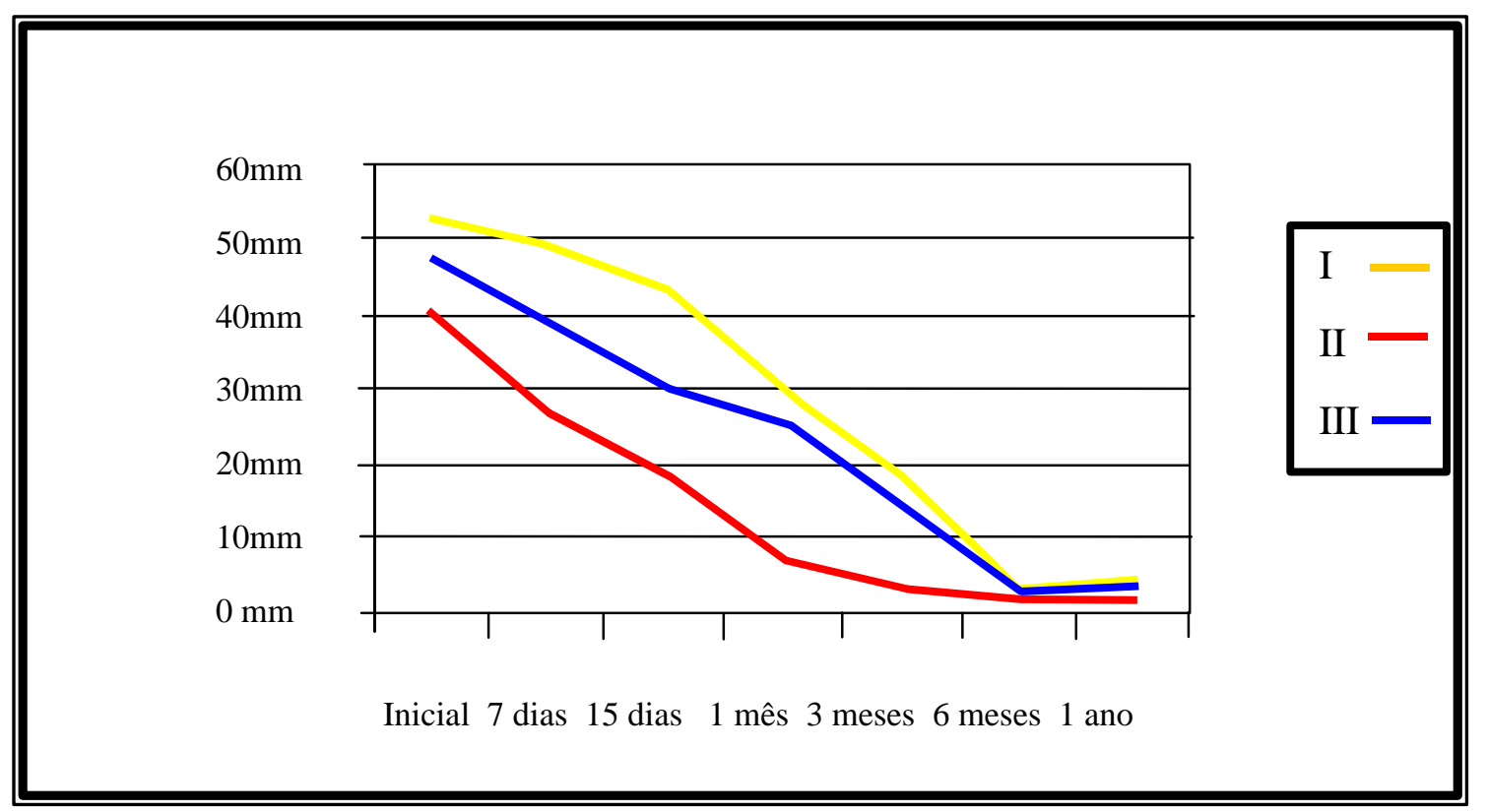

FIGURA 8 - Variação dos valores da Escala de Análise Visual de dor (EAV) nos diferentes grupos

Já para a análise inter-grupos nos diferentes períodos de mensuração, utilizou-se o teste de Kruskal-Wallis, cujos resultados estão expressos na Tabela 19.

TABELA 19 - Avaliação inter grupos da EAV nos diferentes períodos de mensuração (teste de Kruskal-Wallis)

\begin{tabular}{|c|c|c|c|c|c|c|c|}
\hline Período & Inicial & 7 dias & 15 dias & 1 mês & 3 meses & 6 meses & 1 ano \\
\hline "p" & 0,385 & 0,052 & $0,002 *$ & $0,003^{*}$ & $0,005^{*}$ & 0,531 & 0,311 \\
\hline $\mathrm{H}$ & 1,910 & 5,929 & 7,226 & 11,653 & 10,604 & 1,267 & 2,333 \\
\hline g. $1 \times$ g. 2 & $\mathrm{~ns}$ & ns & $*$ & $*$ & $*$ & $\mathrm{~ns}$ & $\mathrm{~ns}$ \\
\hline g. $1 \times$ g. 3 & ns & $\mathrm{ns}$ & $\mathrm{ns}$ & ns & Ns & $\mathrm{ns}$ & $\mathrm{ns}$ \\
\hline g. $2 \times$ g. 3 & $\mathrm{~ns}$ & $\mathrm{~ns}$ & $*$ & $*$ & * & $\mathrm{ns}$ & $\mathrm{ns}$ \\
\hline $\begin{array}{l}\text { g. } 1 \text { - grupo } 1 \\
\text { g. } 2 \text { - grupo I } \\
\text { g. } 3 \text { - grupo I } \\
* \text { - estatistica } \\
\text { ns - estatisti }\end{array}$ & $\begin{array}{l}\text { nte sign } \\
\text { ente não }\end{array}$ & $\begin{array}{l}\text { te } \\
\text { ificant }\end{array}$ & & & & & \\
\hline
\end{tabular}




\section{6 - Ruidos articulares}

Quando analisada a presença de ruídos articulares, nota-se que no início do presente estudo, 40 pacientes $(76,9 \%)$ apresentavam esse sinal em pelo menos um dos lados, estando os restantes 23,1\% livres de estalidos. Já, após o acompanhamento de um ano, aqueles com ausência de ruídos representaram 51,9\%, considerando-se toda a amostra. O teste de Mc Nemar foi utilizado para avaliar o comportamento dessa variável nos diferentes períodos de mensuração. As Tabelas 20, 21, 22 e 23 representam as comparações iniciais e finais de toda a amostra, e para os grupos I, II e III, respectivamente.

TABELA 20 - Avaliação da presença de ruído articular (inicial e final) em toda a amostra $(\mathbf{p}<0,001)$

\begin{tabular}{ccccc}
\hline inicial & final & Sim & Não & Total \\
\hline & Sim & $24(60,00 \%)$ & $16(40,00 \%)$ & $40(100 \%)$ \\
& Não & $1(8,40 \%)$ & $11(91,60 \%)$ & $12(100 \%)$ \\
\hline
\end{tabular}

TABELA 21 - Avaliação da presença de rú́do articular (inicial e final) no grupo I $(p=0,04)$

\begin{tabular}{ccccc}
\hline inicial & final & Sim & Não & Total \\
\hline & Sim & $10(62,50 \%)$ & $6(35,50 \%)$ & $16(100 \%)$ \\
& Não & $1(25,00 \%)$ & $3(75,00 \%)$ & $4(100 \%)$ \\
\hline
\end{tabular}


TABELA 22 - Avaliação da presença de ruído articular (inicial e final) no grupo II $(p=0,02)$

\begin{tabular}{ccccc}
\hline inicial & final & Sim & Não & Total \\
\hline & & $8(53,30 \%)$ & $7(46,70 \%)$ & $15(100 \%)$ \\
& Sim & $0(0 \%)$ & $3(100 \%)$ & $3(100 \%)$ \\
\hline
\end{tabular}

TABELA 23 - Avaliação da presença de ruído articular (inicial e final) no grupo III $(p=0,13)$

\begin{tabular}{ccccc}
\hline inicial & final & Sim & Não & Total \\
\hline \multirow{2}{*}{ Sim } & $5(45,60 \%)$ & $4(44,40 \%)$ & $9(100 \%)$ \\
Não & $0(0 \%)$ & $5(100 \%)$ & $5(100 \%)$ \\
\hline
\end{tabular}

As Tabelas acima demonstram que, quando comparada a amostra como um todo, houve uma diminuição na presença de ruídos. Porém, para o grupo III (controle), essa diminuição não foi estatisticamente significante $(p=0,130)$.

\section{7 - Palpação da ATM}

A presença de pelo menos um ponto sensivel à palpação da ATM também foi avaliada pelo teste Mc Nemar. A Tabela 24 
mostra os valores de "p" nos diferentes períodos, quando comparados com os valores iniciais.

TABELA 24 - Valores de "p" ( teste de Mc Nemar ) na comparação da sensibilidade da ATM à palpação nos diferentes períodos

\begin{tabular}{cccc}
\hline & Grupo1 & Grupo II & Grupo III \\
\hline 1 mês & 0,130 & $0,010^{*}$ & 0,074 \\
3 meses & $0,040^{*}$ & $0,004^{*}$ & 0,100 \\
6 meses & $0,020^{*}$ & $0,003^{*}$ & $0,020^{*}$ \\
1 ano & $0,040^{*}$ & $0,009^{*}$ & $0,020^{*}$ \\
\hline
\end{tabular}

* = estatisticamente significante

$\mathrm{ns}=$ estatisticamente não significante

Note-se que o grupo II já apresentou melhora estatisticamente significante no primeiro mês, enquanto o grupo I somente a partir do 3o mês, enquanto o grupo controle (grupo III) somente a partir do sexto mês.

\section{8 - Palpação muscular}

Para análise entre os grupos da sensibilidade à palpação muscular, foi aplicado o teste de Mc Nemar, que permitiu a verificação da evolução da presença de sensibilidade muscular em cada grupo. 
Em relação à presença de pelo menos um ponto de palpação muscular positiva, $34,62 \%$ de toda a amostra apresentavam essa condição no início.

Em comparação com achados após um ano de acompanhamento, houve uma melhora geral na presença de sensibilidade muscular, independente do grupo $(\mathrm{p}=0,02)$, sendo que entre aqueles que inicialmente sentiam dores musculares à palpação, $61,1 \%$ não mais apresentavam esta condição após um ano.

\section{9 - Relato dos pacientes}

A Tabela 25 mostra os resultados obtidos quando analisada a resposta do paciente quanto à alteração oclusal. Observe que em 15 pacientes $(75,00 \%)$ pertencentes ao grupo I, a oclusão no final de um mês manteve-se inalterada. No grupo II, dez pacientes $(55,55 \%)$ apresentaram esta condição e no grupo III, sete pacientes $(50,00 \%)$ fizeram relato semelhante.

Após seis meses, considerando toda amostra, observase que 41 pacientes $(78,57 \%)$ descreveram que a oclusão manteve-se inalterada.

Ao avaliar os resultados obtidos após um ano, considerando o total da amostra, 43 pacientes $(82,69 \%)$ relataram que a 
oclusão manteve-se inalterada. Observe que não houve qualquer descrição de piora.

TABELA 25 - Relato dos indivíduos amostra em relação a alteração na oclusão nos diferentes períodos de mensuração

\begin{tabular}{|c|c|c|c|c|c|c|c|c|c|c|}
\hline \multirow[b]{2}{*}{ GRUPO } & \multicolumn{3}{|c|}{ Manteve-se } & \multicolumn{3}{|c|}{ Alterou para melhor } & \multicolumn{3}{|c|}{ Alterou para pior } & \multirow{2}{*}{\begin{tabular}{|l} 
\\
$N$
\end{tabular}} \\
\hline & 1 mês & 6 meses & 1 ano & 1 mês & 6 meses & 1 ano & 1 mês & 6 meses & 1 ano & \\
\hline$I$ & $\begin{array}{c}15 \\
(75,00 \%)\end{array}$ & $\begin{array}{c}16 \\
(80,00 \%)\end{array}$ & $\begin{array}{c}17 \\
(85,00 \%)\end{array}$ & $\begin{array}{c}5 \\
(25,00 \%)\end{array}$ & $\begin{array}{c}4 \\
(20,00 \%)\end{array}$ & $\begin{array}{c}3 \\
(15,00 \%)\end{array}$ & 0 & 0 & 0 & $\begin{array}{c}20 \\
(100 \%)\end{array}$ \\
\hline$I I$ & $\begin{array}{c}10 \\
(55,55 \%)\end{array}$ & $\begin{array}{c}14 \\
(77,77 \%)\end{array}$ & $\begin{array}{c}14 \\
(77,77 \%)\end{array}$ & $\begin{array}{c}8 \\
(45,45 \%)\end{array}$ & $\begin{array}{c}4 \\
(22,23 \%)\end{array}$ & $\begin{array}{c}4 \\
(22,23 \%)\end{array}$ & 0 & 0 & 0 & $18(100 \%)$ \\
\hline$I I I$ & $\begin{array}{c}7 \\
(50,00 \%)\end{array}$ & $\begin{array}{c}11 \\
(78,57 \%)\end{array}$ & $\begin{array}{c}12 \\
(85,71 \%)\end{array}$ & $\begin{array}{c}7 \\
(50,00 \%)\end{array}$ & $\begin{array}{c}3 \\
(21,43 \%)\end{array}$ & $\begin{array}{c}2 \\
(14,29 \%)\end{array}$ & 0 & 0 & 0 & $14(100 \%)$ \\
\hline Total & $\begin{array}{c}32 \\
(61,53 \%)\end{array}$ & $\begin{array}{l}41 \\
(78,87 \%)\end{array}$ & $\begin{array}{c}43 \\
(82,70 \%)\end{array}$ & $\begin{array}{c}20 \\
(38,47 \%)\end{array}$ & $\begin{array}{c}11 \\
(21,13 \%)\end{array}$ & $\begin{array}{c}9 \\
(17,30 \%)\end{array}$ & 0 & 0 & 0 & $52(100 \%)$ \\
\hline
\end{tabular}

Com relação ao ruído, analisando a Tabela 26, podemos observar que no final de um mês, considerando o total da amostra, 28 pacientes $(53,84 \%)$ descreveram que o ruído manteve-se, enquanto que $20(38,46 \%)$ descreveram que o ruído alterou-se para melhor. Quatro pacientes $(7,69 \%)$ de toda a amostra descreveram que o ruído alterou-se para pior. No grupo I, 13 pacientes (65,00\%) descreveram que o ruído manteve-se. No grupo II, oito pacientes $(44,44 \%)$ descreveram esta condição e no grupo III, sete $(50,00 \%)$. 
Com seis meses, considerando o total da amostra, 43 pacientes, $(78,57 \%)$, relataram que o ruído manteve-se. Dezessete $(85,00 \%)$ pertencentes ao grupo I, 15 (83,33\%) entre o grupo II e 11 (78,57\%) no grupo III.

Já com um ano, considerando o total da amostra, 45 pacientes $(86,53 \%)$, relataram que o ruindo manteve-se. Dezoito $(90,00 \%)$ pertencentes ao grupo I, 15 (83,33\%) entre o grupo II e $12(85,71 \%)$ entre o grupo II.

Observe que não houve relato de piora quanto a este critério tanto aos seis meses como no final da pesquisa

TABELA 26 - Relato dos indivíduos amostra em relação ao ruído nos diferentes períodos de mensuração

\begin{tabular}{|c|c|c|c|c|c|c|c|c|c|c|}
\hline & \multicolumn{3}{|c|}{ Manteve-se } & \multicolumn{3}{|c|}{ Alterou para melhor } & \multicolumn{3}{|c|}{ Alterou para pior } & \\
\hline GRUPO & 1 mês & 6 meses & 1 ano & 1 mês & 6 meses & 1 ano & 1 mês & 6 meses & 1 ano & $N$ \\
\hline$I$ & $13(65 \%)$ & $\begin{array}{c}17 \\
(85,00 \%)\end{array}$ & $\begin{array}{c}18 \\
(90,00 \%)\end{array}$ & $\begin{array}{c}6 \\
(30,00 \%)\end{array}$ & $\begin{array}{c}3 \\
(15,00 \%)\end{array}$ & $\begin{array}{c}2 \\
(10,00 \%)\end{array}$ & $1(5,00 \%)$ & 0 & 0 & $\begin{array}{c}20 \\
(100 \%)\end{array}$ \\
\hline$I I$ & $\begin{array}{c}8 \\
(44,44 \%)\end{array}$ & $\begin{array}{c}15 \\
(83,33 \%)\end{array}$ & $\begin{array}{c}15 \\
(83,33 \%)\end{array}$ & $\begin{array}{c}8 \\
(44,44 \%)\end{array}$ & $\begin{array}{c}3 \\
(16,66 \%)\end{array}$ & $\begin{array}{c}3 \\
(16,66 \%)\end{array}$ & $2(11,1 \%)$ & 0 & 0 & $18(100 \%)$ \\
\hline$I I I$ & $\begin{array}{c}7 \\
(50,00 \%)\end{array}$ & $\begin{array}{c}11 \\
(78,57 \%)\end{array}$ & $\begin{array}{c}12 \\
(85,71 \%)\end{array}$ & $\begin{array}{c}6 \\
(42,85 \%)\end{array}$ & $\begin{array}{c}3 \\
(21,42 \%)\end{array}$ & $\begin{array}{c}2 \\
(14,28 \%)\end{array}$ & $1(7,15 \%)$ & 0 & 0 & $14(100 \%)$ \\
\hline Total & $\begin{array}{c}28 \\
(53,84 \%)\end{array}$ & $\begin{array}{c}43 \\
(78,57 \%)\end{array}$ & $\begin{array}{c}45 \\
(86,53 \%)\end{array}$ & $\begin{array}{c}20 \\
(38,46 \%)\end{array}$ & $\begin{array}{c}9 \\
(17,30 \%)\end{array}$ & $\begin{array}{c}7 \\
(13,46 \%)\end{array}$ & $4(7,69 \%)$ & 0 & 0 & $52(100 \%)$ \\
\hline
\end{tabular}


A Tabela 27 mostra os resultados obtidos em relação ao conforto relatado pelo paciente nos diferentes períodos de mensuração.

Podemos observar que, ao considerar o total da amostra, no primeiro mês 18 pacientes $(34,61 \%)$ relataram que a sensação de conforto manteve-se em relação a última visita. Dez pacientes (50,00\%) pertenciam ao grupo I, seis $(33,33 \%)$ estavam entre os pacientes do grupo II e dois, pertenciam ao grupo III o que representou $14,28 \%$ dentro deste grupo.

A avaliação após seis meses mostrou, ao considerar o total da amostra, que 18 pacientes $(34,61 \%)$ descreveram que a sensação de conforto manteve-se. Dez pacientes pertencentes ao grupo I, o que representou $50,00 \%$, seis pacientes $(33,33 \%)$ pertencentes ao grupo II e dois pacientes pertencentes ao grupo III o que representou, entre este grupo, $14,28 \%$.

A avaliação de um ano mostrou para o total da amostra, que o conforto manteve-se em 16 pacientes (30,76\%). Oito pacientes $(15,38 \%)$ relataram uma alteração para melhor e $28(53,84 \%)$ não descreveram. No grupo I, nove pacientes o que representou $45 \%$ entre este grupo. No grupo II, seis pacientes o que representou 33,33\% entre este grupo e no grupo III, 1 paciente o que representou 7,14 entre este grupo. Observe que não houve, a partir dos seis meses, qualquer relato de alteração para pior, independente do grupo observado. 
TABELA 27 - Relato dos indivíduos em relação ao conforto nos diferentes períodos de mensuração

\begin{tabular}{|c|c|c|c|c|c|c|c|c|c|c|c|c|c|}
\hline \multirow[b]{2}{*}{ GRUPO } & \multicolumn{3}{|c|}{ Manteve-se } & \multicolumn{3}{|c|}{$\begin{array}{c}\text { Alterou para } \\
\text { melhor }\end{array}$} & \multicolumn{3}{|c|}{$\begin{array}{c}\text { Alterou para } \\
\text { pior }\end{array}$} & \multicolumn{3}{|c|}{ Não sabe } & \multirow{2}{*}{$N$} \\
\hline & $\begin{array}{c}1 \\
m e \hat{e} s\end{array}$ & $\begin{array}{c}6 \\
\text { meses }\end{array}$ & 1 ano & 1 mês & $\begin{array}{c}6 \\
\text { meses }\end{array}$ & 1 ano & $\begin{array}{c}1 \\
m e \hat{s}\end{array}$ & $\begin{array}{c}6 \\
\text { meses }\end{array}$ & 1 ano & $\begin{array}{c}1 \\
m e \hat{e} s\end{array}$ & $\begin{array}{c}6 \\
\text { meses }\end{array}$ & 1 ano & \\
\hline$I$ & $\begin{array}{c}10 \\
(50,00 \\
\%)\end{array}$ & $\begin{array}{c}10 \\
(50,00 \\
\%)\end{array}$ & $\begin{array}{c}9 \\
(45,00 \% \\
)\end{array}$ & $\begin{array}{c}4 \\
(20,00 \\
\%)\end{array}$ & $\begin{array}{c}4 \\
(20,00 \\
\%)\end{array}$ & $\begin{array}{c}4 \\
(20,00 \% \\
)\end{array}$ & $\begin{array}{c}1 \\
(5,00 \% \\
)\end{array}$ & 0 & 0 & $\begin{array}{c}5 \\
(25,00 \\
\%)\end{array}$ & $\begin{array}{c}6 \\
(30,00 \\
\%)\end{array}$ & $\begin{array}{c}7 \\
(35 \%)\end{array}$ & $\begin{array}{c}20 \\
(100 \% \\
)\end{array}$ \\
\hline$I I$ & $\begin{array}{c}6 \\
(33,33 \\
\%)\end{array}$ & $\begin{array}{c}6 \\
(33,33 \\
\%)\end{array}$ & $\begin{array}{c}6 \\
(33,33 \% \\
)\end{array}$ & $\begin{array}{c}4 \\
(22,22 \\
\%)\end{array}$ & $\begin{array}{c}4 \\
(22,22 \\
\%)\end{array}$ & $\begin{array}{c}4 \\
(22,22 \%\end{array}$ & 0 & 0 & 0 & $\begin{array}{c}8 \\
(44,44 \\
\%)\end{array}$ & $\begin{array}{c}8 \\
(44,44 \\
\%)\end{array}$ & $\begin{array}{c}8 \\
(44,44 \\
\%)\end{array}$ & $\begin{array}{c}18(100 \\
\%)\end{array}$ \\
\hline$I I I$ & $\begin{array}{c}2 \\
(14,28 \\
\%) \\
\end{array}$ & $\begin{array}{c}2 \\
(14,28 \\
\%) \\
\end{array}$ & $\begin{array}{c}1 \\
(7,14 \%)\end{array}$ & 0 & 0 & 0 & $\begin{array}{c}1 \\
(7,14 \% \\
1\end{array}$ & 0 & 0 & $\begin{array}{c}12 \\
(85,71 \\
\%) \\
\end{array}$ & $\begin{array}{c}12 \\
(85,71 \\
\%) \\
\end{array}$ & $\begin{array}{c}13 \\
(98,85 \\
\%) \\
\end{array}$ & $\begin{array}{c}14(100 \\
\%)\end{array}$ \\
\hline Total & $\begin{array}{c}28 \\
(34,61 \\
\%) \\
\end{array}$ & $\begin{array}{c}18 \\
(34,61 \\
\%)\end{array}$ & $\begin{array}{c}16 \\
(30,76 \% \\
)\end{array}$ & $\begin{array}{c}8 \\
(15,38 \\
\%) \\
\end{array}$ & $\begin{array}{c}8 \\
(13,38 \\
\%) \\
\end{array}$ & $\begin{array}{c}8 \\
(15,38 \% \\
)\end{array}$ & $\begin{array}{c}4 \\
(7,69 \% \\
0 \\
\end{array}$ & 0 & 0 & $\begin{array}{c}26 \\
(50,00 \\
\%)\end{array}$ & $\begin{array}{c}36 \\
(69,23 \\
\%) \\
\end{array}$ & $\begin{array}{c}28 \\
(53,84 \\
\%) \\
\end{array}$ & $\begin{array}{c}52(100 \\
\%)\end{array}$ \\
\hline
\end{tabular}


6 - DISCUSSÃO 


\section{6 - Discussão}

\subsection{Introdução}

As DTM compreendem uma vasta gama de condições clínicas, freqüentemente justapostas, que podem envolver a ATM, ou o sistema neuromuscular associado às funções mandibulares. A variabilidade de denominações recebidas ao longo do tempo sugere que a etiologia e os mecanismos destas disfunções têm sido pouco compreendidos. Paralelamente, existe uma considerável confusão em relação à etiologia e tratamento. Isto se traduz por opiniões conflitantes entre os profissionais, clinicos gerais e especialistas, pertencentes a diferentes correntes de opiniões e, obviamente, entre os vários países. Uma das explicações para estas diferenças é de que o ensino e o treinamento na compreensão e realização de condutas quanto às DTM têm variado enormemente no currículo das escolas de todo o mundo. Isto também gerou diferentes denominações para um mesmo problema: DCM, DTM, Síndrome-dordisfunção-miofascial (SDDMF), Sindrome de Costen, Sindrome otomandibular, assim como diferentes procedimentos de diagnóstico e controle.

Paralelamente muita confusão a respeito das DTM provavelmente, tem sido devido à falta de definições explícitas e de estudos sistemáticos e controlados. 
O método terapêutico reversivel, é uma possibilidade rara em medicina e os aparelhos oclusais representam esta possibilidade. Este fato tem estimulado várias análises sobre sua efetividade no controle de determinadas patologias. No entanto é preciso cuidado ao se avaliar os resultados de pesquisas realizadas com as placas oclusais.

Devido à grande variabilidade da expressão dos sintomas de DTM, relatos imediatos de efetividade desses aparelhos podem não representar seu real efeito. Ou seja, o caráter cíclico e auto limitante desses processos devem sempre fazer parte da análise desse cenário.

Da mesma forma, sucessos com placas oclusais não devem ser creditados tão somente ao restabelecimento de uma "oclusão normal", pois tal fato pode levar a procedimentos oclusais subsequentes irreversiveis, sem garantias de sucesso a longo prazo.

Atualmente divulga-se internacionalmente o conceito de "evidence based dentistry", ou seja, a realização de procedimentos clínicos baseados em estudos controlados e bem executados. Esse parece ser o futuro no tratamento das DTM, uma vez que relatos isolados de casos clínicos levam a execução de procedimento muitas vezes onerosos e desnecessários. 


\subsection{1-Etiologia}

Diferentes fatores etiológicos têm sido descritos como causadores destes problemas. Inicialmente na década de 20, acreditava-se no relacionamento entre o deslocamento mecânico da mandíbula e a presença de determinados sinais e sintomas ${ }^{113,154}$. Na década de 50, atribuiu-se um papel primário a fatores psicogênicos e às alterações oclusais um papel secundário70,121. Na década seguinte, a má-oclusão crônica foi considerada o principal fator etiológico das desordens mastigatórias ${ }^{8}$. Mais recentemente, considera-se que a oclusão não é o único ou principal fator em todos os pacientes.

No início da década de 70 estudos epidemiológicos sistemáticos começaram a focalizar-se mais nos sinais e sintomas de DTM. Os resultados demonstraram que estes sintomas eram mais freqüentes na população do que se pressupunha. Como resultado disto, os epidemiologistas concluíram que os dentistas do futuro, deveriam se interessar mais no diagnóstico e tratamento das DTM. Da ênfase inicial nos aspectos oclusais, depois na hiperatividade muscular, surgiu nos anos 80 um enorme interesse nos desarranjos internos da ATM. Ao mesmo tempo, a natureza heterogênea das DTM e dores orofaciais começou a ser mais bem compreendida.

Muita confusão a respeito de DTM tem sido devido a falta de definições explicitas e de estudos sistemáticos e controlados. Nos 
anos 90, e ainda hoje, um intenso trabalho vem sendo desenvolvido para melhorar o critério para exame e diagnóstico, o qual auxiliará na subclassificação de várias condições. Isto irá facilitar investigações clínicas comparativas e esperamos que melhore a eficácia dos tratamentos. O futuro das DTM deve basear-se no desenvolvimento de experimentos controlados e observações multidisciplinares, combinando pesquisas básicas, clínicas e epidemiológicas. Tanto o aspecto da dor como o da disfunção nas DTM deverão ser reconhecidos.

Por haver explicações divergentes sobre etiologia das DTM, a causa real dos desarranjos internos da ATM permanece ainda desconhecida ${ }^{36,132,133}$.

Nos últimos anos, o conceito de etiologia multifatorial da DTM tem sido predominante, suportando uma abordagem multidisciplinar para o tratamento $18,19,20,21,22,84,141,142,143$. No entanto a razão do conflito em relação à oclusão como fator etiológico permanece não resolvido, talvez porque o critério para "ma-oclusão" ainda é indefinido.

Uma discussão à respeito da etiologia das patologias intra-articulares da ATM se faz necessário pois o tratamento da dor e disfunção depende da identificação e controle dos chamados fatores contribuintes (predisponentes, iniciantes e perpetuantes).

Assim, hábitos de apertamento dental e, ou bruxismo, deslocamentos de disco articular, fatores oclusais de risco e condições 
sistêmicas (hipermobilidade ligamentar) têm sido associadas às dores da ATM.

As placas oclusais, motivo deste trabalho, auxiliam no controle de alguns dos fatores acima citados, como alterações oclusais e reposicionamentos temporários do disco articular.

\subsubsection{Placas oclusais}

Apesar dos avanços no diagnóstico e tratamento das DTM, os aparelhos oclusais continuam sendo uma das formas terapêticas mais utilizadas em todo o mundo. Em 1995, aproximadamente três milhões de placas oclusais foram confeccionadas e utilizadas pela população americana, com um custo aproximado de 999 milhões de dolares ${ }^{112}$. Apesar deste quadro demonstrar um elevado número de pessoas com placas indicando algum benefício com o seu uso, estes dados podem representar também o uso indiscriminado dessa modalidade terapêutica.

Mesmo utilizada há muito tempo, o mecanismo de ação das placas oclusais ainda não está totalmente esclarecido $26,33,34,71,98$. Várias hipóteses têm sido descritas para explicar a sua aparente eficiência, entre elas: a - o reposicionamento do côndilo e /ou disco articular; b - redução na atividade eletromiográfica dos músculos mastigatórios; c - modificação do comportamento oral prejudicial do paciente; $d$ - modificação na oclusão do paciente. No entanto estas teorias são fracas e inconsistentes, permanecendo incerto o seu verdadeiro valor terapêutico 33,34 . 
Assim como em outras formas de tratamentos propostos, a maioria das avaliações sobre o uso de aparelhos oclusais para o tratamento de DTM não são estudos comparativos controlados, constituindo geralmente estudos de casos sem controle ou artigos técnicos descrevendo formas de confecção destes aparelhos.

Trabalhos de meta-análise descrevem que muitos estudos apresentam metodologia inadequada como a ausência de inclusão aleatória nos grupos, controle inapropriados ou mesmo inexistentes e coleta de dados incompleta e imprecisa, levando a resultados duvidosos sobre a efetividade das placas para determinadas patologias ${ }^{118}$.

Como visto, apesar da utilização maciça das placas por parte dos profissionais, questões relativas ao seu real efeito sobre as estruturas do sistema estomatognático ainda permanecem uma incógnita.

O surgimento das placas de reposicionamento do disco articular vieram trazer ainda mais dúvidas a profissionais e pesquisadores.

Utilizadas inicialmente com a finalidade de recapturar e manter o disco deslocado em posição, verificou-se que em função do protocolo de utilização, varias alterações oclusais seguiam-se ao seu uso, obrigando os profissionais que advogavam aquele tipo de protocolo a realizarem tratamento reabilitador oral ou ortodontia. Essas terapias complementares teriam a finalidade de corrigir as alterações remanescentes, mesmo que para alguns a erupção passiva pudesse corrigir a mordida aberta 
posterior (seja pela intrusão dos dentes, seja pelo remodelamento condilar que adaptava-se a uma posição mais protruída), que aparecia em função do uso deste aparelho.

Assim o real efeito da recaptura do disco articular na melhora de estalidos e dores na ATM não justificaria os possíveis efeitos colaterais dessa modalidade como alterações oclusais permanentes e dores de origem muscular, geradas pelo posicionamento protrusivo da mandíbula. Mesmo havendo autores $5,19,20,21,39,40,41,61,64,78,80,81,82,83,110,116,137,149,150,151,152$, que defendem o uso de placas reposicionadoras existe paralelamente um grupo que contrário a sua utilização $10,48,86,90,96,107,108,109,140$, por diversos fatores, que descreveremos a seguir.

Entre os aparelhos oclusais a placa estabilizadora é sem dúvida a mais utilizada e descrita na literatura $12,16,32,45,69,71,77,93,97,101,102,103,104,105,117$ tanto para redução de sintomas articulares ${ }^{16,45}$, como para os casos de problemas musculares ${ }^{22,97}$.

Por outro lado, as placas estabilizadoras (também chamadas de "relaxamento muscular") não provocam remissão de sintomas na maioria dos casos de desarranjos internos da $\mathrm{ATM}^{7,75,61,78,80,81,83,137}$. Assim, em função de dados que suportam sua efetividade, mas não a sua eficácia, as placas oclusais deveriam ser utilizadas como adjuntas para o controle da dor e não como seu único tratamento ${ }^{33,34}$. 
Portanto a escolha dessas modalidades terapêuticas nesse trabalho deve-se a tentativa de se definir qual a técnica mais efetiva, com menos efeitos deletérios no tratamento das DTM de origem articular.

Especificamente em relação a terapias com placas oclusais, apesar da vasta literatura sobre o assunto, há necessidade de um melhor esclarecimento com relação ao protocolo de utilização e qual o comportamento oclusal frente ao seu uso prolongado, até mesmo para se propor protocolos mais efetivos, com menos efeitos colaterais ao sistema estomatognático.

\subsection{3.- Metodologia Aplicada}

Para se analisar os resultados dos estudos sobre a efetividade de aparelhos oclusais há necessidade de se examinar o desenho do estudo e os métodos para a coleta de dados. Se a validade e precisão dos instrumentos de medidas são determinados e descritos na literatura e efetivamente comprovados, o leitor pode mais claramente compreender e analisar as conclusões dos trabalhos 85 .

Nesse estudo, foi investigado a efetividade de placas reposicionadoras no controle de patologias intra-articulares, comparando os resultados obtidos com uso deste aparelho após um período de um ano com os resultados obtidos com placa de estabilização e com os obtidos sem qualquer tratamento (grupo controle), também em período de avaliação de um ano. 
Esse acompanhamento longitudinal, permitindo a observação da evolução dos sinais e sintomas dentro de um periodo de tempo vem de encontro aos conceitos de trabalhos controlados e aumenta a sua confiabilidade, uma vez que permite a análise da efetividade a longo prazo das terapias propostas, eliminando efeitos imediatos que poderiam mascarar os efeitos reais, como placebo e própria confiança do paciente no profissional. Tais fatores poderiam levar a melhoras iniciais, independente do real efeito da placa.

Estudos de meta-análise mostram que na maioria dos trabalhos, quando o critério de seleção da amostra não é bem elaborado, os resultados obtidos têm baixa validade clínica e, portanto, são de pouca validade científica ${ }^{118}$.

Neste trabalho a inclusão da amostra foi aleatória e selecionada ao acaso e isto vem ao encontro aos critérios de trabalhos que avaliam pacientes com dor. A presença de um grupo controle também é fundamental, pois permite a análise da evolução natural da doença, sem nenhum tratamento.

Com esta metodologia, evita-se o risco de se ter "BIAS" (sujetividade tendenciosa), ou seja, tendência de se alocar indivíduos com mais dor nos grupos que receberiam tratamento para se obter resultados estatisticamente significantes. 
A idade da amostra também é um fator importante em estudos longitudinais.

Como observado, a idade da amostra nos diferentes grupos eram semelhantes. A média da idade de toda amostra foi de 31,84 anos. A diferente evolução das DTM em diferentes idades poderiam alterar os resultados desta pesquisa

Em relação ao gênero, houve predominância do gênero feminino, o que é normal dentro de uma amostra de paciente que procuram clínicas de DTM1,2,3,10,11,22,25,32,44,46,47,50,51,54,56,58,60,73,78,91,92,93,125. Esse fato, porém, esteve presente nos três grupos estudados, ou seja, não houve diferenciação no gênero, entre os três grupos.

Outro fato é como avaliar a possivel melhora dos pacientes. Um teste diagnóstico tem que ter precisão, que é mensurada pela habilidade de detectar doenças, quando se esta presente (sensibilidade), quanto pela habilidade de excluir doenças (especificidade). O nivel de especificidade e sensibilidade de um diagnóstico considerado aceitável para um teste depende da prevalência e gravidade da doença e da estimativa de erros devido ao mau diagnóstico. Ou seja, em razão de somente 4 a $6 \%$ da população geral procurarem por tratamento e de que pacientes com DTM não sofrem risco de vida, baixos niveis de sensibilidade podem ser usados para essa desordem. Em outras palavras, por causa do aspecto moderado dos sintomas e ausência do risco de vida, pode se aceitar baixos níveis de 
sensibilidade para detectar os pacientes com DTM. Por outro lado o paciente assintomático, uma vez incorretamente diagnosticado como tendo doença, poderia esta sujeito a um tratamento desnecessário e potencialmente danoso, levando a custos financeiros e humanos substanciais. Portanto um teste diagnóstico na área da DTM, deve ter uma especificidade alta, pois um falso positivo poderia levar a procedimentos irreversiveis. Análises de dor, movimentação mandibular, palpação dos músculos e ATM, e análise dos ruídos articulares são os mais descritas na literatura $2,8,10,28,33,34,37,43,54,56,57,58,63,79,85,88,103,111,134,141,153,155$.

A EAV foi método por nós utilizado com a finalidade de avaliar o relato dos indivíduos com relação a alterações na percepção de dor durante o período de avaliação.

A EAV, apresenta alto grau de confiabilidade na medição da dor das DTM, sendo sensível a pequenas variações de sensibilidade, representado portanto, uma ferramenta confiável para quantificar a dor.

Em nosso trabalho niveis de EAV iniciais dos três grupos estudados não eram diferentes estatisticamente $(p=0,385)$, o que é um reflexo natural da inclusão aleatória e da ausência de "BIAS" (sujetividade tendenciosa). 


\section{2 - Movimentos mandibulares}

O grau de abertura bucal é um dos parâmetros utilizados com a finalidade de análise de problemas relacionados á ATM de tal forma que a abertura bucal limitada é um dos parâmetros para a identificação de problemas articulares, principalmente aqueles relacionados a desordens de interferência de disco. Neste estudo, os valores médios encontrados para esta variável foi de 50,57 $\mathrm{mm}$ inicial e 53,50 $\mathrm{mm}$ final em média para os grupos. Nesta amostra, observamos que a DTM não foi capaz de limitar a abertura bucal de forma significante. Tem sido descrito que os valores considerados normais para a abertura bucal são de, no mínimo, 40 $\mathrm{mm}$, variando entre $43,3 \mathrm{~mm}$ e $60 \mathrm{~mm}^{74,84,86,88,91,95,103,111,129}$. Ao se analisar a evolução desta variável no presente estudo, observa-se que no início da análise, o grau de abertura já encontrava-se dentro de um padrão de normalidade. Mesmo assim, os resultados finais demostram um aumento no grau de abertura, o que pode ser explicado pela melhora no padrão muscular do paciente, associado a uma melhora no padrão da dor articular devido a um possivel processo de adaptação das superfícies articulares, diminuído assim as dores facilitando a movimentação, tanto de abertura como de lateralidade. Esse fato será motivo de uma discussão futura.

Perceba que no caso do grupo controle houve também um aumento relativo no grau de abertura bucal mesmo que com um tempo 
maior. Este fato comprova o caráter cíclico e auto limitante destas patologias também para o ítem abertura bucal.

Os movimentos laterais e protrusivos também foram aumentados com o passar do tempo $(\mathrm{p}<0,01)$ independente do grupo estudado $(p>0,05)$.

Tem sido descrito que a média de movimento lateralidade situa-se entre 7 e $16 \mathrm{~mm}^{27,35,58,63,84,89,91,103,108,109,11,112,116,155}$. Quando valores inferiores a $7 \mathrm{~mm}$ estão presentes existe a suspeita de alterações musculares ou articulares $74,84,86,88,91,95,103,111,129$. Neste trabalho encontrou-se para a lateralidade direita uma média de inicial de $7,02 \mathrm{~mm}$ e final de $8,13 \mathrm{~mm}$ e para o movimento de lateralidade esquerda uma média inicial de $7,56 \mathrm{~mm}$ e final de $8,46 \mathrm{~mm}$. A protrusão melhorou, em média, de $5,68 \mathrm{~mm}$ para $6,09 \mathrm{~mm}$.

Com relação à essas variáveis neste estudo, os resultados obtidos demostram não haver diferenças estatisticamente significante, ou seja, as pequenas variações observadas entre os grupos em determinado período independem do tipo de placa ou procedimento que foi realizado. Já a análise intra-grupos demonstrou resultados estatisticamente significante $(\mathrm{p} \leq 0,001)$, ao longo do tempo em que se realizou a pesquisa. Assim como para o quesito abertura bucal, essa melhor movimentação pode ser reflexo da melhora das dores articulares e musculares. 
Os dados do presente trabalho confirmam expectativas de trabalhos anteriores, ou seja, existe uma melhora discreta na movimentação mandibular, apesar desta não ser a queixa principal da maioria dos pacientes com problemas na ATM. As médias iniciais aceitáveis dessa amostra confirmam esse fato.

\section{3 - Contatos oclusais}

Um dos grandes problemas descritos com o uso das placas de reposicionamento anterior são as possiveis alterações oclusais que estas podem causar, tendo como conseqüência, muitas vezes, a necessidade de tratamentos ortodônticos ou protéticos, para a correção, com custos onerosos ao paciente.

Mesmo com descrições de sucesso com o uso destes aparelhos, paralelamente, têm sido descrito problemas, como alterações oclusais, intrusão dos dentes posteriores e mordida aberta posterior, principalmente relacionados ao protocolo de utilização $81,82,83$.

Para alguns autores, tais problemas relacionados a alterações oclusais só ocorrem quando não há cobertura oclusal de todos os dentes posteriores com o aparelho ${ }^{18,19,20,21,22}$.

Neste trabalho encontrou-se uma média de 26,96 contatos oclusais inicial e 29,96 contatos, em média de toda amostra, após um ano de análise. Estes contatos efetivos foram registrados com papel 
carbono em posição de MIH (máxima intercuspidação habitual) e acompanhado em intervalos regulares de acordo com o protocolo da pesquisa.

Dentro do protocolo utilizado, não houve alterações oclusais, uma vez que o número de pontos de contato não foi significantemente alterado durante o período de observação, o que vai de encontro a outros trabalhos $19,64,78,80,83,103,110,137,149,150$, que não encontraram alterações oclusais permanentes com o uso de placa de reposicionamento dentro do uso de um protocolo específico, ou seja, uso parcial.

Assim, de acordo com os resultados por nós obtidos, é possivel utilizar esta forma terapêutica, não invasiva, com a finalidade de controlar quadros dolorosos com intervalo de tempo menor e com menos custo em relação a tratamentos irreversíveis propostos no passado com a intenção de controle de dor. Deve ficar claro que estas terapias propunham a recaptura permanente do disco articular, o que não é objetivo da terapia aqui proposta, como será discutido posteriormente.

Uma questão a ser analisada está relacionada ao protocolo de utilização, e ao tempo em que a mandíbula pode permanecer na posição anteriorizada e qual a forma ou método de suspender a sua utilização, pois períodos de uso integral por muito tempo poderiam levar a todos esses efeitos deletérios já descritos. 
Com relação ao método de retorno da mandíbula a posição original, OKESON 102,103,105 faz um retorno gradual para a posição inicial através de reajustes contínuos na placa.

Em nosso estudo, as placas foram utilizadas ininterruptamente por um período de uma semana e mantidas em uso noturno por 3 meses. A partir deste momento, foram imediatamente transformadas em placas estabilizadoras e mantidas em posição por 9 meses, perfazendo um ano de avaliação.

Um outro problema que pode ocorrer com o uso de placas de reposicionamento são alterações a nível condilar. A mudança no posicionamento condilar, mesmo cessando o ruído, pode levar a um remodelamento, dependendo do tempo em que o côndilo permanece anteriorizado ${ }^{89}$, podendo ocorrer reabsorção caso o posicionamento seja excessivo ${ }^{107}$.

No caso desta pesquisa, o posicionamento foi até topo a topo e a altura do aparelho até o ponto em que o ruído desapareceu. Caso um posicionamento excessivo tivesse ocorrido durante a realização deste experimento, este fato teria repercutido em termos de alteração oclusal, dor, e desconforto, por parte do paciente, o que não aconteceu.

Mesmo evidenciando grande número de trabalhos utilizando placas estabilizadoras, outros apresentam limitações quanto a sua 
utilização $7,75,84$, sugerindo aspectos como a reativação das interferências oclusais depois de sua remoção ${ }^{75}$.

Neste estudo com relação ao número de contatos tratados pelo teste de ANOVA para mensurações repetidas a dois critérios, podemos observar que não houve diferença estatisticamente significante na análise inter-grupos $(p>0,05)$. Isto significa que: 1 - a variação no número de contatos não foi expressiva entre os grupos nos diferentes períodos de tempo; 2- A medida que o tempo passou, não houve diferença estatisticamente significante entre os grupos no número de contato; 3 - O número de contatos não varia significantemente entre o grupo de paciente com ou sem a placa independentemente do tipo; 4- tanto faz usar ou não a placa reposicionadora, que ao longo do tempo e dentro do protocolo da pesquisa, o numero de contatos oclusais inicialmente observados se mantiveram.

Esse fato é fundamental para a indicação clínica das placas de reposicionamento anterior com uso apenas parcial. Com todos os efeitos de redução de dor obtidos, não houve nenhuma alteração oclusal significante. Talvez um relato que melhor exemplifique mecanicamente a ação dessas placas é o fato do paciente relatar uma "mordida diferente" pela manhã, devido ao uso noturno da placa.

Porém, num período curto de tempo, o relacionamento oclusal se refaz, com a mandíbula retornando a sua posição original. 
Também, com relação ao conforto relatado, tais placas não são menos toleradas que as estabilizadoras.

\section{4 - Dores articulares}

Poucos estudos de acompanhamento têm sido conduzidos no sentido de avaliar especificamente as técnicas de terapia fisica na redução da dor da ATM. A descrição dos casos clínicos, e a lógica em termos de terapia suportam o tratamento utilizando dieta macia e antiinflamatórios para reduzir a dor aguda em conseqüência do trauma na ATM. No entanto não existe comprovação destas formas terapêuticas, para o caso das dores que assumem caráter crônico.

Alguns estudos mostram que as dores crônicas da ATM parecem responder melhor aos aparelhos de estabilização $18,21,22$. No entanto, necessita-se de mais pesquisas no sentido de comprovar a eficácia destes aparelhos diante desta condição.

$\mathrm{Na}$ presença do disco deslocado, os ligamentos posteriores estão estirados no interior do espaço articular entre o côndilo e a fossa, funcionando como uma base onde se assenta o côndilo ${ }^{41}$.

Ao mesmo tempo, microscopicamente, o desarranjo interno freqüentemente resulta em um posicionamento posterior do côndilo e compressão das estruturas retrodiscais. Existem, ainda, mudanças 
patológicas no disco, incluindo alterações na forma e na orientação e arquitetura do colágeno interno, além de patologias na inserção posterior ${ }^{119}$.

Este fato parece ser responsável pela sintomatologia que acompanha os quadros agudos de desarranjos internos.

Mesmo sendo a placa estabilizadora a forma de terapia mais conhecida e utilizada 16,22,30,45,77,93,97,105, existem vários estudos demonstrando o uso da placa de reposicionamento com a finalidade de reduzir sinais e sintomas articulares como dor e ruido ${ }^{18,19}$, $39,61,64,78,80,81,82,83,102,137,149,150,151,152$.

Com o uso de placas de reposicionamento, mesmo no caso do disco permanecer deslocado, há sempre a possibilidade de uma adaptação do tecido retrodiscal, o que levaria a formação de um pseudodisco, o que por si só, justificaria a utilização de métodos de tratamento conservador ${ }^{106}$, sem a necessidade de recaptura permanente do disco.

Os estudos recentes de acompanhamento clínico e morfológico obtidos com a recaptura do disco mostram que o posicionamento mandibular anterior é efetivo nos casos de deslocamento anterior de disco com redução, basicamente quando o disco encontra-se deslocado em direção anterior ${ }^{134}$. Esse fato não pôde ser analisado no presente estudo devido a ausência de critérios de localização precisa do disco articular, como a realização da ressonância magnética118. 
Apesar de formas terapêticas diferentes, a maioria destas apresenta bons resultados. Uma das prováveis explicações para isto é que a efetividade específica de um método terapêutico é de dificil avaliação, devido a flutuação substancial na severidade os sintomas em grande parte das DTM, e grande influência do efeito placebo, no tratamento de qualquer condição, inclusive da dor. Vários estudos demonstraram que 35 a $60 \%$ de pacientes com DTM relataram melhora com tratamento com placebo, por exemplo, placas oclusais sem alteração na oclusão, desgastes falsos, isto é polindo regiões palatinas ao invés de eliminar interferências oclusais, ou comprimidos de açúcar, substituindo medicação específica ${ }^{4}$.

Apesar da participação do efeito placebo e da própria característica auto-limitante, as placas reposicionadoras demonstraram-se superiores aos demais grupos em relação aos quesitos, relato de dor (EAV) e palpação da ATM.

$\mathrm{Na}$ análise intra-grupos note-se uma melhora generalizada para todos os grupos, com o passar do tempo, ou seja, a própria evolução natural das dores leva a remissão expontânea, ou a regressão à média de valores iniciais, antes da percepção da mensagem dolorosa.

Porém, ao se utilizar a análise inter-grupos nos diversos períodos de avaliação, tem-se que o grupo II diferencia-se dos demais já a partir de 15 dias de utilização, apresentando reduções 
significantes no relato de dor $(p<0,01)$. Somente a partir de seis meses de avaliação os demais grupos passaram a se comportar dessa forma, sem diferenças com o grupo das placas reposicionadoras.

A melhora inicial dos pacientes seguindo um protocolo de uso parcial de protrusão mandibular, é devido a uma descompressão de regiões retrodiscais inflamadas e doloridas. Com o uso da placa no período noturno, possibilita-se uma descompressão dessa área num período comumente afetado pelo aumento de pressão (bruxismo noturno). Esse fato possibilitaria a redução da dor nesse grupo. Além disso, a manutenção do disco articular deslocado durante atividades funcionais diversas possibilitam o estímulo necessário para o fibrosamento das estruturas retrodiscais e formação de um "pseudodisco", também contribuindo para a redução da dor. Diminuição no calibre dos vasos sangüineos, aumento de fibras colágenas e a presença de glicosaminoglicanas fazem parte desse processo de adaptação ${ }^{119,120,137,144,147}$.

Acredita-se, no presente trabalho, que tais alterações aconteceram de forma mais lenta e gradual para os grupos I, e III. (após os seis meses de avaliação).

Ou seja, apesar da tendência de regressão natural, pacientes submetidos a terapia com placas protrusivas puderam desfrutar de um ano livre de sintomas.

Estudos recentes indicam 0 tratamento imediato da sensação de dor para se evitar a formação de conexões centrais complexas, o 
que levaria uma diminuição drástica no prognóstico de melhora da dor (cronificação da dor por sensitização central).

Esse fator reitera ainda mais a necessidade de redução rápida da dor provida pela anteriorização parcial da mandíbula. Tal fato associado a ausência de efeitos "colaterais" na amostra em questão, creditam a utilização de placas protrusivas na redução de dores de origem articular.

Quando realizada a palpação na ATM, pode-se observar que no grupo II, os resultados de diminuição iniciaram-se também a partir do primeiro mês, demonstrando uma ação mais rápida deste aparelho em reduzir a dor articular. Este fato vai de encontro a outros estudos que demonstraram uma efetividade maior das placas de reposicionamento em reduzir a dor de origem articular18,19,39,78,80,81,82,83.

A dor estimulada pela palpação também é um critério importante na avaliação da amostra. A diminuição de sensibilidade a palpação (pelo menos um ponto sensivel nas duas ATM) para o grupo II reafirma a redução do processo inflamatório, possivelmente causador da sensação de dor inicial. Esse dado confirma a maior efetividade já relatada pelos pacientes no relato através da EAV.

Enquanto para o grupo II, observa-se melhoras significantes $(p=0,01)$ já no 1o mês, tais dados somente são observados no 3o mês $(p=0,04)$ e no $6^{\circ}$ mês $(p=0,02)$ para os grupos I e III, respectivamente. Isso também significa que para o grupo I, a redução de sinais (palpação) 
acontecem previamente à redução dos sintomas (EAV), o que foi significante após 6 meses.

Esse fato pode estar relacionado a mecanismos de sensitização central com manutenção da dor, mesmo com a melhora e ausência de estímulos periféricos. Dessa forma, as placas estabilizadoras parecem ter um efeito mais demorado nas estruturas danificadas da ATM assim como de estímulo para a formação de estruturas adaptativas.

\section{5 - Dores musculares}

Um importante sinal clínico da presença de desordens musculoesquelética é a presença de sensibilidade muscular, e o teste de palpação muscular associado ao exame físico e história clínica, auxilia na diferenciação em uma amostra entre pacientes sintomáticos e assintomáticos.

Durante o exame de palpação muscular, obteve-se um percentual de $34,62 \%$ para o total da amostra com pelo menos um ponto sensivel no início da análise.

Em comparação com os resultados após um ano de acompanhamento, houve um melhora da presença de sensibilidade muscular, independentemente do grupo $(p=0,020)$, sendo que entre aqueles que sentiam dores musculares inicialmente, $61,1 \%$, não mais apresentavam esta condição depois de um ano. Este fato pode ser reflexo da melhora das 
dores na ATM, que inibiriam as contrações musculares protetoras e as dores conseqüentes. Esse fato, também refuta a hipótese de que as placas reposicionadoras poderiam levar a instalação e a manutenção de dores musculares.

De uma maneira geral uma da explicações para a redução dos sintomas musculares com o uso das placas é a diminuição da tensão muscular ${ }^{32}$. Este fato tem sido analisado através de estudos eletromiográficos nos diferentes músculos. No entanto o uso de placas oclusais como única modalidade terapêutica é insuficiente para o tratamento das incoordenações musculares ${ }^{7}$.

Do ponto de vista muscular, com o uso de placa de reposicionamento, não há uma significante diminuição da atividade do músculo masséter e temporal em relação a placa estabilizadora ${ }^{152}$.

Esses dados reafirmam o caráter reversível das placas reposicionadoras em uso parcial. Criticadas por muitos autores por criarem contrações musculares anormais e conseqüente dor, note-se aqui que, na verdade, após uma ano de acompanhamento, as dores musculares iniciais se reduzem, provavelmente devido ao processo já descrito.

SFONFRINI et. al. ${ }^{123}$ creditam esse fato a uma mudança na composição das fibras musculares, levando também a processos adaptativos de "mioplasticidade". 


\section{6 - Ruídos articulares}

Uma das mais freqüentes queixas em pacientes com DTM é a presença dos ruídos na articulação. Convém ressaltar que existe uma grande dificuldade em se identificar os ruídos articulares e isto pode responder por resultados diferentes em relação àqueles encontrados na literatura. No presente estudo a presença do ruído foi identificada através de inspeção manual.

Apesar do disco deslocado apresentar uma freqüência maior em pacientes com DTM, uma parcela de indivíduos assintomáticos apresentam essa alteração morfológica, não necessitando tratamento $34,66,71,85,87,90,98,134,147$. Para estes pacientes, a ausência de dor e disfunção é devido a processos adaptativos de alterações teciduais que acorrem na inserção posterior. Entre estes pacientes somente uma pequena parcela podem vir a apresentar problemas futuros, o que contra indica tratamentos invasivos para a eliminação do estalido.

Mesmo com a dificuldade em se estabelecer um método científico diagnóstico alguns autores descrevem como sinais patognomônicos de DTM, ruídos articulares e dor na abertura 101, 102, 103, 104, 105, 142.

A origem do ruído tem sido descrita como sendo de problemas ligamentares ${ }^{46}$, de excessivas modificações substitutivas nas fibras do disco57, de mudanças estruturais da superficie do disco e da 
articulação $^{11}$ e de alterações dos movimentos do disco em relação ao posicionamento mandibular ${ }^{138}$.

Várias formas de terapia tem sido descritas para tais problemas: cirurgias $^{6}$, placas de reposicionamento $5,18,19,20,21,22,137$, fisioterapia e placa estabilizadora56 entre outras.

A placa de reposicionamento anterior tem sido descrita desde 1971 com a finalidade de controlar casos de estalido 39,18,19,78,80,81,82,83, com relatos de sucesso com o uso deste aparelho tanto para os casos de ruído recíproco em pacientes com desordens internas da ATM74,78,80,81,82,83,116 como também para diminuição de fadiga muscular ${ }^{80}$.

Para alguns autores ${ }^{119,120}$ quando há desarranjo interno a porção posterior da cápsula e posterior do disco, que é vascularizada e enervada e portanto com mecanoceptores, são puxadas para frente entre os componentes ósseos, sendo comprimidas. Quando do uso dos aparelhos de reposicionamento, a descompressão faz com que também a coordenação entre o disco e o côndilo retorne ao normal por não haver mais o estimulo nos mecanorreceptores ${ }^{61}$.

O fato de muitos trabalhos mostrarem que a presença do estalido denuncia o disco deslocado e que isto predispõe o indivíduo a apresentar processos degenerativos, fez com que muitos voltassem suas formas terapêuticas para a eliminação do mesmo, pois assim estariam recuperando a posição do disco, evitando possiveis quadros futuros de 
degeneração, assumindo-se assim um relacionamento entre desarranjo interno e osteoartrite $24,38,72,100$.

$$
\text { Outros autores } 27,28,66,78,119,120,137 \text { verificaram que }
$$

articulações com hipermobilidade condilar e "estalido" recíproco não apresentam mais alterações degenerativas do que as articulações hipermóveis e que não apresentavam o "estalido". Com base nesses achados os autores não encontraram relacionamento entre desarranjos internos e osteoartrite ${ }^{36}$.

Ainda, foram encontradas ATM com degenerações e um relacionamento disco/condilo normal ${ }^{36}$. Esses autores acreditam que os deslocamentos possam vir a ser consequência de degenerações iniciais através de perda de coordenação com o côndilo alterado em sua forma.

Dessa forma a presença de ruídos articulares com ausência de dor, não indica necessariamente que devam ser tratados 54 . Paralelamente, nem sempre a presença do ruído indica o disco deslocado ${ }^{131}$, 132, 133. Métodos não invasivos estariam indicados para o controle destas patologias e entre estes incluem-se as placas oclusais reposicionadoras, havendo entretanto, necessidade de mais pesquisas, no sentido de avaliar a evolução do ruído a longo prazo após a remoção das mesmas ${ }^{132}$.

Assim, o ruído não é parâmetro para se definir sucesso com o uso destes aparelhos oclusais ${ }^{132}$. 
Desta maneira, acredita-se hoje que, um método terapêutico aceito seja a manutenção do disco deslocado como meta de tratamento, desde que não exista sintomatologia dolorosa na ATM. Sob este aspecto o uso de placa reposicionadora, como pode-se observar no presente estudo, e de acordo $\quad$ com $\quad$ outros trabalhos $19,20,21,39,40,41,51,64,78,80,81,82,110,116,137,149,150,151,152$, mostrou-se eficiente na redução deste sintoma.

No presente trabalho, ao se considerar toda a amostra, houve uma redução significante de ruídos após um ano $(p<0,01)$, assim como para os grupos I e II ( $p=0,04$ e $p=0,02$, respectivamente). Já o grupo controle também apresentou redução, porém não significante $(p=0,13)$.

Resultados de 39\% de sucesso na redução dos estalidos após 19 meses de acompanhamento têm sido descrito ${ }^{21}$. Quando comparado com placa lisa, especificamente em relação ao ruído, um porcentual de sucesso maior tem sido observado ${ }^{5}$.

Estes dados de sucesso maior com o uso de placas de reposicionamento não são semelhantes aos obtidos nesta pesquisa, que encontrou sucesso tanto com o uso de placa lisa como de placa reposicionadora, na redução do ruído ao final de um ano.

O fato do ruído ter diminuído significativamente nos grupos I e II, não significa que houve reposicionamento permanente no disco, até porque, o simples desaparecimento do ruído não é critério para se 
afirmar que houve recaptura86. A eliminação do mesmo até no grupo controle também reintera o caráter auto-limitante desses processos. Assim, a resolução do estalido, pode representar simplesmente um fato extra ao tratamento realmente necessário, que é voltado para o controle da dor.

Dessa forma, apesar do caráter aparentemente "benigno" da evolução natural das patologias da ATM, quando se tem dor o tratamento deve ser realizado. Placas de reposicionamento, quando utilizadas inicial e parcialmente não determinam alteração negativas a nível muscular, articular ou oclusal de caráter permanente, trazendo beneficios em relação a dor.

Portanto, os ruídos devem ser vistos como um reflexo de incoordenações disco/côndilo, passiveis de adaptação. Como salientado anteriormente, o tratamento do estalido pode representar uma frustração para o cirurgião-dentista, devido a freqüêntes recidivas.

A perda de características de assentamento próprio talvez impeçam a manutenção permanente de um disco recapturado ${ }^{111}$. No presente trabalho acredita-se que o desaparecimento do estalido deve-se a alterações na forma do disco, embora tal afirmação (a não recaptura do disco) precisasse de meios diagnósticos mais sofisticados como "gold standard" (ressonância magnética). 
7 - CONCLUSÕES 


\section{7 - Conclusões}

Os resultados mostraram que:

1. placas oclusais reposicionadoras foram mais efetivas na redução da dor relatada pelos pacientes;

2. menores médias de palpação de ATM foram observadas com o uso de placa de reposicionadora; todos os grupos apresentaram redução na dor muscular;

3. todos os grupos apresentaram aumento na movimentação após 1 ano de acompanhamento;

4. os grupos com tratamento apresentaram reduções significantes nos ruídos articulares;

5. o número de contatos oclusais aumentou com o tempo, independente do grupo estudado;

6. o grupo controle mostrou resultados semelhantes aos grupos com tratamento após 6 meses de avaliação.

Baseado nos resultados apresentados, parece-nos lícito concluir:

1. O uso de aparelhos de reposicionamento de acordo com o protocolo de utilização, é efetivo na redução de ruídos articulares, não implicando este fato na recaptura de disco articular.

2. Estes aparelhos não determinam alterações siginificativas no padrão oclusal.

3. O aparelho de reposicionamento reduz a sintomatologia dolorosa mais rapidamente em relação a placa estabilizadora.

4. Os aparelhos de reposicionamento não determinam alterações significantes a nível muscular, articular ou oclusal de caráter permanente.

5. O protocolo de 1 semana de uso initerupto e sequencialmente o uso parcial por um ano da placa de reposicionamento, mostrou ser efetivo no controle de sintomas dolorosos articulares e musculares que acompanham os pacientes portadores de DTM, sem determinar alterações oclusais permanentes. 
REFERÊNCIAS BIBLIOGRÁFICAS 


\section{Referências Bibliográficas}

1. AGERBERG, G.; CARLSSON, G.E. Funtional disorders of the temporomandibular system. I - Distribution of symptoms according to age and sex as judged from investigaton by questionnaire. Acta odont. scand., v.30, n.6, p. 597-613, 1972.

2. AGERBERG, G; CARLSSON, G.E. Late results of treatment of functional disorders of the mastigatory system: a follow-up by questionnairy. $\mathbf{J}$. oral Rehab., v.1, p. 309-16, 1974.

3. AGERBERG, G.; CARLSSON, G. E. Symptoms of functional disturbances of the mastigatory system - a comparison of frequencies in a population sample in a group of patients. Acta odont. scand., v.33, n.3, p.183-90, 1975.

4. ALENCAR JUNIOR, F.G.P. Avaliação do efeito placebo no tratamento de pacientes portadores de disfunção cranio-mandibular ( DTM ) e placas não oclusivas (PNO). Bauru, 1994. 114p. Dissertação ( Mestrado )- Faculdade de Odontologia de Bauru, Universidade de São Paulo.

5. ANDERSON, G.C. Comparative study of two treatment methods for internal derangement of the TMJ. J. prosth. Dent., v. 53, n. 3, p. 392-7, Mar. 1985.

6. ANNANDALE, T. Displacement of the inter-articular cartilage of the lower jaw, and treatment by operation. Dent. Record, v.7, p.110-2, 1887.

7. BEARD, C.C., CLAYTON, J.A. Effects of occlusal splint therapy on TMJ dysfunction. J. prosth. Dent., v.44, n.3, p.324-35, 1980.

\footnotetext{
* Normas recomendadas para uso no âmbito da Universidade de São Paulo, com base no documento "Referências Bibliográficas: exemplos", emanado do Conselho Supervisor do Sistema Integrado de Bibliotecas
} 
8. BELL, W.E. Clinical diagnosis of the pain-dysfunction syndrome, J. Amer. dent. Ass., v.79, n.36, p.154-60, July 1969.

9. BEWER; D. C. Biomechanical and physiologic processes leading to internal derangements with adhesion. J. craniomandibular. dis. fac. oral pain, v.3, p.44-9, 1989.

10. BOERO, R.P. The physiology of splint therapy: literature review. Angle Orthod., v.59, p.165-80, 1989.

11. BOEVER, J.A. Functional disturbances of the temporomandibular joints. In:_ Oral sciences reviews: temporomandibular joint-function and dysfunction. 1973. v.1, p.100-17.

12. BORROMEO, G.L.; READE, P.C. A comparison of the effect of group function and canine guidance interocclusal device on masseter muscle electromyographic activity in normal subjects. J. prosth. Dent., v.174, n.2, p.174-80, Aug. 1995.

13. BROWN, D.T.; GAUDET, E.L. PHILlIPS, C. Changes in vertical tooth position and face height related to long-term anterior repositioning splint therapy. Cranio, v.12, n.1, p.19-22, Jan. 1994.

14. CARLSON, $\mathrm{N}$. et al. Comparison of muscle activity between conventional and neuromuscular splints. J. prosth. Dent., v. 70, n. 1, p. 39-43, July 1993.

15. CARPENTIER, P. et al. Insertions of the lateral pterygoid muscle: an anatomic study of the human temporomandibular joint. J. Oral Maxillofac. Surg., v.46, n.6, p.477-82, June 1988.

16. CARRARO, J.J.; CAFESSE, R.G. Effect of occlusal splints on TMJ symptomatology, J. prosth. Dent., v.40, p.563-6, 1878. 
17. CELENZA, F.V. Posição condilar: na doença e na saúde (quando nós atuamos?). In:__ Review em ATM e oclusão - artigos clássicos. Rio de Janeiro, Quintessence, 1988. p.3-15.

18. CLARK, G.T. A critical evaluation of orthopedic interocclusal appliance therapy: design, theory and overall effectiveness. J. Amer dent. Ass., v. 108, p.359-64, 1984.

19. CLARK, G.T. Treatment of jaw clicking with temporomandibular repositioning: an analysis of 25 cases. J. craniomandibular. dis., v.2, p.263-70, 1984.

20. CLARK, G.T. The TMJ repositioning appliances: Technique for construction, insertion and adjustment. J. craniomandibular Pract. v.4, p.37-46, 1986.

21. CLARK, G.T; LANHAN, F; FLACK, V.F. Treatament outcome for consecutive TMJ clinic patients. J. craniomandibular dis., v.2, p.87-95, 1988.

22. CLARK, G.T. et al. Nocturnal electromyographic evaluation of myofascial pain dysfunction in patients undergoing occlusal splint therapy. J. Amer dent. Ass., v.99, p.607-11, 1979.

23. COHEN, H.V.; BARAGONA, P. M. Long -term orthopedic appliance therapy. Dent. Clin. N. Amer., v.35, n.1, p. 109-21, Jan. 1991.

24. COHEN, S.G.; MACAFEE, K.A. The use of magnetic ressonance imaging to determine splint position in the management of internal derangements of the temporomandibular joint, $\mathbf{J}$. Craniomandibular Pract., v.12, n.3, p.167-171, July 1994.

25. CONTI, P.C.R. et al. A cross-sectional study of prevalence and etiology of signs and symptoms of temporomandibular disorders in High 
School and University Students. J. orofac. pain., v.10, n.3, p.25462, Summer 1996.

26. CONTI, P.C.R. Patologias oclusais e disfunções craniomandibulares. In: Prótese fixa. São Paulo, Artes Médicas, 1988. Cap. 2, p. 23-40.

27. CONTI, P.C.R.; MIRANDA, J.E.S.; ARAUJO, C.R.P.; Relationship between systemic joint laxity, TMJ hypertranslation, and intraarticular disorders. CRANIO, v.18, n.3, p.192-197, july, 2000.

28. CONTI, P.C.R. et. Al.; Joint sounds and signs of TMJ intrarticular disorders: a comparative study between manual inspection and a computer based analysis. J. Orofac. pain, v.13, n.2, p.140, june 1999. /Apresentado à American Academy of Orofacial Pain, 24 Annual Scientific Meeting Colorado Springs, USA, 1999-Abstract.

29. COSTEN, J.B. A syndrome of ear and sinus symptoms dependent upon distuberd functions of TMJ. Ann. Otol. (St. Louis), v.43, n.1, p.1-15, Mar. 1934.

30. COSTEN, J.B. Neuralgias and ear symptoms associated with disturbed function of the temporomandibular joint. J. Amer. med. Ass., v.107, n.3, p.252-64, 1936

31. COSTEN, J.B. Correlation of ray findings in the mandibular joint with clinical signs, especially trismus. J. Amer dent. Ass., v.263, p.405-7, Mar. 1939.

32. DAHLSTRÖN, L.; CARLSSON, G.E.; CARLSSON S.G. Comparison of effects of eletromiographic biofeedback and occlusal splints therapy on mandibular dysfunction. Scand. J. dent. Res., v.90, p.151-6, 1982. 
33. DAO, T.T.T.; LAVIGNE, G.J. The efficacy of oral splints in the treatment of myofascial pain of the muscles: a controlled clinical trial. Pain, v.56, p 85-94, 1994.

34. DAO, T.T.T.; LAVIGNE, G.T. Oral splints: the crutches for temporomandibular disorders and bruxism. Pain, v.9, n.3, p. 345$61,1998$.

35. DAWSON, P.E. Avaliação, diagnóstico e tratamento dos problemas oclusais. 2.ed. São Paulo, Artes Médicas, 1993.

36. DE BONT, L.G.M. et al. Osteoarthritis and internal derangements of the temporomandibular joint: a light microscopic study. J. oral Maxillofac. Surg., v.44, n.11, p.634-43, Nov. 1986.

37. DE LAAT, L.D.; VAN STENBERGME, D.; LESAFFRE, E. Occlusal relationships and temporomandibular joint dysfunction. Part. II. Correlations between occlusal and articular parameters and symptoms of TMJ dysfunction by means of stepwise logistic regression. J. prosth. Dent., v.55, n.1, p.116-9, Jan. 1986.

38. ERIKSSON, L.; WESTESSON, P. Clinical and radiological study of patients with anterior disc displacement of the temporomandibular joint. Swed. dent. J., v.7, p.55-64, 1983.

39. FARRAR, W.B. Diagnosis and treatament of anterior dislocation of the articular disc. N. Y. J. dent., v.41, p.348-51, 1971.

40. FARRAR, W.B. Differentiation of temporomandibular joint dysfunction to simplify treatment. J. prosth. Dent., v. 28, p.629-36, 1972.

41. FARRAR, W.B.; MCCARTY, W.L. Inferior joint space arthrography and characteristics of condylar paths in internal derangements of the TMJ. J. prosth. Dent., v.41, n.5, p. 548-55, May 1979. 
42. GAREFIS, P. et al. Effectiveness of conservative treatment for craniomandibular disorders: A 2 year longitudinal study. J. Orofac. Pain, v.8, n.3, p.309-14, Summer, 1994.

43. GIANNIRI, A.I. et al. Occlusal contacts in maximum intercuspation and craniomandibular dysfunction in 16- to 17-year-old adolescents. J. oral Rehab., v.18, p.49-59, Jan. 1991.

44. GLASS, E.G.; GLAROS, A.G.; MCGLYNN, F.D. Myofascial pain dysfunction: Treatments used by ADA members. Cranio, v.11, p.25-9, 1993.

45. GOHARIAN, R.K; NEFF, P.A. Effect of occlusal retainers on temporomandibular joint and facial pain. J. prost. Dent., v.44, p.206-8, 1980 .

46. GOODFRIEND, D. J. Symptomatology and treatament of abnormalities of the mandibular articulation. Dent. Cosmos., v.25, Sept. 1933.

47. GOODMAN, P; GREENE, C.S; LASKIN,D.M. Response of patients with myofascial pain-dysfunction syndrome to mouth equilibration. J.Amer.dent.Ass., v.92, p.755-8, Apr. 1976

48. GRABER, T.M. Temporomandibular joint disturbances and the periodontium. Int. J. Periodont. Restorat. Dent., v. 6, n.5, p.8892. 1984.

49. GREENE, C.S.; LASKIN, D.M. Splint Therapy for the myofascial paindysfunction (MPD) syndrome: a comparative study. J. Amer dent. Ass., v.84, n.3, p.624-8, 1972.

50. GREENE, C.S; LASKIN, D.M. Influence of the doctor-patient relationship on placebo therapy for patients with myofascial pain- 
dysfunction (MPD) syndrome. J. Amer. dent. Ass., v.85, p.892-4, Oct. 1972 .

51. GREENE, C.S; LASKIN, D.M. Long term evaluation of treatment for myofascial pain dysfunction syndrome: a comparative analysis. J. Amer. dent. Ass., v.107, p.235-8, Aug. 1983.

52. GREENE, C.S; LASKIN, D.M. Meprobanate therapy for the myo-fascial pain-dysfunction ( MPD ) syndrome: a double-blind evaluation. J. Amer. dent. Ass, v.82, p.587-90, Mar. 1971.

53. GRIFFIN, C.J.; SHAPE; C.J. Distribution of elastic tissue in the human temporomandibular meniscus especially in respect to compression areas. Aust. dent. J., v.7, n.1, p.71-2, 1962.

54. GROSS, A.; GALE, E.N. A prevalence study of the clinical signs associated with mandibular dysfunction. J. Amer. dent. Ass., v.107, n.6, p.932-6, Dec. 1983.

55. HARGREAVES, A.S.; WARDLE, J.J.M. The use of physiotherapy in the treatment of temporomandibular disorders. Br. dent. J., v.155, n.4, p.121-4, Aug. 1983.

56. HELKIMO, E.; WESTLING, L. History clinical findings, and outcome of treatament of patients with anterior disk displacement. Cranio, v.5, p.269-76, 1987.

57. HELKIMO, M. Studies on function and dysfunction of the masticatory system. IV - Age and sex distribution of symptoms of dysfunctions of the masticatory system in Lapps in the north of Finland. Acta odont scand., v,32, n.4, p.255-67, Mar. 1974.

58. HELKIMO, M. Epidemiological surveys on dysfunction of the masticatory system. In:___ Oral sciences reviews: 
temporomandibular joint function and dysfunction III. 1976. v.7, p.54-69.

59. HOLMGREN, K.; SHEIKHOLESLAM, A.; RIISE, C. Effect of a full-arch maxillary occlusal splint on parafunctional activity during sleep in patients with nocturnal bruxism and singns and symptoms of craniomandibular disorders. J. prosth. Dent., v.69, n.3, p.293-7, Mar. 1993.

60. HOSOKI, H. et al. Follow-up examination of the temporomandibular joint disk after splint therapy by magnetic resonance imaging - case report. J. craniomandibular Pract., v.13, n.3, p.1193-7, July 1995.

61. ISAKSSON G.; ISBERG, A.; PERSSON, A. Loss a directional orientation control of lower jaw movements in persons wity internal derangements of the temporomandibular joint. Oral Surg., v.66, p.8-12, 1988.

62. ISBERG-HOLM, A.M.; ISACSSON, G. Tissue reactions of the temporomandibular joint following retrusive guidance of the mandible. J. craniomandibular. Pract., v.4, p.143-8, 1986.

63. ISBERG-HOLM, A.M.; WESTESSON, P.L. Movement of disc and condyle in temporomandibular joints with and without clicking. Acta odont. Scand., v.40, p.165-77, 1982.

64. ITO T. et al. Recommended chewing side with an anterior repositioning splint. J. prosth. Dent., v.55, p.610-4, 1988.

65. KAI, S. et al. The significance of posterior open bite after anterior repositioning splint therapy for anteriorly displaced disk of the temporomandibular joint. Cranio, v.11, n.2, p.146-52, Apr. 1993. 
66. KANO, S., et al.; "TMD Symptoms and Management Strategies: A oneyear clinical experience". J. Orofac. pain, v.13, n.2, p.140, fev. 1997. /Apresentado à American Academy of Orofacial Pain, 24 Annual Scientific Meeting San Digo-California, USA, 1977-Abstract.

67. KERSTENS et al. Inclination of the temporomandibular joint eminence and anterior disc displacement. Int. J. oral Maxillofac. Surg., v.18, p.228-32, 1989.

68. KIRK JUNIOR., W.S. Magnetic resonance imaging and tomographic evaluation of occlusal appliance treatment for advanced internal derangement of the temporomandibular joint. J. oral Maxillofac. Surg., v.49, n.1, p.9-12, Jan. 1991.

69. KOYANO, K. et al. Effects of occlusal splint on mastigatory movement in healthy individuals. Cranio, v.15, n.2, p.127-31, 1997.

70. KROGH; P.W.G.; OLSSON, A. Occlusal disharmonies and dysfunction of the stomatognathic system. Dent. clin. N. Amer., p.627-35, Nov. 1966.

71. KURITA, H., KURASHINA, K., KOTANI, A. Clinical effect of full coverage occlusal splint therapy for specific temporomandibular disorder conditions and symptoms. J. prosth. Dent., v.78, n.5, p.506-10, 1997.

72. LAGER, H. The individual growth pattern and stage of maturation as a basis for treatment of distal occlusion overjet. Trans Eur. Orthod. Soc., p.137-45, 1967.

73. LASKIN, D.M. Etiology of the pain-dyfunction syndrome. J. Amer. dent. Ass., v.79, n.1, p.147-53, July 1969. 
74. LE BELL, Y.; KIRVESKARY,P. Treatment of reciprocal clicking of the temporomandibular joint using a mandibular repositioning splint and occlusal adjustment. Proc. Finn. Dent. Soc., v.81, p.251-7, 1985.

75. LEDERMAN, K.H., CLAYTON, J.A. Patients with restored occlusions. Part III: The effect of occlusal splint therapy and occlusal adjustments on TMJ dysfunction. J. prosth. Dent., v.50, n.1, p.95-100, 1983.

76. LEIB, ALDEN M. The occlusal bite splint- A noninvasive therapy for occlusal habit and temporomandibular disorders. Compendium, v.17, n.11, p.1081-90, Nov. 1996.

77. LIST, T. et al. Acupunture and occlusal splint therapy in the treatment of craniomandibular disorders. Swed. Dent. J., v.16, n.4, p. 125-41, 1992 .

78. LUNDH, H.; WESTESSON, P.L. Long-term follow-up after occlusal treatment to correct abnormal temporomandibular joint disk position. Oral Surg., v.67, n.1, p.2-10, Jan. 1989.

79. LUNDH, H.; WESTESSON, P.L. Clinical signs of temporomandibular joint internal derangement in adults: an epidemiológic study. Oral Surg., v.72, n.6, p. 637-41, Dec. 1991.

80. LUNDH, H, WESTESSON, P.L.; TILLISTRON, B. et al. Anterior repositioning splint in the treatment of temporomandibular joints with reciprocal clicking: comparison with a flat occlusal splint and an untreated control group. Oral Surg., v.60, p.131-6, 1985.

81. LUNDH, H.; WESTESSON, P; KOOP, S. A three-year follow-up of patients with reciprocal temporomandibular joint clicking. Oral Surg., v.63, p.530-3, 1988. 
82. LUNDH, H. et al. Changes in mandibular positioting during treatment with disk repositioning onlays: A roentgen stereophotogrammetric study. Oral Surg., v.65, p.657-62, 1988.

83. LUNDH, $\mathrm{H}$. et al. Disk repositioning onlays in the treatment of temporomandibular joint disk displacement: Comparison with a flat occlusal splint and with no treatment. Oral Surg., v.66, p.155-62, 1988.

84. MAGNUSSON, T; CARLSSON, G.E. Treatament of patients with functional disturbances in the masticatory system: a survey of 80 consecutive patients. Swed dent. J., v.4, p.318-28, 1979.

85. MAJOR, P. W.; NEBBE, B. Use and effectiveness of splint appliance therapy: Rewiew of literature. Cranio, v.15, n.2, Apr. 1997.

86. MANZIONE, J.V. et al. Artrografically guided splint theraphy for recapturing the temporomandibular joint meniscus. Oral Surg., v.57, n.3, p.235-40, 1984.

87. MARTINI, G.; MARTINI, M.; CARANO, A. MRI study of a physiotherapeutic protocol in anterior disk displacement without reduction. Cranio, v.14, n.3, p.216-24, July 1996.

88. MCCALL, W.D. et al. A quantitative measure of mandibular joint dysfunction: phase plane modeling of jaw movement in man. Archs. oral Biol., v.21, p.685-9, 1976.

89. MCNAMARA, J.A.; CARLSON, D.S. Quantitative analysis of temporomandibular joint adaptations to protrusive function. Amer. J. Orthodont., v.76, p.593-611, 1979. 
90. MCNAMARA, J.A.; SELIGMAN, D.A.; OKESON, J.P. Occlusion, orthodontic treatment and temporomandibular disorders: a review. J. Orofac. Pain, v.9, p.73-90, 1995.

91. MCNEILL, C. Temporomandibular disorders. Guidelines for classification, assessment and management. 2.ed. Chicago, Quintessence, 1993.

92. MCNEILL, C. et al. Craniomandibular (TMJ) disorders - the state of the art. J. prosth. Dent., p.434-7, 1980.

93. MEJERSCO, C.; CARLSSON, G.E. Long term results of treatment for temporomandibular joint -pain dysfunction. J. prosth. Dent., v.49, n.6, p.809-15, 1983.

94. MOCAYO, S. Biomechanic of pivoting appliances. J. Orofacial Pain, v.8, n.2, p.190-6, Spring 1994.

95. MOLINA, F.O. Disfunção da ATM. In: Fisiopatologia craniomandibular. Oclusão e ATM. São Paulo, Pancast, 1989. Cap.5, p.183-232.

96. MOLONEY, F.; HOWARD, J.A. Internal derangements of the temporomandibular joint: anterior repositioning splint terapy. Aust. dent. J., v.31, n.1, p.30-9, Feb. 1986.

97. MONGINI, F; IBERTIS, F.; MANFREDI, A. Long-term results in patients with disk displacement without reduction treated conservatively. Cranio, v.14, n.4, p.56-59, Oct. 1996.

98. NELSON, S.J. Principles of stabilization bite splint therapy. Dent. Clin. N. Amer., v.39, n.2, p.403-21, Apr. 1995.

99. NITZAN, D.W. Intraarticular pressure in the functioning human temporomandibular joint and its alteration by uniform elevation of 
the occlusal plane. J. Oral Maxillofac. Surg., v.52, n.7, p.671-9, July 1994.

100. OGUS, H. Degenerative disease of the temporomandibular joint in young adults. Brit. J. Oral Surg., v.17, n.1, p.17-26, 1979.

101. OKESON, J.P. The effects of hard and soft occlusal splints on nocturnal bruxism. J. Amer. Dent. Ass., v.114, p.788-91, 1987.

102. OKESON, J.P. Long-term treatment of disc-interference disorders of the temporomandibular joint with anterior repositioning occlusal splints. J. prosth. Dent., v.60, p.611-16, 1988.

103. OKESON, J.P. Terapia por aparelhos oclusais. In: Fundamentos de oclusão e desordens temporomandibulares. 2.ed. São Paulo, Artes Médicas, 1992. Cap.16, p.321-43.

104. OKESON, J.P. Pains of muscular origin. In: Bell's orofacial pains, 5 ed. Chicago, Quintessence, 1993. Cap.12, p.259-94.

105. OKESON, J.P.; KEMPER, J.T.; MOODY, P.M. A study of the use of occlusal splints in the treatment of acute and chronic patients with craniomandibular disorders. J. prosth. Dent., v.48, n.6, p. 70812, Dec. 1982.

106. ORENSTEIN, E.S. Anterior repositioning appliances when used for anterior disk displacement wity reduction: a critical review. J. craniomandibular Pract., v.2, n.2, p. 141-52, Apr. 1993.

107. OWEN, A, H. Orthodontic/orthopedic treatment of craniomandibular pain dysfunction. Part III: Anterior condylar displacement. J. craniomandib Pract., v.3, p.31-45, 1984.

108. OWEN, A. H. Orthodontic/orthopedic therapy for craniomandibular pain dysfunction. Part B. Treatment flow sheet, anterior disk 
displacement, and case histories. J. craniomandib Pract., v.6, n. 1, p.48-63, 1988.

109. PAGE, D.C. Functional jaw orthoapedics dental targeted treataments medical "Co-incidental" results. Funct. Orthodont., v.5, p.12-21, Fev. 1988.

110. PALLA, S.; ANTONNI, C. Short-term treatment outcome of TMJ clicking. J. oral Rehab., v.12, p.560-6, 1985.

111. PERTES, R.A.; GROSS, S.G. Clinical management of temporomandibular disorders and orofacial pain. Chicago, Quintessence, 1995. 368p.

112. PIERCE, C.J. et al. Dental splint perception patterns: a survey. J. Amer. dent. Ass., v.126, p.125-248, 1995.

113. PRENTISS, H. A preliminary report upon the temporomandibular articulation in the human type. Dent. Cosmos, v.60, p.505-12, June 1918.

114. PUllinger, A.G.; SEligman, D.A.; GORNBEIN, J.A. A multiple logistic regression analysis of the risk and relative odds of temporomandibular disorders as a function of common occlusal features. J. dent. Res., v.72, n.6, p.968-79, June 1993.

115. RAMFJORD, S.P.; BLANKENSHIP, J.R. Increased occlusal vertical dimension in adult monkeys. J. prosth. Dent., v.45, p.74-83, 1981.

116. RAMOS JR, L., CONTI, P.C.R.; MIRANDA, J. E. S.; Placas protrusivas, Rev. brasileira de perio prótese oclusão, v.1, n.2, p.276-282, 1998. 
117. RUBINOFF, M.S.; GROSS, A.; MCCALL, W.D. Conventional and nonoccluding splint therapy compared for patients with myofascial pain dysfunction syndrome. Gen. Dent., p.502-6, Nov./Dec. 1987.

118. SANTACATTERINA, A. et al. A comparision between horizontal splint and repositioning splint in the treatment of disc dislocation with reduction. Literature meta analysis. J. oral Rehab., v.25, p. 81-8, 1998.

119. SCAPINO, R.P. Histopathology associated with malposition of the human temporomandibular joint disk. Oral Surg., v.55, p.382-97, 1983.

120. SCAPINO, R.P. The posterior attachment: Its structure, function, and appearance in TMJ imaging studies. Part 2. Cranio, v.5, p.155-66, 1991.

121. SCHWARTZ, L. Pain associated with the temporomandibular joint. J. Amer. dent. Ass., v.51, n.10, p.394-401, Oct. 1955.

122. SEligmAN, D.A.; PULlingeR, A.G. The role of functional occlusal relationships in temporomandibular disorders: a review. J. Craniofac. dis.Oral Facial Pain, v.5. n.4, p.265-79, 1991.

123. SFONDRINI, G. et al. Adaptations of masticatory muscles to a hyperpropulsive appliance in the rat. Amer. J. Orthodont. Dentofac. Orthop., v.10, n.6, p.612-7, Dec. 1996.

124. SHAN, S.C.; YUN, W.H. Influence of an occlusal splint on integrated electromyography of the masseter muscles. J. oral Rehab., v.18, p.253-6, 1991.

125. SHEIKHOLESLAM, A. et al. A clinical and electromyographic study of the long-term effects of an occlusal splint on the temporal and 
masseter muscles in patients with functional disorders and nocturnal bruxism. J. oral Rehab., v.13, p.137-45, 1986.

126. SHORE, N. A. Treatament of temporomandibular dysfunction. J. prosth. Dent., v.10, n.2, p.366-73, Mar./Apr. 1960.

127. SIMMONS, H.C.; GIBBIS, S.J. Recapture of temporomandibular joint disks using anterior repositioning appliances: an MRI study. J. craniomandibular Pract., v.13, n.4, p.227-37, Out. 1995.

128. SINGH, B. P.; BERRY, D. C. Oclusal changes following use of soft occlusal splints. J. prosth. Dent., v.54, n.5, p.711-15, Nov. 1985.

129. SOLBERG, W. K. Temporomandibular disorders clinical significance and TMD changes. Brit. dent. J. v.4, p. 231-6, 1996.

130. SOLBERG, W.K. Malocclusion associated with temporomandibular joint: changes in young adults at autopsy. Amer. J. Orthodont., v.89, n.4, p.326-30, 1986.

131. STEGEnGA, B.; DE BONT, L. G. M.; BOERING, G. Osteoarthrosis as the cause of craniomandibular pain and dysfunction: a unifying concept. J. oral Maxillofac. Surg., v.47, n.3, p.249-56, Mar. 1989.

132. STEGENGA, B.; De BONT, L.G.M.; BOERING, G. Classification of temporomandibular joint osteoarthrosis and internal derangement. Part I: diagnostic significance of clinical and radiographic symptoms and signs. J. craniomandibular. Pract., v.10, n.2, p.96-106, Apr.1992.

133. STEGENGA, B. et al. Tissue responses to degenerative changes in the temporomandibular joint. J. oral maxillofac. Surg., v.49, n.9, p.1079-88, Sept. 1991. 
134. SUMMER, J.D.; WESTESSON, P.L. Mandibular can be effective in the treatment of reducing TMJ disk displacement. A long-term clinical and MR imaging follow-up. J. craniomand. Pract., v.15, n.2, p.107-20, Apr. 1997.

135. TADDEY, J.J. Rationale for sequential use of both maxillary and mandibular orthopedic appliances in the treatment of TMJ disorders. J. craniomandibular dis. fac. oral Pain, v.4, p.273-5, 1990.

136. TAKENOSHITA, Y. et al. Occlusal contact area and temporomandibular joint symptoms. Oral Surg., v.72, n.4, p.38894, Oct. 1991.

137. TALLENTS, R.H. et al. Use of protrusive splint therapy in anterior disk displacement of the temporomandibular joint: A 1- to 3- year follow-up. J. prosth. Dent., v.63, p.336-41, 1990.

138. TOLLER, P.A. Non-surgical treatment of dysfunctions of the temporomandibular joint. In: . Oral sciences reviews: temporomandibular joint function and dysfunction. 1976, v.7, p.70-85.

139. TURK, D.C.; ZAKI, H.S.; RUDY, T.E. Effects of intraoral appliance and biofeedback/stress management alone and in combination in treating pain and depression in patients with temporomandibular disorders. J. prosth. Dent., v.70, n.2, p.158-64, Aug. 1993.

140. WARD, D.M.; BEHRENTS, R.G.; GOLDBERG, J.S. Temporomandibular synovial fuid pressure response to altered mandibular positions. Amer. J. Orthod. Dentof. Orthop. v.98, p.22-8, 1990 
141. WEINBERG, L.A. An evaluation of occlusal factors in TMJ dysfunction-pain syndrome. J. prosth. Dent., v.41, n.2, p.198208, Feb. 1979.

142. WEINBERG, L.A. The etiology, diagnosis, and tratament of tmj dysfunction-pain syndrome. J. Prosth. Dent., v.42, n.3, p. 42-53, July 1980.

143. WEINBERG, L.A The role of muscle deconditioning for occlusal corretive procedures. J. prosth. Dent., v.66, p.250- 5, 1991.

144. WENNEBERG, B; NYSTROM, T.; CARLSSON, G.E. Occlusal equilibration and other stomatognathic treatment in patients with mandibular dysfunction and headache. J. prosth. Dent., v.59, n.4, p.478-83, Apr. 1988.

145. WESTESSON, P.L.; LUNDH, H. Temporomandibular joint disk displacement: arthrographic and tomographic follow-up after 6 month's treatment with disk-repositioning onlays. Oral Surg., v.66, n.3, p.271-8, Sept. 1988

146. WESTESSON, P.L.; BRONSTEIN, S.L.; LEIDBERG, J. Internal derangement of temporomandibular joint: Morphologic description with correlation to joint function. Oral surg., v.59, p.323-31, 1985.

147. WIDMALM, S.E. Use and Abuse of Splints. Copemdium, v.20, n.3, p. 249-60, Mar. 1999.

148. WILKINSON, T.M.; CROWLEY, C.M. A histologic study of retro discal tissues of the human temporomandibular joint in the open and closed position. J. Orofac. Pain, v.8, n.1, p.7-17, Winter 1994. 
149. WILLIANSON, E.H. Mandibular Orthopedic change and closure of anterior open bite following reduction of disk dislocation. Facial Orthop., v.7, n.3, p.3-7, July 1986.

150. WILLIANSON, E.H. Treatment of acute anterior dislocation without reduction followed by functional jaw orthopedics and class II correction. Facial Orthop., v.7, n.6, p. 3-7, June 1986.

151. WILLIANSON, E.H.; SHEFFIELD. J.W. The treatment of internal derangement of the temporomandibular joint: A survey of 300 cases. J. craniomandibular. Pract., v.5, p.120-4 1987.

152. WILLIANSON, E.H. et al. A comparison of eletromyographic activity between anterior repositioning splint therapy and a centric relation splint. J. craniomandibular Pract., v.11, n.3, p.120-124, July 1993.

153. WINDMER, C.G. Temporomandibular joint sounds: a critique of techniques for recording and analysis. J. craniomandibular dis. fac. oral Pain, v.3, n.4, p.213-7, july. 1989.

154. WRIGHT, W. Deafness as influenced by malposition of the jaws. $\mathbf{J}$. Nat dent. Ass., v.7, n.12, p.979-92, Dec. 1920.

155. YAMAMOTO, M.K.; LUZ, J.G.C. Avaliação das excurções mandibulares máximas em indivíduos assintomáticos. Rev. Ass. paul. cirurg. Dent., v.46, n.3, p.781-4, maio/jun. 1992.

156. YAP, A.U.J. Effects of stabilization appliances on nocturnal parafunctional activities in patients with an without signs of temporomandibular disorders. J. oral Rehab., v.25, p.64-8, 1998. 
ANEXOS 


\title{
Anexos
}

\section{Anexo I_-}

\section{Autorização para pesquisa clínica e execução de tratamento}

\section{Faculdade de Odontologia de Bauru-USP \\ Departamento de Prótese \\ Clínica de Disfunção Temporomandibular e Dores Orofaciais}

Título do projeto: Efetividade de placas reposicionadoras no controle de patologias intraarticulares: comparação com placas estabilizadoras e grupo controle

\author{
Responsável: CD João Evandro da Silva Miranda \\ Tese - Doutorado \\ Orientador: Prof: Dr: Paulo César Rodrigues Conti
}

Nome do paciente:

Por este instrumento de autorização por mim assinado, dou pleno consentimento a FACULDADE DE ODONTOLOGIA DE BAURU-USP para, por intermédio de seus professores, profissionais e alunos devidamente autorizados, fazer diagnóstico, planejamento de tratamento, fotografias, modelos, injeções diagnósticas quando necessário e tratamento odontológico em minha pessoa de acordo com os conhecimentos enquadrados no campos dessa especialidade.

Concordo também, que documentação referente a exames efetuados e quaisquer outras informações concernentes ao planejamento de diagnóstico e tratamento constituem propriedade exclusiva desta Faculdade, a qual dou pleno direito de uso para fins de ensino e de divulgação, repeitando os respectivos códigos de ética.

Concordo ainda em retornar a esta clínica sempre que solicitado, pois fui informado sobre esta necessidade não só para a conclusão da pesquisa da qual sou componente voluntário, mas também porque recebi informação de que o uso de placas oclusais a longo prazo sem o devido acompanhamento pode causar problemas em meus dentes.

Dessa forma eu asseguro que li e entendi os Termos deste documento, aceitando me submeter a este estudo e aos cuidados dos profissionais e estudantes desta Faculdade

Bauru, de de 199 $\mathrm{N}^{\mathrm{o}}$ : 


\section{Anexo II_-Ficha A}

\section{Ficha de histórico e exame clínico}

Faculdade de Odontologia de Bauru-USP

Departamento de Prótese

Disfunção Temporomandibular e Dores Orofaciais

Tese - Doutorado: João Evandro da Silva Miranda

Orientador: Prof: Dr: Paulo César Rodrigues Conti

\section{História e Exame}

Nome: Tel :

Idade:

Data:

Grupo $\mathrm{N}:$

Acidentes relacionados: $\quad$ Sim $\quad$ Não

Queixa principa ${ }^{(\mathrm{is})}$ : (em ordem de severidade)

1.

2.

Queixa principal 1:

Início:

Localização:

Frequência:

Intensidade:

Qualidade:

Queixa principal \# 2:

Início:

Localização:

Frequência:

Intensidade:

Qualidade:

Medicação atual e doses: 
Medicação passada e doses:

Testes ou radiografias realizadas:

História médica/cirúrgica:

$\mathrm{EAV}=$

Hábitos parafuncionais e ocupacionais:

Ranger os dentes

Apertamento

Morder unhas

Mascar chicletes

Uso contínuo do telefone

Uso contínuo do computador

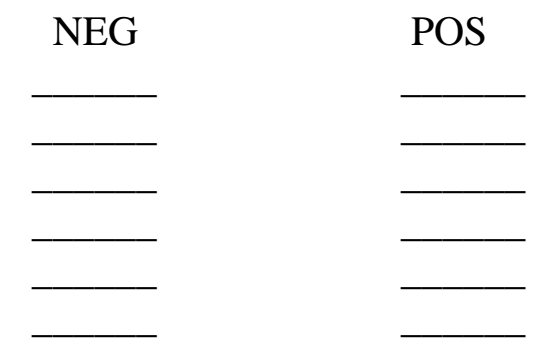

\section{Exame Clínico}

I- Avaliação de CABeÇa e Pescoço:

Palpação de cabeça e pescoço:

Linfonodos:

Avaliação Facial:

Assimetria Facial:

Não

Sim

2. Avaliação da ATM:

A - Movimentação

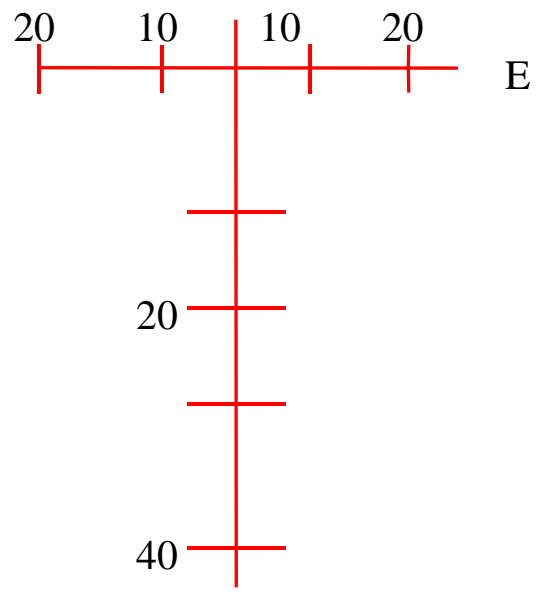

Dor

Abertura máxima $\mathrm{mm}$ (incluindo trespasse)

Protrusivo

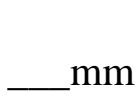

Lateralidade direita

mm

Lateralidade esquerda $\mathrm{mm}$ 

Abertura:
Simétrica
Desvio
Deflexão

B-Ruídos Articulares:

$\underline{\text { Abertura }}$

D E

ESTALIDO

Inicial $\quad(0-15 \mathrm{~mm})$

Intermediário (16-30mm)

Tardio (31-50mm)

Crepitação

Hipermobilidade

\section{Fechamento}

D E
ESTALIDO

Inicial (31-50mm)

Intermediário (16-30mm)

Tardio (0- 15mm)

Crepitação

\section{C-Palpação da ATM:}

$0=$ Sem dor

$$
1=\text { Dor leve }
$$

2 = Dor moderada

$3=$ Dor severa

D

E

Aspecto lateral

Aspecto posterior:

Edema?

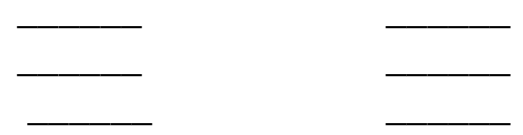

\section{Exame Muscular - Sensibilidade À PalpaÇão:}

$0=$ Sem dor $\quad 1=$ Dor leve $2=$ Dor moderada $3=$ Dor severa

D

$\mathbf{E}$

\section{Temporal:}

Anterior

Médio

Posterior

Inserção

Masseter Superficial:

Origem

Corpo

Inserção

Masseter Profundo: 


\section{$\underline{\text { Pterigoideo Medial }}$}

4. Avaliação Dental e OClusal:

$\mathrm{X}=$ Ausente

$\begin{array}{cccccccccccccccc}18 & 17 & 16 & 15 & 14 & 13 & 12 & 11 & 21 & 22 & 23 & 24 & 25 & 26 & 27 & 28 \\ 48 & 47 & 46 & 45 & 44 & 43 & 42 & 41 & 31 & 32 & 33 & 34 & 35 & 36 & 37 & 38\end{array}$

Próteses:

Tratamento Ortodôntico:

Sim Não

5. IMPRESSÕES DiAgNóSTICAS:

Capsulite / Sinovite

D E

Deslocamento de disco

c/redução D E

Deslocamento de disco s/redução D $\mathrm{E}$

Hipermobilidade

D E 


\section{Anexo III - Ficha B FICHA DE REÁAVALIAC̄̃̃O}

Faculdade de Odontologia de Bauru-USP

Departamento de Prótese

Disfunção temporomandibular e Dores Orofaciais

Tese - Doutorado: João Evandro da Silva Miranda

Orientador: Prof: Dr: Paulo César Rodrigues Conti

Nome: Tel

Idade:

Data:

Grupo $\mathrm{N}$

\section{Controle Número:}

$\mathrm{EAV}=$

1. Hábitos parafuncionais e ocupacionais:

2.

$\bullet$ Ranger os dentes

$\odot$ Apertamento

$\odot$ Morder unhas

- Mascar chicletes

- Uso contínuo do telefone

- Uso contínuo do computador
NEG POS

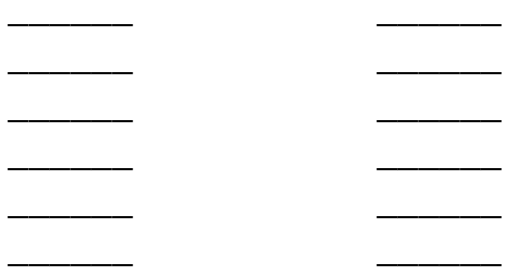

3. Exame clínico

Avaliação facial

๑ Assimetria facial

SIM

NÃO

4. Avaliação da ATM: 
5. Movimentação

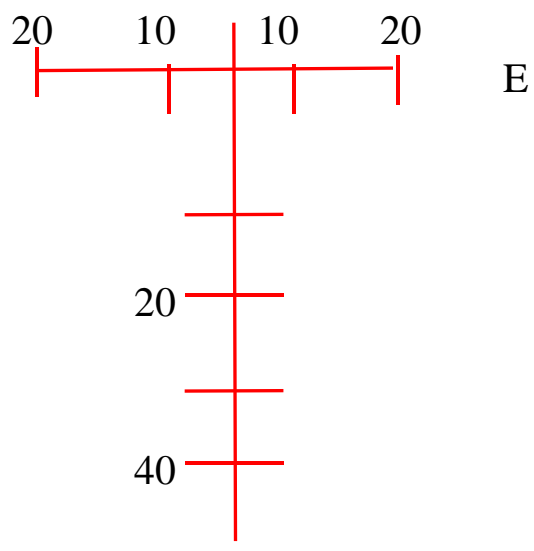

Dor

Abertura máxima

$\ldots \mathrm{mm}$

(incluindo trespasse)

Protrusivo

$\mathrm{mm}$

Lateralidade direita

$\mathrm{mm}$

Lateralidade esquerda

$\mathrm{mm}$

Abertura: Simétrica Desvio Deflexão

Movimentação ativa: Macia Descoordenada Irregular

$\Theta$ Ruídos Articulares:

$\underline{\text { Abertura }}$

D E

ESTALIDO

Inicial

$(0-15 \mathrm{~mm})$

Intermediário (16-30mm)

Tardio

(31-50mm)

Crepitação

Hipermobilidade

\section{Fechamento}

D E

ESTALIDO

Inicial $(31-50 \mathrm{~mm})$

Intermediário (16-30mm)

Tardio (0-15mm)

Crepitação

๑ Palpação da ATM:

$\theta$

$\underline{0=\text { Sem dor } \quad 1=\text { Dor leve } \quad 2=\text { Dor moderada } \quad 3=\text { Dor severa }}$

\begin{abstract}
Aspecto lateral
Aspecto posterior:

Edema?
\end{abstract}

$\mathrm{D}$

$\mathrm{E}$ 
4. Exame Muscular -:

$\underline{0=\text { Sem dor }}$

$1=$ Dor leve

2= Dor moderada

$\underline{3=\text { Dor severa }}$

*=Trigger Point

$\underline{\mathrm{NE}=\text { Não examinado }}$

D E

- Temporal:

Anterior

Médio

Posterior

Inserção

- Masseter Superficial:

Origem

Corpo

Inserção

- Masseter Profundo:

- Pterigoideo Medial

6 - IMPRESSÕES DIAGNÓSTICAS:

Capsulite / Sinovite

D E

Deslocamento de disco c/redução D $\quad$ E

Deslocamento de disco s/redução $\quad \mathrm{D} \quad \mathrm{E}$

Hipermobilidade

D E

7- Avaliação Final pelo paciente 
$\Theta$ Em relação a oclusão

Manteve-se

Alterou-se para melhor

Alterou-se para pior

$\bullet$ Em relação ao estalido

Manteve-se

Alterou-se para melhor

Alterou-se para pior

$\Theta$ Em relação ao conforto placa reposicionadoras placa lisa

Manteve-se

Alterou para melhor

Alterou para pior

Não sabe 


\section{Anexo IV_Ficha C}

$\underline{\text { Ficha de mapeamento dos pontos de contato oclusal }}$
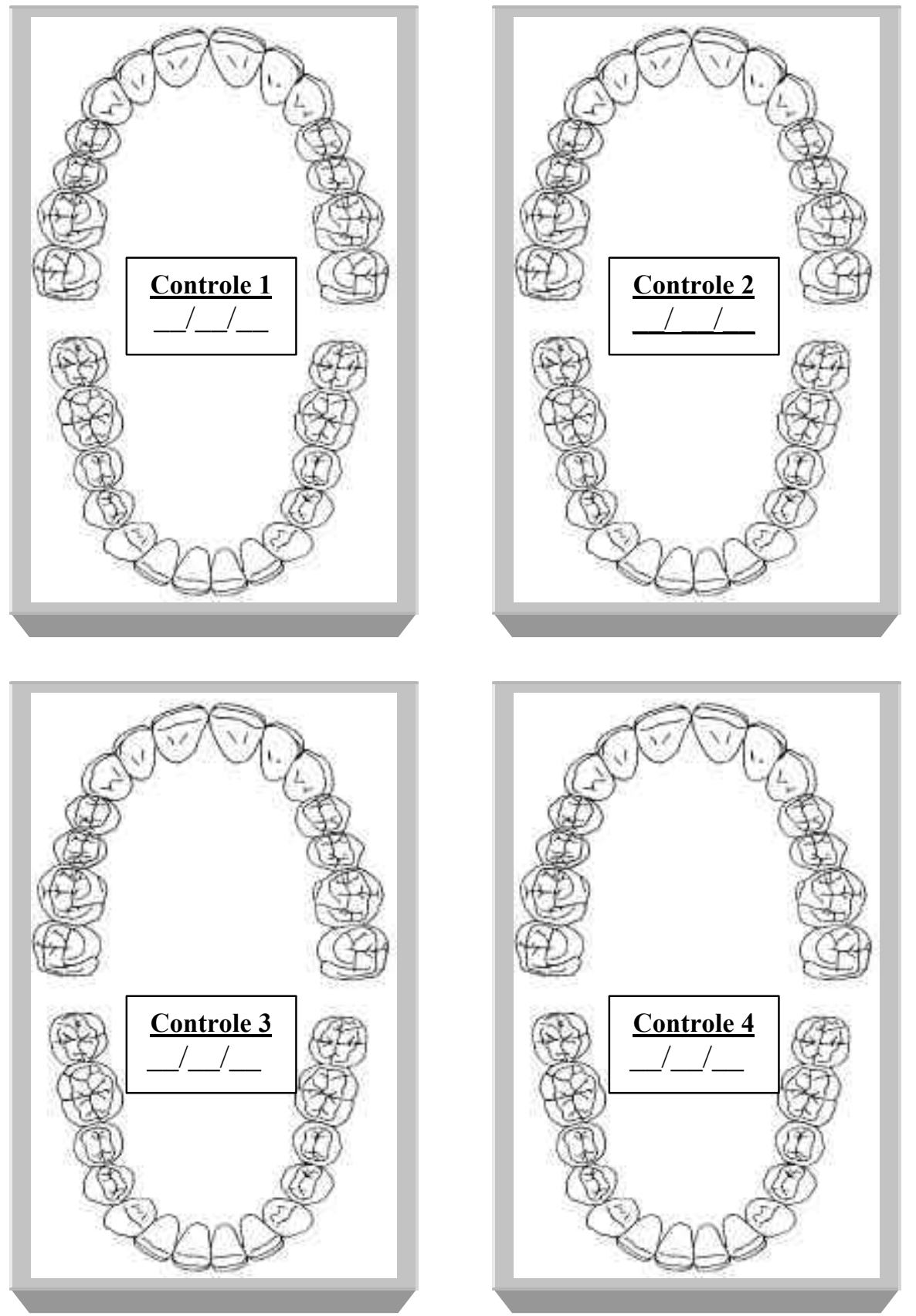

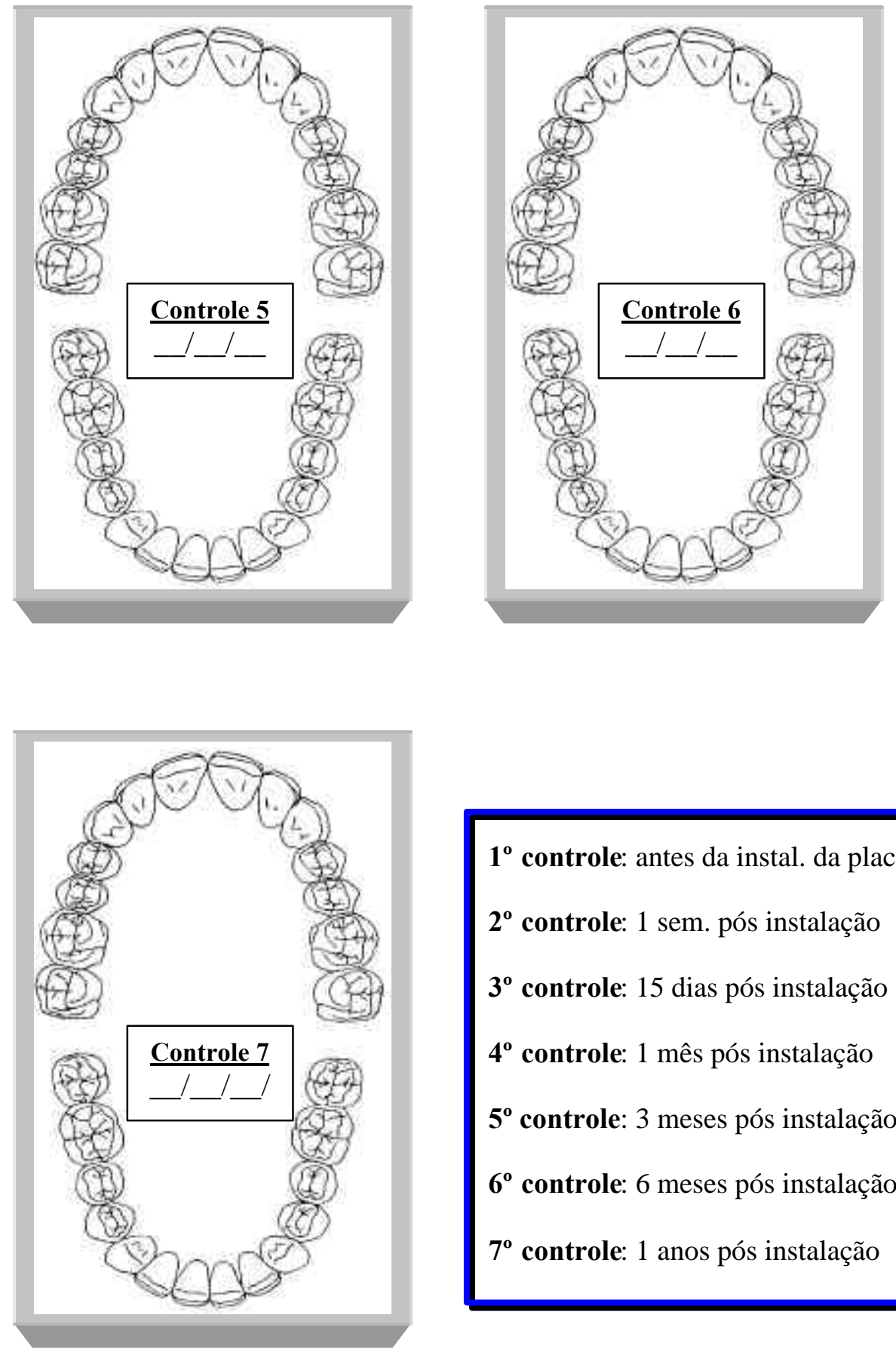

$\mathbf{1}^{\mathbf{o}}$ controle: antes da instal. da placa

$\mathbf{2}^{\mathbf{0}}$ controle: 1 sem. pós instalação

$\mathbf{3}^{\mathbf{0}}$ controle: 15 dias pós instalação

$4^{\mathbf{0}}$ controle: 1 mês pós instalação

$5^{\mathbf{0}}$ controle: 3 meses pós instalação

$\mathbf{6}^{0}$ controle: 6 meses pós instalação

$7^{\circ}$ controle: 1 anos pós instalação 
ABSTRACT 


\section{Abstract}

The aim of this study was to evaluate the effectiveness of repositioning occlusal splints partial use in the management of TMJ intra-articular disorders. A comparison group (using stabilization splints) a control group (with no treatment) were also part of this study.

The sample was constituted by 52 patients with complaints of TMJ noises and pain, randomly divided into three groups: I stabilization splints $(n=20)$, II - repositioning splints $(n=18)$ and III (no treatment).

The whole sample was evaluated by means of TMJ and muscle palpation, mandibular range of motion, occlusal contacts and pain Visual Analogue Scale (VAS) for one year. Repeated measurements ANOVA, two way ANOVA, Kruskal-Wallis and Mc Nemar's tests accounted for the statistical analysis. Results have shown a significant improvement $(p<0,01$ in pain report (VAS) and palpation index for group II. No significant occlusal changes were present in any group. Indeed, muscle palpation values also decreased regardless the group studied $(\mathrm{p}<0.05)$. Similar results for pain and join noises reduction were observed after the sixth month of follow-up for the entire sample (including the control group). 
Based on that, it was concluded that the partial use of repositioning splints are important tools in the management of TMJ pathologies. 